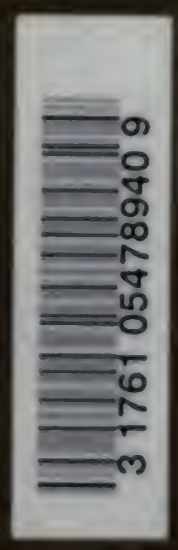

S\&M

A

450 

Ryous 



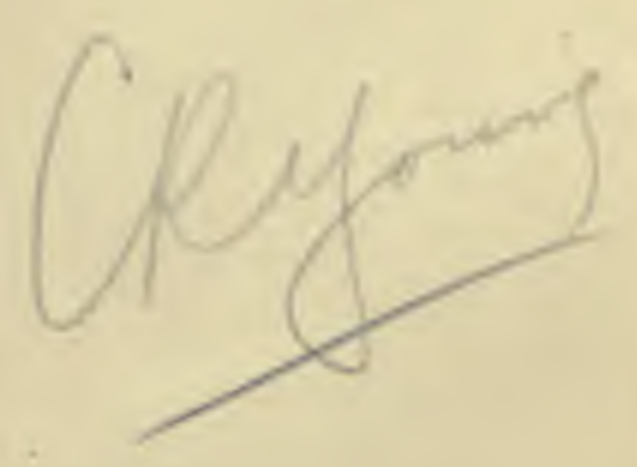



Digitized by the Internet Archive in 2007 with funding from Microsoft Corporation

http://www.archive.org/details/notesonplategird00hudsuoft 
WORKS OF

\section{CLARENCE W. HUDSON}

PUBLIBIED BT

\section{JOHN WILEY \& SONS}

Notes on Plate-Girder Design.

8 vo, vii +75 pages, figurea throughout the text and 2 folding plates. Clotb, $\$ 1.50$ net.

Deflections and Statically Indeterminate Stresses.

Small 4 to, xiii +258 pages, profusely illustrated with figures in the text, and full page plates Cloth, $\$ 3.50$ net. 
NOTES

10

\title{
PLATE-GIRDER DESIGN
}

\author{
II \\ CLARENCE W: HUDSOS, C. K \\ MEx A Ne RE

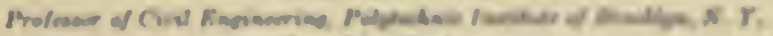 \\ Condiver fingions
}

FIRST EDITIOS

vitst THOEsasn

NEW YORK

JOIIS WII.FY of SONS

Losous: CHAl'MAS \& IlAL, Lamb

1911 
Copyright, 1011,

Bx

CLARENCE W. HUDSON

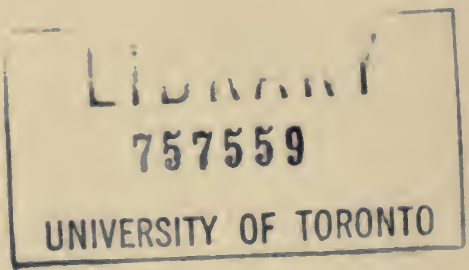

TWE SCIENTIFIC parse

nocent denuegno ano comiant

EตOOKLVN, N. Y. 


\section{PREFACE}

Tu: following Notes on Plate-finder Dexign have been used by the author to givo his eivil enginceriag students the theoretical and praetical information ace. essary to enable them to make a dewigu and general detailed drawing for a through plate-girler railway bridge. The theory of the plate girder has been developed no that it may be applied to such struetures for any duty. The notes may easily be given to the avernge elase in one recitation per week for one semester of the college year. They have greatly facilitated the computation ased drawing-room work with my own classes.

It is with the hope that they may be usedul to other teachers, and engineers, that they are published.

C. W. Heosos.

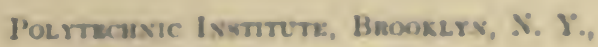
January, 12, 1011. 



\section{CONTENTS}

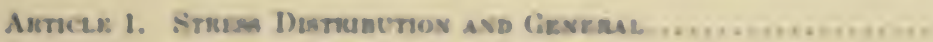

Theory of atres distribution. Limits of the eas of the plate ginler. Design and detail drawing fos a meble-track drek plate

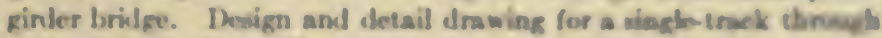
platerginder bridge. The weight of a plate ginder. Prothes.

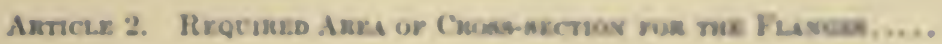

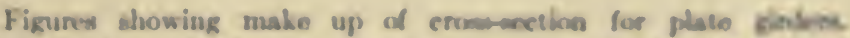
Formula for obtaining the required anes of the tesaline sasp. Problesms.

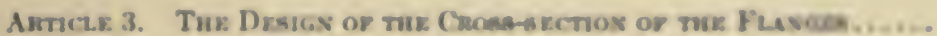

Compowition of the Alangrse. Minimum pitch of rivets in teckle

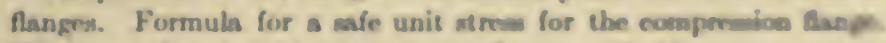
Thicknes of material in compresion flasgos. Iroblems.

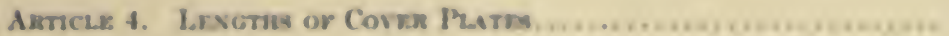

Furmulas for the kngth of cover plates for kinlem earrging vilfams

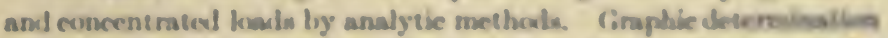
of lengthe of cover plates. Kicamplos of the applicatiea of the formulas for finling bengths of cover plates. Problhme.

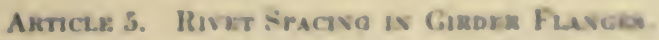

Rivet spacing a function of tho shear. Formulan far suaciea rivets connocting Rangen to the weh. Formular for spocts g tho rivets connecting the component parts of the tangen. Formula for rivet spacing at the cods of cover plates. Probleme. 
ABTICLE 6. WARK

Stresses on the faces of an element of the web. Stresses of maximum intensity and the planes on which they act. Computation of the stress intensity at various points in the web for a definite case. Problems.

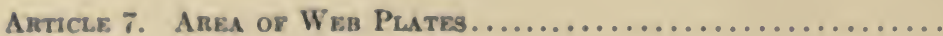

Discussion of stress distribution throughout the web plate. Relalation of shearing and compression unit stresses. Unit stresses for shear and compression in web plates. Problems.

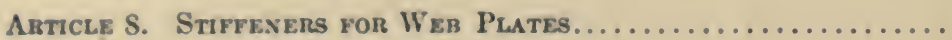

Functions of stiffeners. Intermediate stiffeners. Concentrated load stiffeners. Formulas for size of stiffeners. Spacing of stiffeners. Problems.

Article 9. Splices for Web Plates

Arrangement of splices. Duty of a web splice. Thickness of web splice plates. Number and arrangement of rivets in the splice. Maximum stresses on the rivets of a web splice. Problems.

Article 10. Splices for the Component Parts of the Flanges...

Location of splices in flange material. Disposition of flange splicing material. Rivets for splicing the component parts of the flanges. Problem.

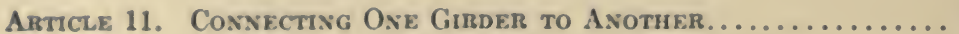

Size and arrangement of the material for the connection. Rivets for the various parts of the connection.

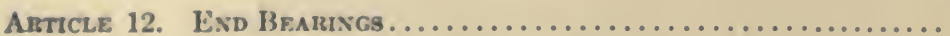

The duty of end hearings. Area of bearing on masonry. Proper length and width of bearings. Thickness of bearing plates. Different forms of end bearings. Problem. 


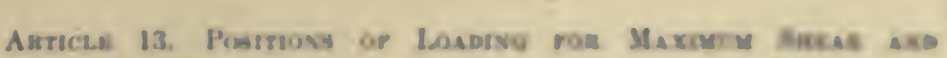

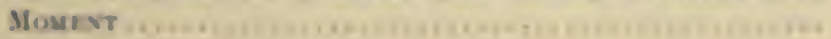

Maxionum end sheap. Maxissum theor at say point. Macisoses motuent at any definite poine. Aleslute ma cisuves monest and the poist at which it cecuns. Prothems.

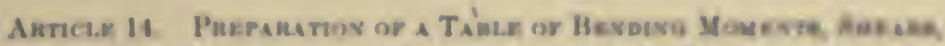

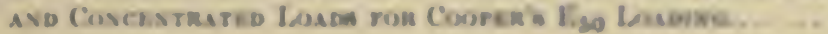

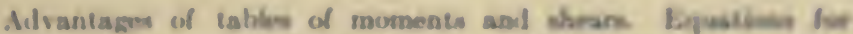

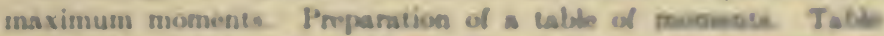

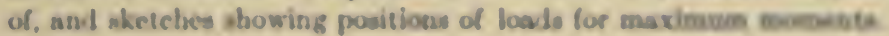
Probleme.

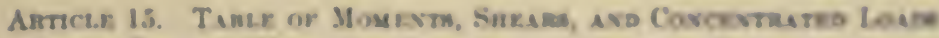
ron Courbais Bgo......, . ............. 



\section{NOTES ON PLATE-GIRDER DESIGN}

\section{ART. 1. STRESS DISTRIBUTION AND GENERAL}

The theory of stress distribution for plate girdens is the same as that for solid beams of uniform material, it being generally assumed that the common theory of Bexure applins with sufficient accuracy to the built-up girder. This avumption is certainly not strictly true. The rivet connecting the various parts together cause a local and small irnegularity of stress distribution; splices of the various parte, and non-prismatic form, produce quite marked irregularity of this distribution. The "Theory of Flexure" properly applied to plate-girder design, however, leads to a thoroughly good enginecring structure, as an imunense tonnage of wueh wark constructed during the past forty years and doing excel. lent duty witnesses.

This wide use of the plate girder for anrvice under greatly varying conditions has increased the knowledge of its capacity and given valuable practical information a to the design of eertain of its features.

The requirements for its fabrication, shipment and erection have also affected its design. These requiremens are not fixed in their nature, although in certain nepecte, 
such as minimum thickness of material in web plates, and minimum edge distances for punching, they fix a limit to the size of certain parts.

The correct design of plate girders therefore requires theoretical knowledge and either practical experience or formulated rules, based on practical experience, and so carefully and closely drawn as to prevent a poor design.

Plate girders are used for bridges anywhere from 18" deep and $15^{\prime}$ long to $126^{\prime \prime}$ deep and $130^{\prime}$ long, and even beyond these limits; they are also used in buildings and other important engineering work to a great extent. In general, the lower limit of their use is the I beam, which will furnish the proper strength at a less cost per pound of material; their upper limit is the truss, whose total cost is less than the heavier but cheaper per pound girder.

In order to design properly any structure it is necessary to understand the composition and relation of each to each of the various parts. The following drawings are meant to illustrate some of the most essential features of plate-girder construction. They are therefore not meant to be casually inspected, but thoroughly studied, and the function of the various parts in carrying a load to the -supports, the makeup of the parts and their connection, each to each clearly understood.

Fig. $1 a$ shows a single-track deck plate-girder bridge.

Fig. $1 b$ shows a single-track through plate-girder bridge.

The computation of the stresses in any structure is the preliminary step in the design. The stresses themselves are a function of the weight of the structure, and hence an early estimate of the weight of each portion of the 


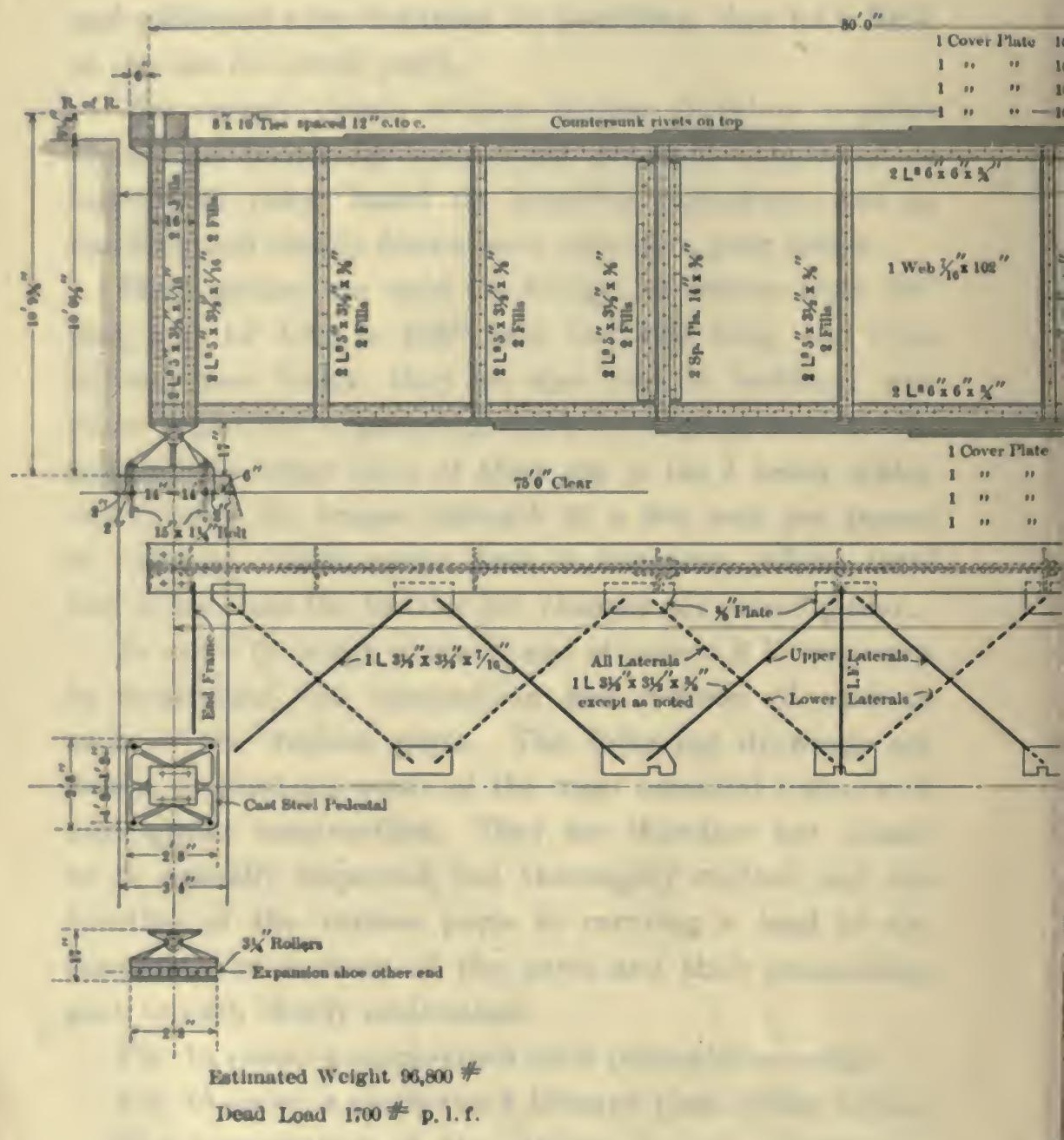

Live Loud Diugram per Ti

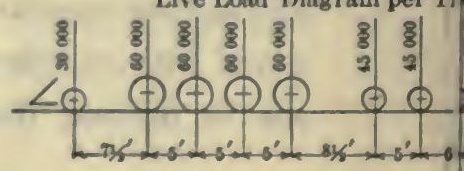




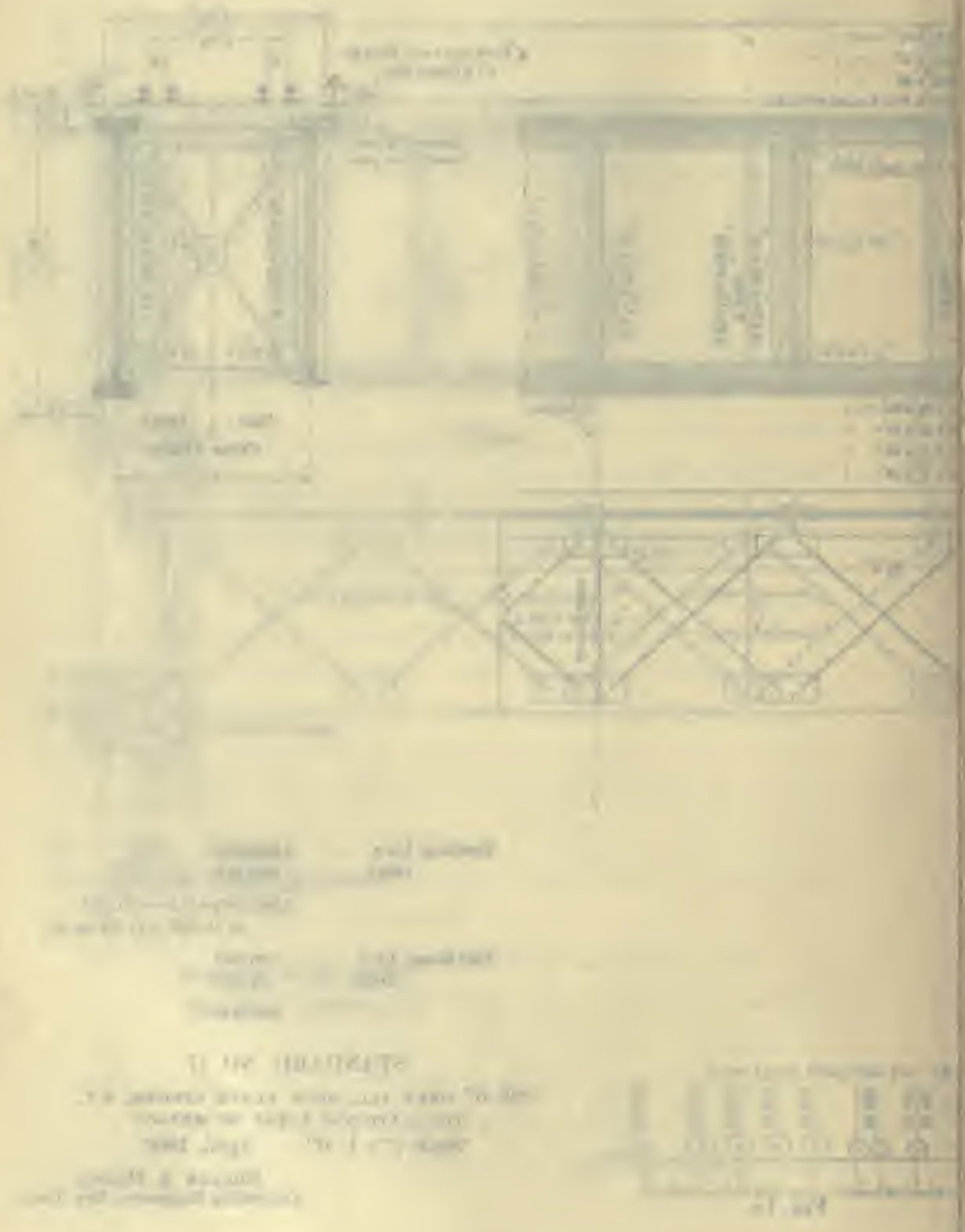




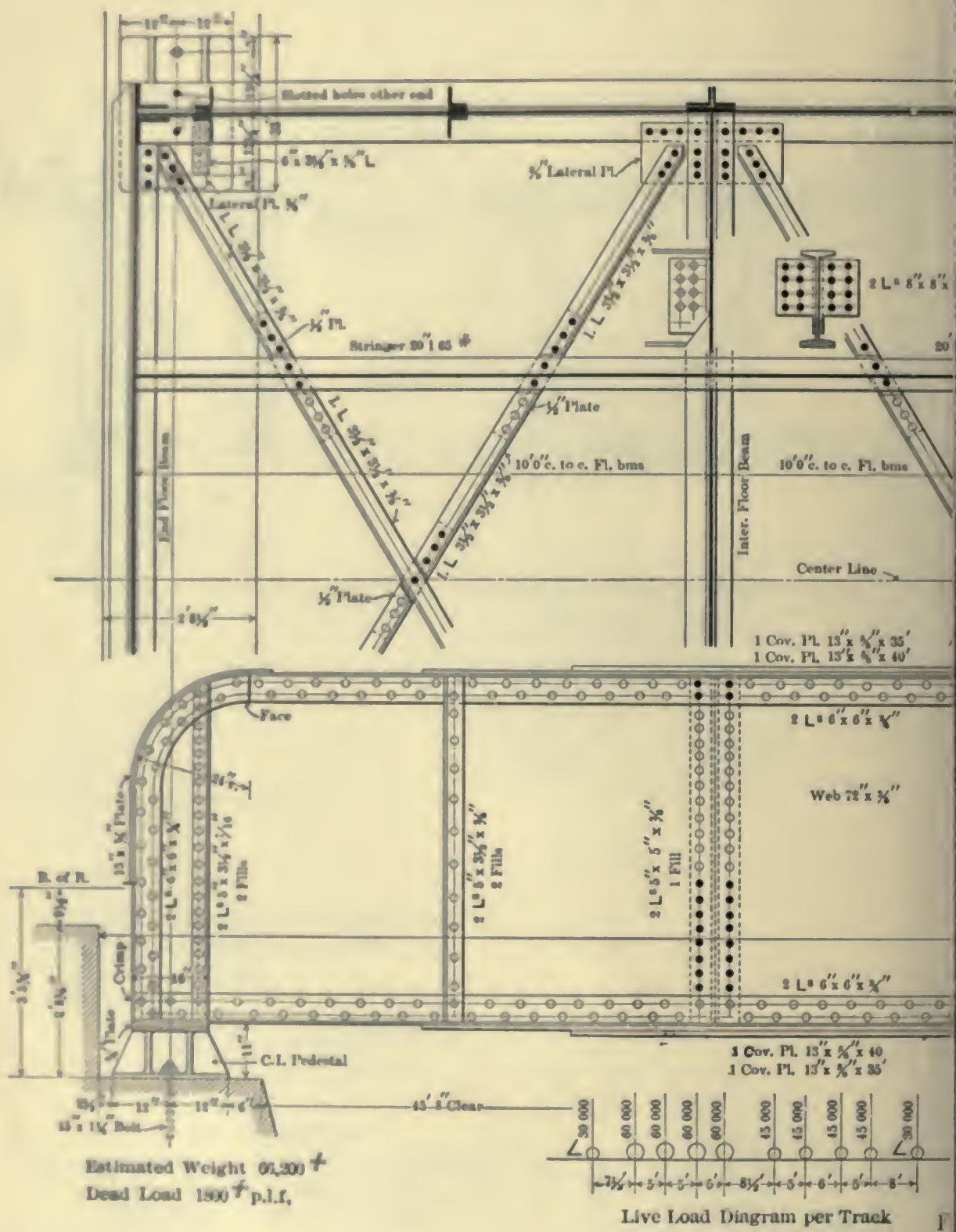




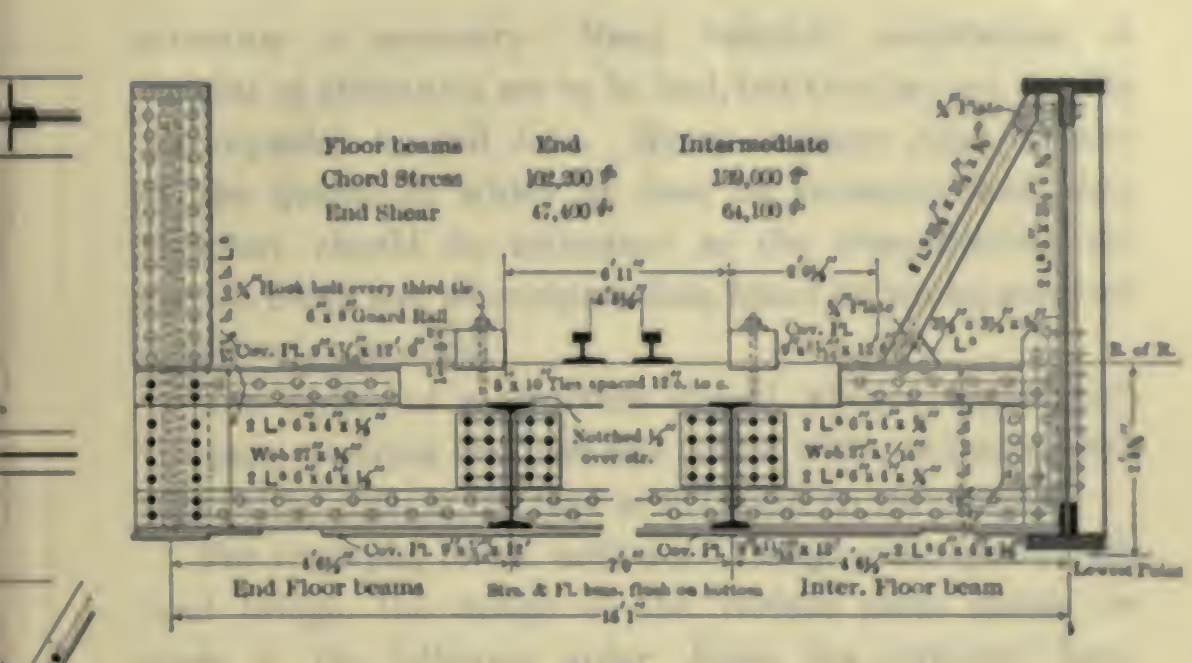

Stringers

Nendiag Moment

End Shear

1.014,00 Inch It:

14, 100 ites.

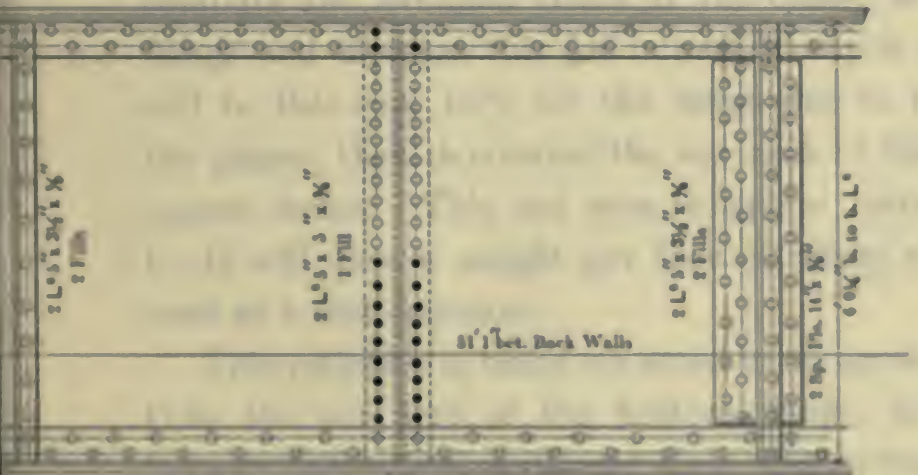

STAND.ARD NO. 12

Girder

Chord stress $\quad 822,000 t$

Load on end shoo lispont

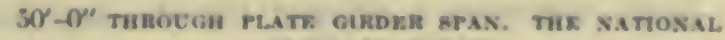
B.s.es or arexico

scale $f^{\prime \prime}-1^{\prime}-0^{\circ}$. April. $1900^{\circ}$

BOrusk \& Hobse: Conoultine Eisdneen, New look 


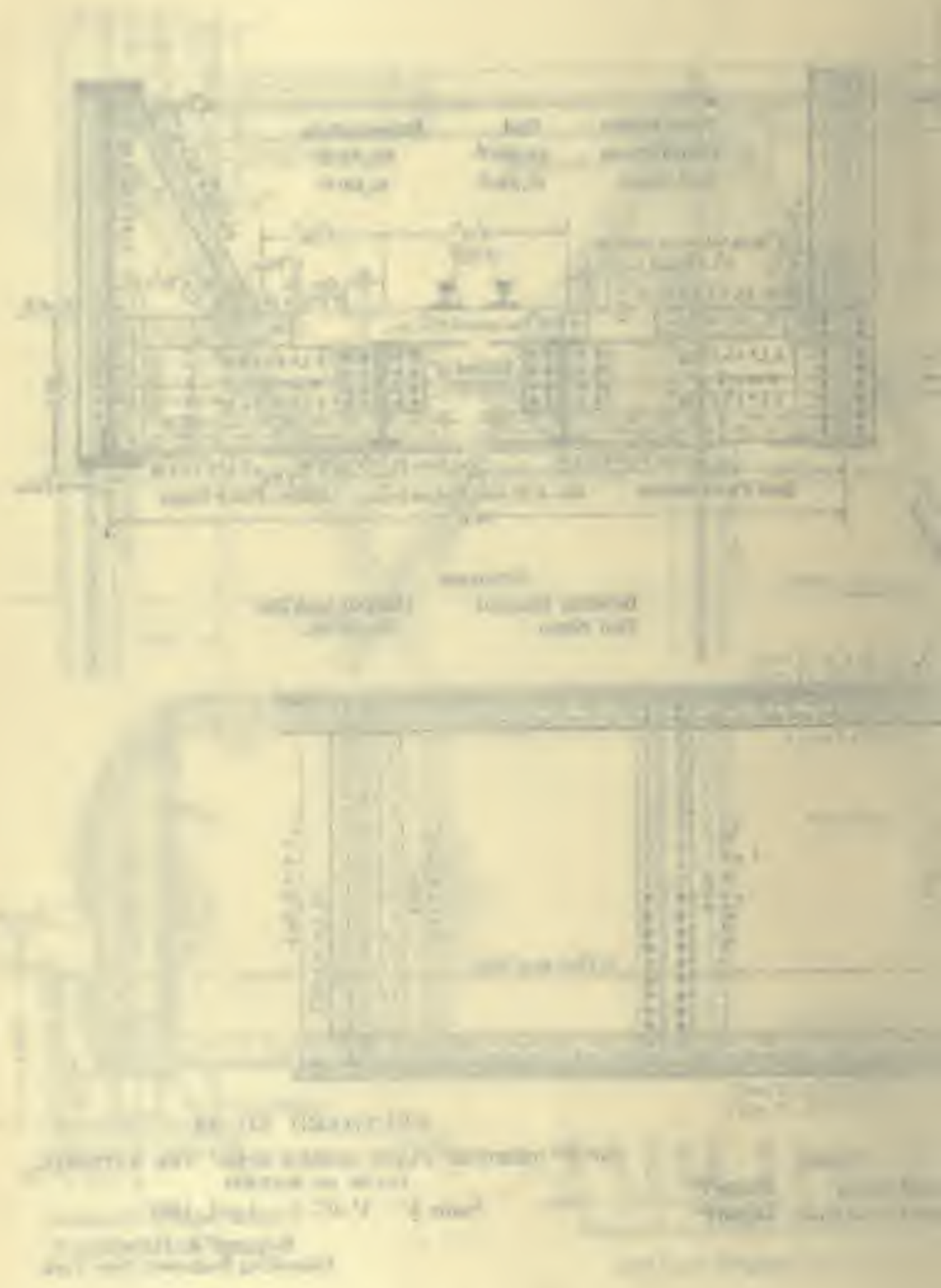


structure is necessary. Many valuable compilations of weights of structures are to be had, but they are not usually accompanied by full data. Every engineer must be sure of the quantities which go into his structure, and they therefore should be estimated as the computations are carried along and all computations based on wrong assumed dead loads corrected.

The design of a structure should always begin with the part receiving the load and follow with each successive part in the path of the load as it travels to the support.

For example, in an ordinary through plate-girder railroad bridge, the design of the various parts should be made in the following order: Rails, ties, stringers, floorbeams, lateral bracing, and main girders.

In making a first estimate of the weight of any girder, compute the live-load stress at the center of the bottom flange and increase this for impact if any is to be added, add to this sum $15 \%$ for the stress due to the weight of the girler, then determine the net area of this member in square inches. This net area in square inches multiplied by 14 will give a weight per foot of girder which may be used as a first estimate.

This estimate is based on equal gross areas $15 \%$ greater than the net area of the bottom flange, for top flange, bottom flange, and web, and their sum increased $15 \%$ for details. An error of $1 \%$ in the total stress due to a wrong first assumed dead load should require a corrected dead loal to be used.

It is very diffeult to give a good general rule for estimating the weight of girders, as the weight obviously is a 
function of the depth, loading, unit stresses, and many other things.

\section{PRORIEAS}

1a. Sketch the crase-section of a plate girder with and without rover plates, and write the name of each part on the sketches.

1h. Sketch the plan of single-track railroad deck plate-girder bridge and write the names of the various parts on the sketch.

1c. Sketch the plan of single-track railrond through plate-girder bridge, and write the names of the various parts in the sketch.

\section{ART. 2. REQUIRED AREA OF CROSS-SECTION FOR THE FLANGES}

The plate girder is a built-up strueture, and may be made with a variety of cross-sections depending on the requirements of the case. The forms of cross-section most frequently used are those of $a, b$ and $c$ of Fig. 2.
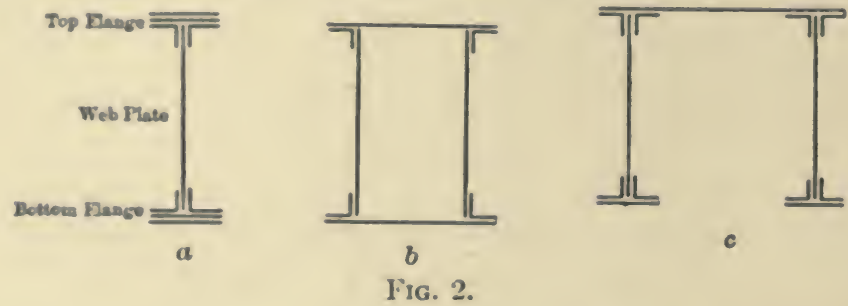

The object of these forms being to take advantage of the known law of stress distribution in flexure.

The relation between the moment of the outer forces and inner stresses for homogeneous bodies subject to flexure is given from the formula

$$
M=\frac{S I}{c},
$$


in which $M$ is the moment of the outer forees;

$S$ is the unit stress in the extreme fiber of the cross-section under consideration:

$I$ is the moment of incrtia of the cross-bection;

$c$ is the distance from the neutral axis to the extreme fiber of the cross-section.

Any existing straight pristnatic girder may be examined for intensity of flexural stress in a plane normal to the axis by means of this formula. The plate girder of prac-

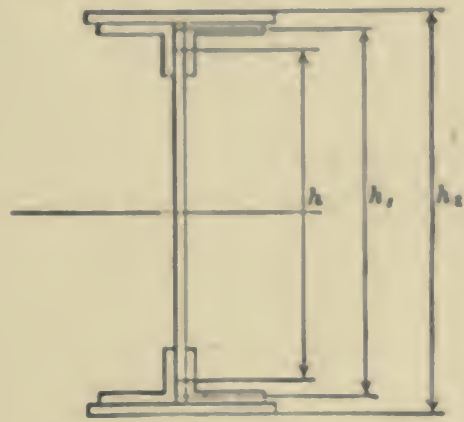

Fig. 2d.

tice is, however, far from the ideal prismatic bar of the Theory of Flexure. The application of the preceding formula to the design of girders is very tedious, and while it could be greatly facilitated by the use of tables of $\frac{I}{c}$ for a great variety of eases, the labor of its application to problems of design is not warranted.

The almost universal method of plate-girder fange design will now be developed, with the aid of the following nomenclature and Fig. 2d. 
Let $A$ be the net area of each flange;

$h$ be the distance c. to c. of gravity of flanges;

$S$ be the allowable unit stress for tension or compression produced by flexure;

$h_{1}$ be the depth of the web plate;

$t$ be the thickness of the web plate;

$h_{2}$ be the depth out to out of flanges;

1 , be moment of inertia of each flange about its own horizontal axis.

Then the flexure formula becomes

$$
\begin{aligned}
& M=\frac{S I}{c}=\frac{S}{\frac{h_{2}}{2}}\left[2 \times A \times\left(\frac{h}{2}\right)^{2}+\frac{t h_{1}^{3}}{12}+2 I_{f}\right], \\
& M=S\left[A \cdot h \cdot \frac{h}{h_{2}}+\frac{t h_{1}}{6} \cdot h_{1} \cdot \frac{h_{1}}{h_{2}}+\frac{4 I_{1}}{h_{2}}\right] .
\end{aligned}
$$

The right half of this equation represents the moment of the internal stresses; of the three terms which make up this half it may be said:

The term $\frac{4 I_{f}}{h_{2}}$ is sinall in most cases, but for shallow girders it is relatively quite large, its omission from the expression requires the other terms to be larger.

The value of $\frac{h}{h_{2}}$ is always less than unity, and in shallow girders considerably less, frequently as much as $10 \%$.

The value of $\frac{h_{1}}{h_{2}}$ is usually less than unity, for very shallow girders without cover plates it is often equal to unity, and for girders with two or more cover plates it may be as much as $10 \%$ less than unity. 
If $h, h_{1}$, and $h_{2}$ be taken equal, and the term $\frac{4 l_{1}}{h_{2}}$ be dropped the formula may be written:

$$
M=S\left(A \cdot h+\frac{t h_{1}}{6} \cdot h\right)-S h\left(A+\frac{t h_{1}}{6}\right) .
$$

That is, the approximate moment of the internal stroses equals the unit stress times the depth times the net area of one flange plus $f$ of the area of the web plate. Many engineers drop the $\frac{t h_{1}}{6}$ from the expression, as its value is small and it is on the side of safety to do so. Others include it with the idea that as the web takes a part of the horizontal stresses these horizontal stressess should be considered in designing the flanges and web splices. Where stiffeners or splices are used on the web it is impossible to maintain the full web section, and the web available as flange is usually taken as $\frac{t h_{1}}{\mathrm{~g}}$, which corresponds to a vertical rivet pitch of about 4 ". The preceding formula should be written for the purpose of design:

$$
A=\frac{M}{h s} \frac{t h_{1}}{6}, . . \text { (1) or } A=\frac{M}{h_{s}}-\frac{t h_{1}}{s} . .
$$

In this formula $\frac{M}{h}$ is known as the flange stress, just as in the case of trusses the moment divided by the depth is the chord stress. 


\section{PROBLEMS}

2n. Compute the net area required in the flanges of a plate girder 30 long and $45^{\prime \prime}$ deep out to out of flange angles, when carrying two loads, of 160,000 lbs. each, spaced 5 from the center of the girder and a uniform load of 300 lbs. per linear foot. Assume a web plate of $45 \times 3 "$.

2b. Make up a section for the bottom fange of the girder of Prob. $2 a$, using only two angles.

2c. Make up a section for the bottom flange of the girder of Prob. $2 a$, using two cover plates and two angles.

\section{ART. 3. THE DESIGN OF THE CROSS-SECTION OF THE FLANGES}

Flanges of plate girders are generally composed of angles in pairs or angles in pairs and plates, as is shown in Fig. $2 a, 2 b$, and $2 c$. The several parts are connected by rivets. The holes for the rivets are generally punched to a diametcr $\frac{1}{16}$ " greater than that of the rivet, or to a diameter of $\frac{3}{16}$ " less and subsequently reamed to $\frac{1}{16}$ " greater, or, as in the best class of railway work, drilled to a diameter $\frac{1}{16}$ " greater than that of the rivet. It is customary in designing tension members to allow for a hole $\frac{1}{8}$ " greater in diameter than that of the rivet, that is, for a $\frac{7}{8}$ " rivet a hole $1^{\prime \prime}$ in diameter should be deducted. The number of holes to be dedueted from any tension flange depends on the number of rows of rivets and the spacing of the rivets in the rows. Much might be written on this point, but here only little will be given.

For the flange shown in $a$ in section, the views of $c$ and $d$ are longitudinal developments of one of the angles showing common methods of grouping the rivets. 
It is clear that a symmetrical arrangement of rivets such as shown in $c$ is better than that of $d$, for the center of gravity of the net area through $x-x$ and $y-y$ of $c$ lies in the root of the angle, while for the corresponding sec-

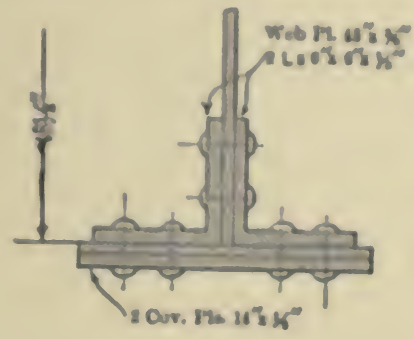

(r)
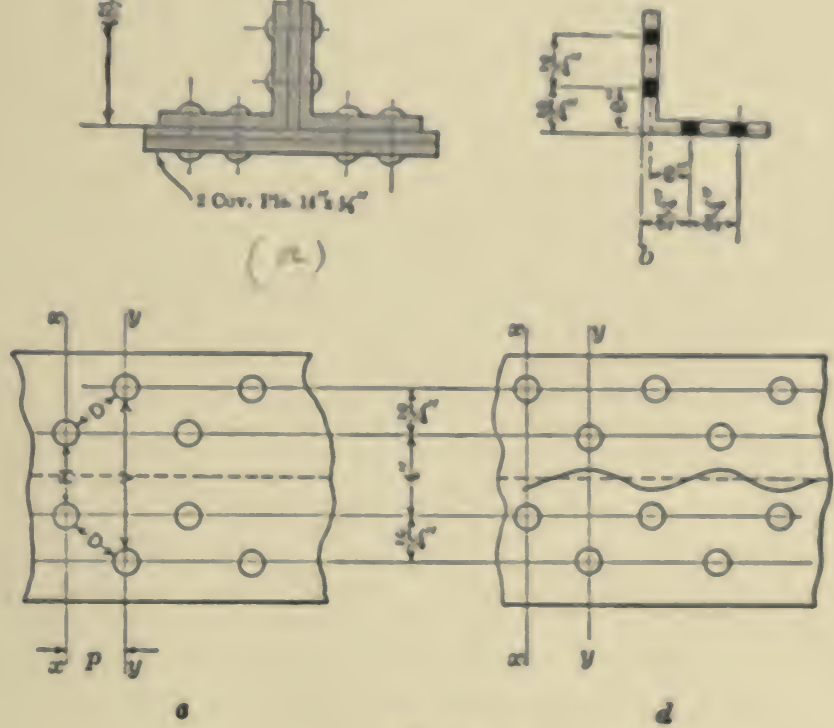

Fio. 3.

tions of $d$ it is first to the right of the root and then to the left, as indicated. The arrangement at $d$ is sometimes chosen because it permits a little more freedom in driving one of the inner lines of rivets. Care must be taken in locating the sections $x$ and $y$ so that $2 D+H \equiv V$; for the case selected the longitudinal pitch $p$ cannot be less than $\sqrt{3.25^{2}-2.25^{2}}-\sqrt{\frac{88}{16}}-\frac{1}{4} \sqrt{88}-2.35^{\prime \prime}$. In fact the stresses 
passing through the space marked $D$ are considerably bent and thereby increased, and therefore the distance $p$ for a good stagger for this case should be $3^{\prime \prime}$. It should be noted that most girders have an excess of strength except at the point of maximum bending moment and at the ends of cover plates, and hence care in staggering the rivets need only be exercised at these points.

The entire flange stress is developed in small increments by the web and transmitted to the flange by the rows of rivets connecting the vertical legs of the angles to the web. It is elear that these angles then should comprise a considerable part of the total flange areasome engineers require $50^{\%}$, others permit as little as $33 \frac{1}{3} \%$. The girder which has a flange stress developed in a short distance requires heavier angles than one in which the stress is developed in a great distance. The foregoing provision for maintaining net section applies particularly to the tension flange. The compression flange is usually made equal in gross area to the tension flange.

The compression flange is in somewhat the condition of a column as far as liability to failure in a sidewise direction is concerned. For girders with a constant top flange section the maximum unit stress occurs only at the point of maximum moment, for a flange with cover plates; that is, for a flange which varies closely as the flange stress, the unit stress is nearly constant throughout. The web stiffeners, if any are used, give considerable lateral stiffness to the top flange, reaching and connecting, as they do for half their length to material in tension. The sketch of Fig. $3 e$ will help make this point clear. The tension flange 


\section{DESIGN OF THE CROSSSECTION OF FLANGES II}

is held in line by virtue of its stress; any tendency to sidewise deflection of the compression flangr is resiated by the tension flange if stiffenens are used.

If the unit stress for static loads in tension is 16,000 the. per square inch, then $16,000-70 \frac{l}{r}$ is a corresponding unit stress for a compression member, in which the quantities need no definition. If it be assumed that a girder fange

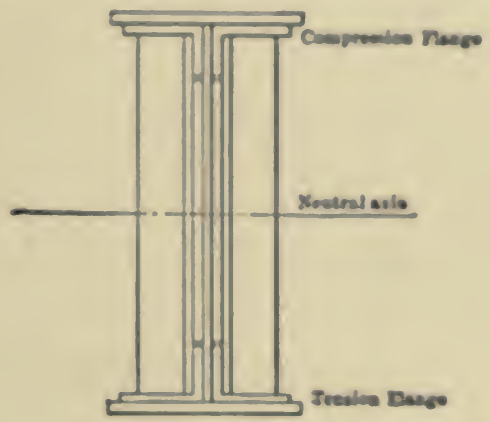

Fig. 3e.

is similar to a column in its action and that its section is a rectangle whose width $-b$, then

$$
\left(16,000-70 \cdot \frac{l}{r}\right)-\left(16,000-70 \cdot \frac{l}{b} \sqrt{\frac{1}{12}}\right)-16,000-242 \frac{l}{b} \text {, }
$$

or

$$
16,000-240 \frac{l}{b}, \ldots . . .
$$

gives a compressive unit stress for a girder flange corresponding to $16,000 \mathrm{lbs}$. per square inch in tension. As the stress in a girder flange is only a maximum for. $n$ 
small part of its length a formula for the safe compressive and unit stress

$$
P=16,000-200 \frac{l}{b}, \quad . \quad . \quad . \quad .
$$

may be used.

Experience has shown that no material should be used which is less in thickness than $\frac{1}{16}$ of the distance between the rivets in the direction of the action of the stress, $\frac{1}{s}$ of the distance from the center of a rivet to the edge of the piece at right angles to the line of stress, or that any angle leg when used alone in a girder flange shall be longer than 12 times its thickness, otherwise the girder flange may fail in detail rather than as a whole.

For simplicity and ease of construction the compression flange should not be made of greater section than the tension flange, therefore the compression flange must be supported in a sidewise direction at frequent intervals, which, from the preceding formula, will be about every ten times the flange width. It is customary to consider that the rivets completely fill the rivet holes in the compression flange and that the full gross section of the flange may be assumed to act to resist compression. This assumption with regard to the rivets always filling the holes is open to serious question, and if they do fill the holes they do not offer the same resistance to lateral deformation which takes place under compression as the unpunched material. However, it is fair to assume that they partially make up the punched-out material. The formula for the unit stress for the compression flange is believed to be severe enough to allow it to be applied to the gross area 
of the flange. The depth $h$ (called the effective depth) of formula (1) is obtained by taking the gross area of both flanges in computing the location of the eenter of gravity of the flanges.

It should be borne in mind that if there is no lateral deflection of the top flange that its maximum unit strens depends entirely on $\frac{l}{c}$, the section modulus, as it is sometimes called. While rivet holes affect the position of the neutral axis for the sections in which they occur, probably two-thirds or one-half of the length of a girder will be undiminished by holes, hence in applying the formula $M=\frac{S I}{c}$ to check the results of formula (1) it will be bent to determine the position of the neutral axis from the gross section, and find the moment of inertia of the net section of the entire girder section for $I$ in the formula.

\section{PROBLENS}

3a. Compute the probable maximum unit stress in the tension flange of the girder of Prob. 2b, by means of the formula $M=\frac{S I}{c}$.

3b. Compute the probable maximum unit stross in the tension tlange of the girder of Prob. $2 c$, by means of the formula $M=\frac{S I}{c}$.

3c. Compute the probable maximum unit streas in the comprestion flanges of Probs. $3 a$ and $3 b$, by tweans of the formula $M=\frac{S I}{c}$. 


\section{ART. 4. LENGTHS OF COVER PLATES}

The plate girder, being a composite structure, may easily be constructed so that its cross-section may vary approximately as the moments and shears require. The full flange section being required only where the moment is a maximum, a method of determining where the parts may be omitted when no longer required is necessary to economically design the girder. In general the cover plates are the only parts of the flange which do not extend the full length. Two methods will be developed for finding where cover plates (or any other part of the flange) may be omitted.

The first: For girders which carry a uniform load, or a load which may be closely represented by a uniform load. Deck plate girders for railway bridges may be inclucled in this classification.

In Art. 2 the approximate moment of the internal stresses at any section $=S h \times\left(A+\frac{t h_{1}}{6}\right)$ in which $\left(A+\frac{t h_{1}}{6}\right)$ is the net flange area, designating this area by $a$ for simplicity, the moment of the internal stresses becomes Sha.

Let $w=$ the uniform load per foot of girder, or for locomotive loading the uniform load which would produce the same end shear, then the bending moment at any point distant $x$ from the end $=\frac{w l x}{2}-\frac{w x^{2}}{2}$, and this must equal the moment of the internal stresses.

$$
\therefore \quad \frac{v l x}{2}-\frac{w x^{2}}{2}=\text { Sha, }
$$


if it is desired to find the location of the point $n$, where the first cover plate must begin, substitute for $S, h$, and a their value for the portion of the girder between the end and $n$ and solve for $x$. It is more enovenient in practice to have the formula in such form as to give the length of cover plate direct. For this puprome

Let $c=$ the theoretieal length of any cover plate $-l-2 x$; $C$ - the practical length of any cover plate $c+y$ $(y-$ from 2 to 5 feet) the additional length $y$ being required for locating a few rivets, so that the plate may be capable of taking stress where it is theoretically required.

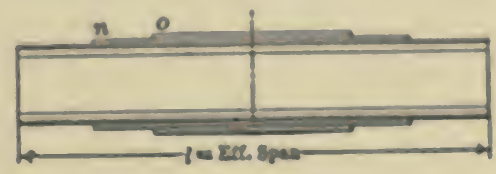

Fic. ta.

From the foregoing relation between the moments of the outer and inner forces may be written

$$
\begin{aligned}
& x^{2}-l x+\frac{l^{2}}{4}=\frac{l^{2}}{4} \frac{2 S h a}{w} \text { and from this } x-\frac{l}{2}-\sqrt{\frac{l^{3}}{4}-\frac{2 S h a}{v} .} \\
& \therefore \quad C-y+c-y+l-2 x \\
& \quad=y+l-2\left(\frac{l}{2}-\sqrt{\frac{l^{2}}{4}-\frac{2 S h a}{v}}\right)-y+2 \sqrt{\frac{l^{2}}{4} \frac{2 S h a}{w}} .
\end{aligned}
$$

To use the formula to find the length of the sccond plate, take $a$ and $h$ for the portion of the girder between $n$ and $o$. 
Another simple formula by the author for finding the lengths of cover plates for this class of loading is given in Eng. News, XXXII, page 278, the issue of Oct. 4, 1894.

The second: For girders carrying loadings which may not be represented by a uniform load. Girders of this class receive their loads through other girders or columns at definite points. The main girders of through plate girder spans with floorbeams are common examples of this class.

As before the resisting moment $=S h a$, where

$a=$ area of flange at end of any cover;

$h=$ depth c. to c. of gravity of flanges at end of any cover;

$S=$ unit stress.

The bending moment $M$ at any point along the length of the beam and distant $x$ from the left end, where $P_{1}$, $P_{2}, P_{3}$, etc., of Fig. $4 b$ are the concentrated loads, $w$ the

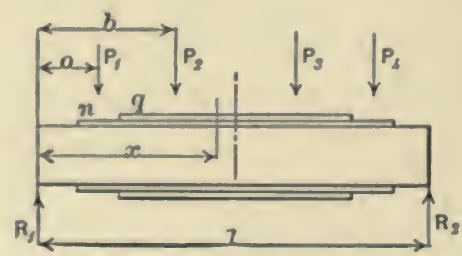

Fig. 4 .

uniform load per foot of length, and $R_{1}$ the left hand reaction, is given from

$$
M=R_{1} x-w x \cdot \frac{x}{2}-P_{1}(x-0)-P_{2}(x-b)-\text { etc. }
$$


Since the moment of the exterual forces - moment of internal stresses

$$
R_{1} x-\frac{u x^{2}}{2}-P_{1}(x-0)-P_{3}(x-6)+\text { etc. }=\text { She, . }
$$

in which every quantity is known except $x$.

To spply this to any point $n$ between the finst concentrated and the end the above becomes

$$
R_{1} x-\frac{w x^{2}}{2}-\operatorname{shh} a, . . . \cdot
$$

in which $R_{1}$ and Sha are known, and the solution of which is a very simple matter. It should be noted that the proper position for the live load is that which makes $R_{1}$ a maximum.

To apply it to any point $q$ between two loading points the formula becomes,

$$
R_{1} 0+\left(R_{1}-P_{1}\right)(x-o)-\frac{u x^{2}}{2}-S h a . \quad . \quad .\left(4^{\prime \prime}\right)
$$

The position of the live load must be taken, finst, so as to make the bending moment at $P_{1}$ a maximum; second, so as to make the bending moment at $P_{2}$ a maximum.

This gives two equations of the form of ( $\left.f^{\prime \prime}\right)$ each of which must be solved for $x$.

The value of $x$, which is least, i.e., the one requiring the longest cover, is to be taken.

The lengths of cover plates are realily found by a graphic method which needs no explanation beyond the following sketch: tc. The full line is drawn to reprosent 
the resisting moment of the various portions, and the dotted line the moments of the outer forces.

The applieation of formulas (3) and (4) will now be made to finding the lengths of cover plates; for this purpose assume a girdor $43^{\prime}$ long c. to c. end bearings, 60 ${ }_{2}^{\prime \prime}$

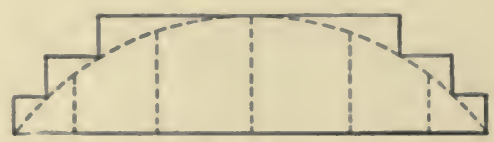

Fig. $4 c$.

deep out to out of flange angles and of the following composition:

1 web plate $60 \times 3{ }^{\prime \prime}=22.50$ sq.in. $\times \frac{1}{8}=2.81$ sq.ins.

2 top angles $6 \times 6 \times 19.6=11.52+2.81=14.33 \mathrm{sq}$.ins.

1 top plate $14 \times \frac{1}{2}=7.00+14.33=\quad=21.33$ sq.ins.

1 top plate $14 \times \frac{1}{2}=7.00+21.33=\quad=28.33$ sq.ins.

2 bottom angles $6 \times 6 \times 19.6=11.52-2.00=9.52+2.81$ $=12.33 \mathrm{sq} . \mathrm{ins}$.

1 bottom plate $14 \times \frac{1}{2}=7.00-1.00=6.00+9.52=$

18.33 sq.ins.

1 bottom plate $14 \times \frac{1}{2}=7.00-1.00=6.00+15.52=$ $24.33 \mathrm{sq}$.ins.

The girder will first be assumed to act as in a singletrack deck railway bridge, using formula (3), Maximum bending moment $=1,938,410 \mathrm{ft}$.lbs.

Maximum end shear $=193,500$ lbs. $\left(w=\frac{193,500}{21.5}=9000\right)$.

$$
\begin{aligned}
& a=12.33,18.33 \text {, and } 24.33 \text { sq.in. } \\
& h=4.77,4.85 \text {, and } 4.93 \mathrm{ft} \text {. }
\end{aligned}
$$


For first cover $\quad C_{1}=y+2 \sqrt{\frac{(4.3)^{2}}{1} \frac{2 \times 12.33 \times 4.77 \times 16,000}{9000}}$

$$
\begin{aligned}
& -y+2 \sqrt{462.2-209.1}-y+2 \sqrt{253.1} \\
& -2+2 \times 16-34^{\prime} \text { long. }
\end{aligned}
$$

For second cover $C_{3}-y+2 \sqrt{462.2-2 \times \frac{1 \times 3.3}{4000} \times 4.85 \times 16,000}$

$$
\begin{aligned}
& -y \times 2 \sqrt{462.2-316.1-y+2 \sqrt{146.1}} \\
& -2+24-26^{\prime}
\end{aligned}
$$

The girder will now be assumed to have floorbeams attached to it as indicated in Fig. 4d. The reaction $R_{1}$, when the moment at $P_{1}$ is a maximum, is 136,500 lbs. and the own weight of the girder 300 thes. per linear foot.

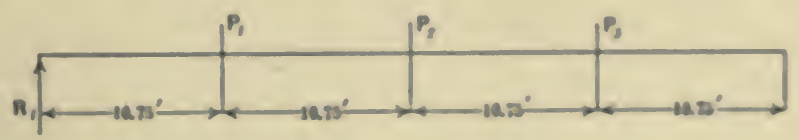

Fig. 4d.

Then for the first cover

$$
136,500 x-300 \frac{x^{2}}{2}=12.33 \times 4.77 \times 16,000-941,000 .
$$

$$
\begin{gathered}
91\left(0 x-x^{2}-6273 \text { or } x^{2}-910 x+207025=-628+207025\right. \\
x=45.5-38=7.5 .
\end{gathered}
$$

The length of the first cover $C_{1}=2+(43-15)=30^{\prime}$.

For the second cover

$$
\begin{aligned}
136,500 x-150 x^{2}- & 18.33 \times 4.85 \times 16,000=1,422,400 . \\
& x^{2}-910 x-9485 \\
& x=455-445=10 .
\end{aligned}
$$

The length of the second cover $C_{2}=2+(43-20)=25^{\prime}$. 


\section{PROBLEMS}

4a. Iet each of the flanges of the girder of this Art. consist of

2 angles $6 \times 6 \times 17.2 \mathrm{lbs} .=10.12$ sq.ins.

1 cover plate $14 \times \frac{1}{1} \cdots-5.25$

1 cover plate $14 \times \cdots=5.25 \quad \cdots$

1 cover plate $14 \times$ " $\cdots=5.25$ “

and $\frac{1}{8}$ of the web plate $60 \times 3$.

Find the lengths of the cover plates when it acts as a part of a deck railway bridge.

4h. Find the lengths of the cover plates when the girder of Prob. $4 a$ acts as a part of a through bridge. The concentrated load $P_{1}=105,000$ lbs. The loads being spaced as shown in Fig. 4d.

\section{ART. 5. RIVET SPACING IN GIRDER FLANGES}

The connection between the web and flanges of girders, as in other composite structures, is made by means of rivets. These rivets are spaced with reference to the horizontal component of the stress in the flange, for at the extreme fiber the direction of the stress is horizontal and the maximum shearing unit stresses in the flanges are very small, and hence the horizontal component is the only stress of importance.

The one important exception to the foregoing is where the girder load is applied to one of the flanges, here the rivets have to transmit the loading which the girder carries together with the horizontal stress increments between the flanges and web. The exceptional case will receive special consideration.

The moment of the external forces at any point in a girder equals the moment of the internal stresses, there- 
fore between any two point it is essential that there be enough rivets to properly develop the strenues produced by the maximum increase in moment betwern the points. The inerement in the moment is constantly varying throughout the girder length. The gerneral requation for moment for a simple gireler as given in Art. 4 is

$$
M=R_{1} x \frac{w x^{2}}{2}-P_{1}(x-0)-I_{2}(x-b)-\text { ete. }
$$

The derivative of $M$ with respect $10 x$ is,

$$
\frac{d M}{d x}-R_{1}-w x-P_{1}-P_{2}-c t c_{0}, \text { and is the shear. }
$$

It is therefore seen that the greatest increase in the bending moment occurs when the shear has the greateet possible value.

The increase in bending moment between two points so close together that the load between them may be neglected, is the shear multiplied by the distance between the points; the increase in flange stress is this increase in moment divided by the depth.

Let $V$-the maximum shear at any point on the girder; $h$-the effective depth, i.e., the depth c. to c. of gravity of flange, in inches;

$R$-the least value of the rivet to resist either crushing or shear, and

$p=$ the space between two adjacent rivets in inches. Then $\frac{V \times 1}{h}-$ the maximum increase in flange stress in a space of 1 inch

$\frac{R}{p}$-stress per inch of girder length carried by the rivets 
For the proper ilegree of strength $(a)$ should equal (b).

$$
\therefore \quad \frac{V}{h}-\frac{R}{p} \text { or } p=\frac{R h}{V} . . . .
$$

In order to show the application of (5) to determining rivet pitch: Let Fig. $5 a$ represent a portion of the girder

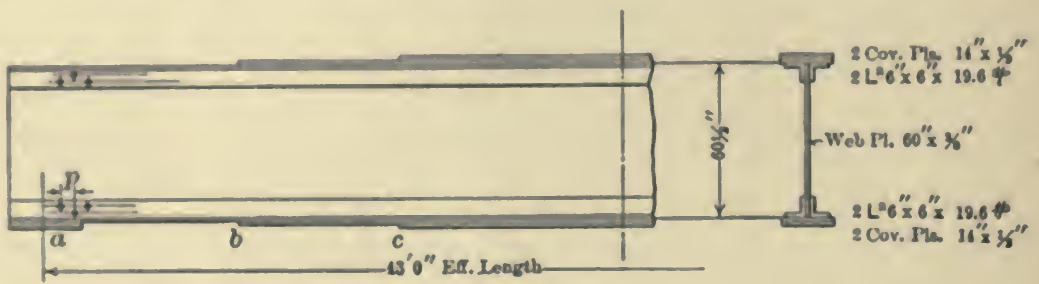

Fig. $5 a$.

used to illustrate the method of finding lengths of cover plates in Art. 4.

The shear at $a=193,500$, at $b=153,000$, and at $c=118,000$.

The value of a rivet in bearing $=24,000$, and in shear 12,000 lbs. per sq.in.

The pitch for " ${ }_{\mathrm{g}}^{\prime \prime}$ rivets, at $(a)=$

$$
p=\frac{4.77 \times 12 \times 7876}{193,500}=2.34^{\prime \prime}
$$

provided the flange angles are designed to carry the entire flange stress at this point. If, however, as was assumed in finding the length of the cover plates, the portion of the web used as flange area is 2.81 sq.in., then the pitch $=\frac{2.34 \times 12.33}{(12.33-2.81)}=\frac{2.34 \times 12.33}{9.52}=3.03^{\prime \prime}$. The pitch of 2.34" would require that two lines of rivets be used, as good construction requires that the rivets be not eloser 
than 3". It is also customary to use two rows of rivets to connect a $6^{\prime \prime}$ angle leg to the web.

If the load is applied directly to the girter flange then the previous computation needs modification for the rives pitch in the vertical legs of the angles of the loaded flangre. Lat Fig. 56 represent a part of the top flange of the girder of Fig. $5 a$ and assume that it carries one-half a railway track on the top flange. One engine wheel wroighing $50,000 \mathrm{lbs}$. including impact, will then be carried in a space of about

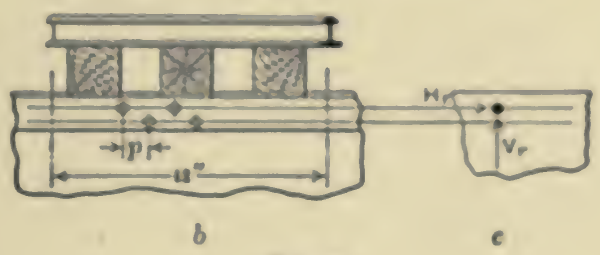

Fัเ. 3.

$42^{\prime \prime}$, it being the custom to asssume that three tics carry

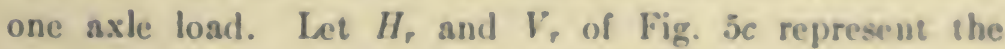
resultant horizontal and vertical forces on the rivet as applied to the rivet by the girder web; the resultant of these two forces $R$ should not exceed the ability of the rivet to safely resist either shear or crushing. To determine the pitch for this case,

Let $W=$ the wheel loal inchding impact (or other eos. centrated load);

$a=$ total fiange area

$a_{1}=$ total flange area with the part of web uact

for flange deducted;

$s=$ three times the distance $c .800$ of ties in inches, $h=$ effective depth of the girder in inches; 
$h_{r}=$ horizontal increment of stress in a length of one inch carried by $a_{1}$;

$v_{r}=$ vertical load per inch of length of flange affected by the concentrated load,

$r_{r}=$ resultant of $h_{r}$ and $v_{r}=\sqrt{h^{2}{ }_{r}+v^{2}}$

$$
=\sqrt{\left(\frac{V}{h} \cdot \frac{a_{1}}{a}\right)^{2}+\left(\frac{W}{s}\right)^{2}}
$$

Then if $R=$ the value of the rivet, as before,

$$
p=\frac{R}{r_{r}}=\frac{R}{\sqrt{\left(\frac{V \cdot a_{1}}{h \cdot a}\right)^{2}+\left(\frac{W}{s}\right)^{2}} .}
$$

Let this be applied to finding the pitch for connecting the top flange angles to the web for the end of the girder of Fig. $5 a$.

$$
\begin{aligned}
\frac{V a_{1}}{h a} & =\frac{193,500 \times 9.52}{57.24 \times 12.33}=\frac{193,500 \times 9.52}{705.77}=2610 ; \\
\frac{W}{s} & =\frac{50,000}{42}=1190 ; \\
p & =\frac{7876}{\sqrt{2610^{2}+1190^{2}}}=\frac{7876}{2710}=2.91^{\prime \prime} .
\end{aligned}
$$

For the heavier concentrated loads, such as columns bring when carried on the flanges of the girders, the flange angles will often not contain enough rivets for security, and stiffeners must be used, as will be explained later. The foregoing gives a simple method for finding the maximum permissible pitch of the rivets connecting the vertical legs of the flange angles to the web.

The determination of the pitch of the rivets for con- 
necting the cover plates to the horizontal leg of the fange angles is not a simple matter if theoretical accuracy is desired.

At 6 , Fig. 5a, the point where the fint cover plate begins the flange angles have in them all the strus they can earry. It is clear, therefore, that from b to $c$ with the rivets connecting the first cover to the flange angles spaced to take only the flange stress increment, the flange angles simply transmit the increments of stress to the first cover plate. At $c$ the first cover plate and angles have all the stress they can carry, and with rivets spaced as before the increments of flange stress from $c$ fo the point of maximum flange stress are simply transferred through the angles and first cover to the second cover. Rivets connecting a cover plate to a flange are generally spaced to take the increments of flange stress which occur from the end to the point of maximum stress in the cover. If $n$ be the number of lines of rivets connecting the cover to the flange then

$$
p=\frac{n R h}{V}
$$

Assuming two lines of rivets in the cover plates the pitch at $b$ for connecting the first cover to the flango angles $-\frac{2 \times 7216 \times 57.24}{153.000}-5.41^{\prime \prime}$. This is the maximum that may be used; the actual pitch would be made considerably less and usually a multiple of 1,7 , or $1^{\prime \prime}$ and at the same time such a pitch as would stagger well with the rivets in the vertical legs of the flange angles. If the maximum 
pitch permissible were used the stress per square inch in the first cover plate would be zero at $b$ and increase to 16,000 at c. This is highly undesirable, as there would exist in the girder in juxtaposition the angles with a unit stress of 16,000 and a cover with an average of $8000 \mathrm{lbs}$. The girder flange material cannot act in any such way without undue bending stresses on the rivets.

For this important reason cover plates should be made longer than a mere consideration of their relation to the moment polygon would require. The additional length, designated by $y$ in formula (3) required, is a function of the number of rivets necessary to equalize the flange unit stress in all the flange material, and may be determined as follows:

Let $n=$ number of rows of rivets in the cover plates;

$a=$ area of flange without the cover plate under consideration, with unit stress $s$;

$a_{1}=$ area of flange, including the cover plate under consideration, with unit stress $s_{1}$;

$p=$ pitch in inches of the cover plate rivets in each line;

$R=$ value of one rivet connecting the cover to the flange;

$y_{1}=$ additional length of cover plate required at each end in $\mathrm{ft} .=\frac{y}{2} . \quad y_{1}=\frac{\left(a_{1}-a\right) s_{1}}{12 R n} \cdot p$.

$$
y=\frac{\left(a_{1}-a\right) s_{1}}{6 R \cdot n} \cdot p=\frac{S \cdot a \cdot p}{6 a_{1} \cdot R \cdot n}\left(a_{1}-a\right) .
$$




\section{RIVET SPACING IN GIRDER FLANGES}

The value of $y$ for the finst cover of the fint example used to illustrate the method of finding the lengths is:

$$
y=\frac{16,000 \times 12.33 \times 6}{6 \times 18.33 \times 7216} \cdot \frac{p}{n}-\frac{3}{2} \cdot \frac{p}{n}
$$

If the rivets be placel 3 " apare in two rows $y=2.25$.

If enough rivets are used at the end of a cover plate as at $b$ of Fig. $5 a$ to trausmit to it its full proportion of the flange stress, the rivet pitch required to conseet the cover plates to the flange at any point will be the following:

$$
p=\frac{A_{2}}{A} \cdot \frac{n \cdot R h}{V}
$$

In which $A_{1}$ is the total flange area, and $A$ the area of all the cover plates, at the point under consideration. The number of rivets as determined by $\left(5^{\prime}\right)$ and $\left(5^{\prime \prime}\right)$ should be increased by $20 \%$ to allow for the bending stresses. To still further limit these bending stresses no rivet passing through angles and covers should have a grip more than five times the diameter of the rivet.

\section{PROBLEMS}

6a. U'sing unit stresses of 10,000 and 20,000 the. for rivets in Nhear and crushing, compute the required rivet pitch for connecting the bottom flange angles to the web at $c$ of Fig. 5a.

5\%. For the data of Prob. 5a compute the rivet pitch for connerting the top flange angle to the web at a point vertically over $c$, including the effect of a locomotive wheel load.

6c. Using the unit strusses of sa compute the value of $y$ for the smond cover plate.

6.d. Compute the pitch of the rivets in the cover plate of $b e$ just adjacent to the portion $y$. 


\section{ART. 6. WEB PLATES}

The maximum stresses that the web of a beam or girder must resist are of varying intensity and direction throughout its area.

For any elementary parallelopiped cut from the body of a beam in equilibrium subject to flexure, the forces on the faces of the element perpendicular to the plane of the drawing may be represented for the most general case

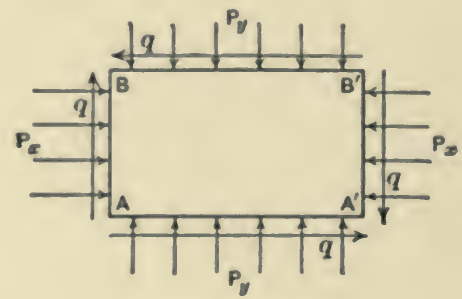

FIG. $6 a$.

as shown. The weight of the elementary particle may le neglected, as it is an infinitesimal of the third order as compared with the amount of stress on the faces, which are infinitesimals of the second order.

As the length of the sides of the particle approach zero as a limit, the intensities of the oppositely directed forces $p_{y}$ are equal, and also the forces $p_{x}$. If the oppositely directed normal forces are of equal intensity the tangential or shearing forces $q$ are also of equal intensity. The intensity of the shearing stresses at any point in a homogeneous prismatic body subject to flexure is given 
from $q=\frac{V Q}{b I}$, a well-known formula of Mechanica of Materials, in which

q- the unit shearing stress;

$V=$ the total shear;

$b$-the width of the borly at the point under eonsideration;

$Q$-statical moment of the portion of the botly above the point under consideration with referenee to the neutral axis of the body, and

$I$-moment of inertia of the borly with reference to the neutral axis.

The intensity of stress $p_{s}$ at any point is given from the Hexure formula $p_{s}=\frac{M / y}{I}$, in which the quantities are too well known to need definition.

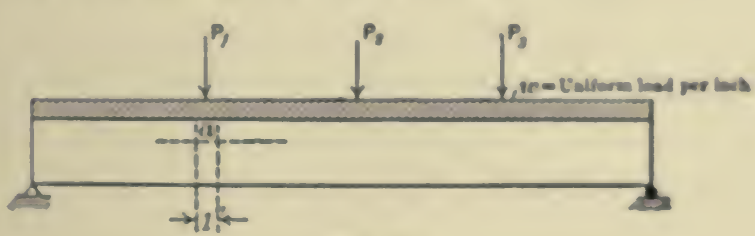

Fio. 6 .

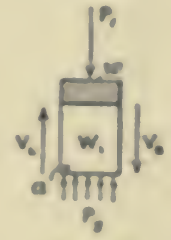

Fio. Ge.

The intensity of stress $p_{y}$ may be found as follows: let Fig. $6 b$ represent any beam subject to flexure and a any point in the beam. Assume two planes distant 1" apart on either side of $a$ as shown by the dotted lines.

The vertical forces on the portion of the beam above $a$ and between the parallel lines are as indicated on the larger scale sketch, Fig. $6 c$, in which $V_{R}$ is the sum of 
the shearing resistances of the right surface above $a$, $V_{L}$ is the sum of the shearing resistances of the left surface above $a$.

$W=\left(P_{1}+w+W_{1}\right)=$ the total load between the two assumed planes above the point $a$, and $A=$ the area in square inches of the horizontal surface through $a$. Then

or

$$
V_{t}-V_{k}-W+p_{y} A=0
$$

$$
p_{y}=\frac{V_{l}+W-V_{l}}{A} .
$$

Care must be taken in giving the proper signs to $V_{k}$ and $V_{L}$.

Having a method for finding $p_{x}, p_{y}$ and $q$ for any point in a beam, there remains to be found the plane in which their combined action has the greatest intensity.

The stresses per square inch $p_{x}, p_{y}$ and $q$ may be produced in any manner, even in an arbitrary manner or $p_{x}$ and $q$, and $p_{y}$ and $q$ may be the rectangular components into which the actual stresses on any elementary parallelopiped have been resolved, as far as the following argument is concernerl.

Let Fig. $6 d$ be a redrawing of $6 a$. Let the plane $O P$ be passed through the elementary particle perpenclicular to the face and making the angle $\theta$ with $A A^{\prime}$, consider the elementary figure to have a dimension of unity perpendicular to the plane of the drawing.

Let it be required to find $\theta$ so that the stresses on $O P$ will be normal and therefore either the maximum or minimum stresses in the body. 


\section{WEB PI.ATES}

Let $p$ represent the intensity of atreen on $O P$, then $\overline{O P} \times p \times \frac{A P}{O P}=p_{2} \times A P+q \times A O$, or $p-p_{0}-q \cot 0$. and $\overline{O P} \times p \times \frac{A O}{O P}=p_{y} \times A O+q \times A P$, or $p-p_{y}=q \tan 0$.

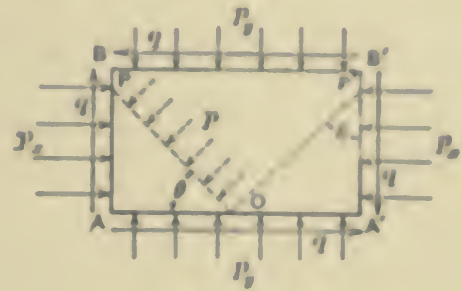

Fig. Gd.

Subtracting the second form of (b) from (a),

$$
p_{y}-p_{z}-q(\cot \theta-\tan \theta)=q \cdot \frac{1-\tan ^{2} \theta}{\tan \theta}-q \cdot \frac{2}{\tan 2 \theta^{\circ}}
$$

or $\tan 20-\frac{2 q}{p_{y}-p_{s}}$. The solution of this gives two values of 0 , one of which corresponds to $O P$ and the other to $O P^{2}$.

Further, multiplying $(a)$ by $(b)$,

$$
\begin{gathered}
\left(p-p_{s}\right)\left(p-p_{y}\right)-q^{2} \tan 0 \cot 0-q^{2} \\
p^{2}-p\left(p_{s}+p_{y}\right)-q^{2}-p_{z} p_{y} \\
p^{2}-p\left(p_{z}+p_{y}\right)+\left(\frac{p_{z}+p_{y}}{2}\right)^{2}-\left(\frac{p_{z}+p_{y}}{2}\right)^{2}+q^{2}-p_{s} p_{y} \\
p \frac{p_{z}+p_{y}}{2}- \pm \frac{1}{\left(p_{z}+p_{y}\right)^{2}+4\left(q^{2}-p_{z} p_{y}\right)} \\
p=\frac{1}{2}\left[p_{x}+p_{y} \pm \sqrt{\left(p_{x}+p_{y}\right)^{2}+4\left(q^{2}+p_{z} p_{y}\right)}\right] \\
-\frac{1}{2}\left[p_{x}+p_{y} \pm \sqrt{\left(p_{z}-p_{y}\right)^{2}+4 q^{2}}\right] .
\end{gathered}
$$


The two values of $p$ given from (9) correspond to the maximum and minimum values and occur on either $O P$ or $O P^{\prime}$.

For an extended treatment of the subject of combined stresses see Wood's Analytical Mechanics, Chapter V.

If either or all of the quantities $p_{z}, p_{y}$ or $q$ have a direction opposite to that shown in Fig. $6 d$ they should be entered in the formulas with a minus sign.

The planes of maximum shear make angles of $45^{\circ}$ with the lines of maximum direct stress.

The amount of $p_{y}$ is small, except for large concentrated loads, with reference to $p_{x}$ and $q$. If $p_{y}$ be neglected, at the end of the beam where $p_{x}=0$ the angle $0=45^{\circ}$ and $p=q$, that is the direct stresses are equal to the shears in intensity and make an angle of $45^{\circ}$ with them.

If $p_{y}$ be neglected, at all points on the neutral axis where $p_{x}$ is zero, $p=q$ and makes an angle of $45^{\circ}$ with the axis.

In determining the location of the plane on which $p$, the principal stress intensity, is a maximum note, the values of the component stresses and inspection will show about the direction the resultant must have. If difficulty occurs in applying formula (9) it will be better to derive a special formula for the case at hand.

\section{PROBLEM}

6a. A plate girder of $14^{\prime}$ effective length carries a total load of $10,000 \mathrm{lbs}$. per linear foot of length, the load being applied to the top flange. Consider the structure to be solid and of a cross section composed of 4 angles $4^{\prime \prime} \times 4^{\prime \prime} \times \frac{1}{2}$ and 1 plate $24 \times \frac{1}{2}$, as shown in the sketch, determine the maximum stress intensity and the direction of 
its action at each nutnbered point as in indicated for points Nos, 3, 7. 9, 11, and 15 of Fig. Ge.

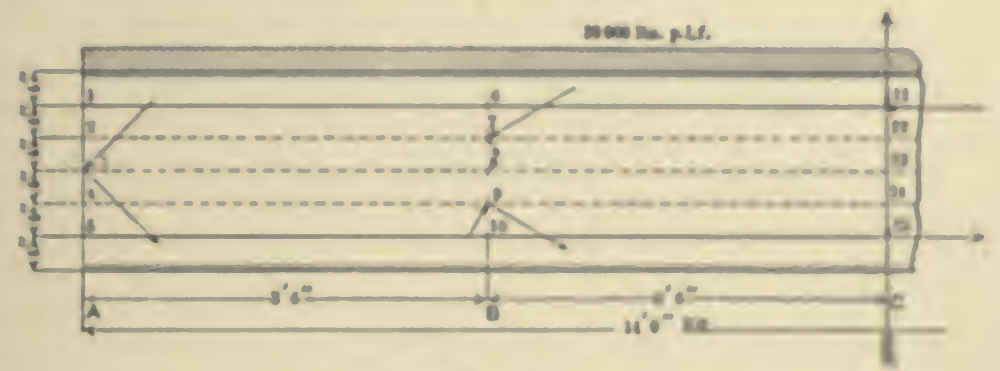

Fio. Ge.

This problem is so important for a proper undentanding of the stress distribution on web plates that it is completely solved for points $\operatorname{Nos} .3,7,9,11$ and 15, and much of the computation made for the remaining points, in what follows in this article. In Fig. Ge arrows acting towand a point indicate compression and away from the point tension.

The computations for $p_{s}, p_{y}$ and $q$ should be made about as follows:

$$
\begin{aligned}
I_{z}=\mathrm{I}^{2} \times 1 \times(24)^{3} & -576.00 \\
5.56 \times 4 & =22.24 \\
4 \times 3.75 \times 10 . \overline{5.2}= & 1756.0 \mathrm{~S} \\
& =2354.32 \\
M_{A} & =0 \\
M_{B} & =2,205,000 \mathrm{in.-1bs.} \\
M_{C} & =2,940,000 \mathrm{in.} . \mathrm{lbs} .
\end{aligned}
$$

At points Nos. 1, 2, 3, 4 and $5, p_{s}=0$

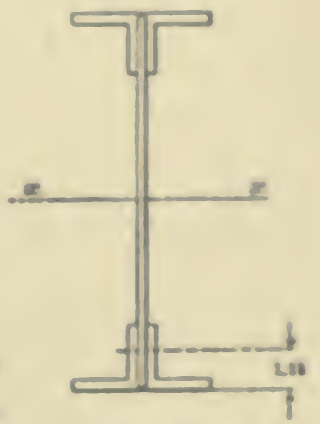

Fเo. 6. 
At points Nos. 7 and 9 ,

$$
p_{x}=\frac{2,205,000 \times 4}{2354.32}=3,740
$$

At points Nos. 11 and $15, \quad p_{2}=\frac{2,940,000 \times 8}{2354.32}=10,000$

$$
\begin{aligned}
Q_{11}=2 \times 3.75 \times 10.82= & 81.15 \\
+2.00 \times 10.00= & 20.00 \\
& =101.15 \\
Q_{7}=2 \times 3.75 \times 10.82= & 81.15 \\
2.00 \times 10 \quad & 20.00 \\
2.00 \times 6 \quad & 12 \\
q=V \cdot \frac{113.15}{b I}=\text { for } \quad & 117.15 \\
Q_{3}=113.15+2 \times 2 & \\
\text { No. } 3=V \cdot \frac{117.15}{.5 \times 2354.32} & =70,000 \times .0993=6960 \\
\text { No. } 7=V \cdot \frac{113.15}{.5 \times 2354.32} & =35,000 \times .0960=3360 \\
\text { No. } 11=V \cdot \frac{101.15}{.5 \times 2354.32} & =0000 \times .0853=0000
\end{aligned}
$$

From formula (7) there is found

$$
\begin{aligned}
& \text { at No. } 3, p_{y}=\frac{833 \frac{1}{3}-833 \frac{1}{3} \times .5}{.5} \quad=830 \\
& \text { at No. } 7, p_{y}=\frac{833 \frac{1}{3}-\left(833 \frac{1}{3}\right) .304}{.5} \quad=1240 \\
& \text { at No. 11, } p_{y}=\frac{833 \frac{1}{3}-\left(416 \frac{2}{3}+416 \frac{2}{3}\right) \cdot 121}{.5}=\frac{733}{.5}=1470
\end{aligned}
$$

Values of $Q, \frac{Q}{b I}$, and $\frac{V Q}{b I}$ should be tabulated as follows: 


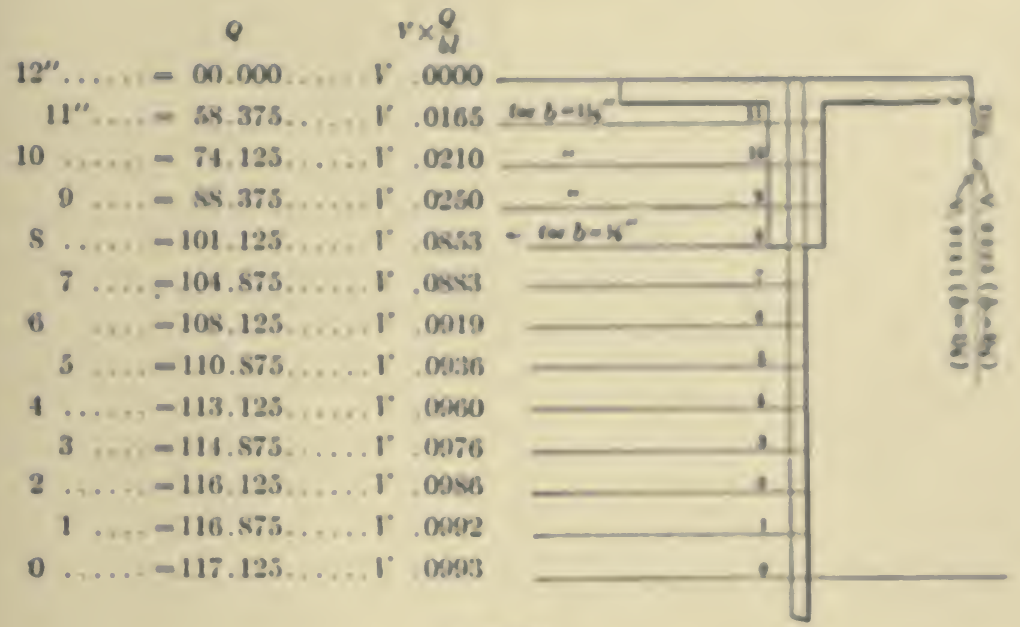

Fic. 6y.

Let $A_{1}=$ the area above division No. $11-4.25+.75=5.00$ sq.ins.

$A_{2}-$ the area above division .0. $10-5.00+1.50=$ $6.50 \mathrm{sq}$. ins., etc.

Values of $q \times$ areas:

$$
\begin{aligned}
q \times A_{1} & =V \times .017 \\
A_{3} & =V \times .046 \\
A_{3} & =V \times .081 \\
A_{1} & =V \times .121 \\
A_{3} & =V \times .165 \\
A_{6} & =V \times .210 \\
A_{7} & =V \times .257 \\
A_{8} & =V \times .304 \\
A_{8} & =V \times .352 \\
A_{10} & =V \times .401 \\
A_{11} & =V \times .450 \\
A_{13} & =V \times .500
\end{aligned}
$$

$$
\begin{array}{r}
q \times A_{13}=V \times .550 \\
A_{14}=V \times .599 \\
A_{15}=V \times .645 \\
A_{16}=V \times .696 \\
A_{18}=V \times .743 \\
A_{18}=V \times .790 \\
A_{18}=V \times .835 \\
A_{20}=V \times .879 \\
A_{21}=V \times .919 \\
A_{22}=V \times .954 \\
A_{23}=V \times .953 \\
A_{24}=V \times .1000
\end{array}
$$


At No. 3:

$$
\begin{aligned}
\tan 2 \theta & =\frac{2 \times 6960}{830-0}=\frac{13,920}{830}=16.771 \\
20 & =86^{\circ}-36^{\prime \prime} \\
\theta & =43-18^{\prime \prime} \\
p & =1\left[0+830 \pm \sqrt{(830)^{2}+4(6960)^{2}}\right] \\
& =\frac{1}{2}[830 \pm 13,940] \\
& =+7380-6550
\end{aligned}
$$

At No. 7:

$$
\begin{aligned}
\tan 2 \theta & =\frac{2 \times 3360}{1240-3740}=\frac{6720}{2500}=2.683 \\
2 \theta & =65^{\circ}-10^{\prime} \\
\theta & =34^{\circ}-05^{\prime} \\
p & =\frac{1}{2}\left[3740+1240 \pm \sqrt{\left.(2500)^{2}+4(3360)^{2}\right]}\right. \\
& =\frac{1}{2}[4980 \pm 7170] \\
& =+6080,-1100 .
\end{aligned}
$$

At No. 9:

$$
\begin{aligned}
p_{x} & =-3740 \\
p_{y} & =\frac{833 \frac{1}{3}-833 \frac{1}{3} \times .696}{.5}=510 \\
q & =3360 \\
\tan 20 & =\frac{2 \times 3360}{510+3740}=\frac{6720}{4260}=1.59 \\
2 \theta & =57^{\circ}-50^{\prime} \\
\theta & =28^{\circ}-55^{\prime} \\
p & =\frac{1}{2}\left[-3740+510 \pm \sqrt{(4250)^{2}+4 \times \overline{3360}^{2}}\right] \\
& =\frac{1}{2}[-3230 \pm 7950] \\
& =-5590,+2360 .
\end{aligned}
$$


At No. 11:

$$
\begin{aligned}
\tan 20 & =\frac{2 \times 0}{1470-10,000}-\text { an infiniteaimal } \\
\theta & =0 \\
p & =\frac{1}{1}\left[10,000+1470 \pm \sqrt{(8530)^{2}+4 \times 0}\right] \\
& =1[11,470 \pm 8530] \\
& =+10,000,+1470 .
\end{aligned}
$$

At No. 15:

$$
\begin{aligned}
& p_{z}=-10,000 \\
& p_{y}=\frac{833\}-(416\}+416\})}{.5} \cdot 879-\frac{100}{.5}=200 \\
& q=0
\end{aligned}
$$

$\tan 20=\frac{2 \times 0}{200-10,000}=$ an infinitesimal $-\frac{1}{3}[-9500 \pm 10,200]$

$$
\begin{aligned}
& 0=90 \text { or } 0 \\
& p=\frac{1}{3}\left[-10,000+200 \pm \sqrt{(10,200)^{2}+4 \times(0)^{2}}\right]
\end{aligned}
$$

\section{ART. 7. AREA OF WEB PLATES}

The preceding article has shown that the stresses in the web of a plate girder are of greatly varying directions and intensities. The tensile stresses need an alequate amount of material to resist them, the amount of which is a direct function of the stress.

The action of the compressive stresses is augmented th a much greater degree than for tension, by secondary stresses if the material be even very slightly lacking in uniformity. That is, a certain kind of column action is set up.

The maximum tensile and compressive stresses in the 
web cross each other at right angles; at the neutral axis they are approximately equal, and make angles of approximately $45^{\circ}$ with the axis and equal the shearing stresses in intensity; above the neutral axis the compressive stress intensity is increasing while the tensile is decreasing; below the axis the opposite relation exists.

The shearing stresses are of the greatest intensity at the neutral axis, on horizontal and vertical planes, for any cross-section. At the cross-section where the greatest resultant shear occurs, there, on the neutral axis will be found the maximum shearing unit stresses. For simple spans the shear is a maximum at the ends of the span.

It is the practice to design web plates so that they will resist the shear at the point of maximum shear, and have enough thickness to provide ample bearing for the rivets connecting flange angles to the web; this latter very frequently determines the thickness of the web plate. The design of the web plate is also governed by practical considerations, such as requirements for handling in shop and field and requirements to resist corrosion.

The best practice requires as a minimum for the thickness of girder webs: $\frac{7}{16} "$ for railway, s" 3 " for highway, and $\frac{5}{16}$ " for builling work. It is the practically universal custom to make the web plate, for a girder, of uniform section throughout its length.

The shearing unit stress should be about $20 \%$ less than that used for direct tension, that is, where 16,000 is used for tension, 13,000 is a consistent unit for the maximum shearing stress intensity. Where the shearing stress is assumed to be uniformly distributed over the girder 
web this unit should be reduced to $10,000 \mathrm{Itw}$. por square inch and applied to the net section.

The web plate is also designed to rexint any tendency to buckling or sidewise failure. The tensile streases which act on any element of the web tend to pull the element back into its proper position if from any caune the clement is displaced laterally. In the portion of the web below the neutral axis the excess of tensile over compresive stress would give a component perpendicular to the web which would tend to take out any buckle that might exist. In the portion above the neutral axis the corresponding component would tend to increase any buckle. This can readily be seen by a study of Fig. $7 a$.

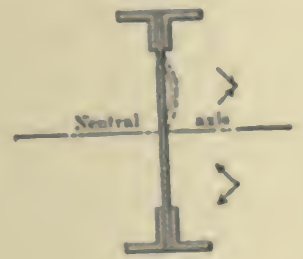

Fig. $7 a$.

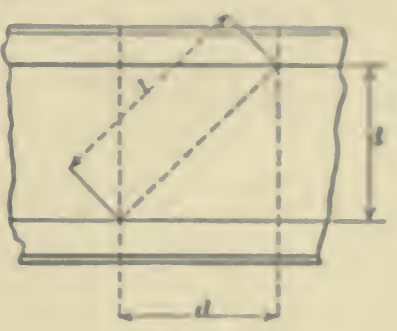

Fin. 76.

In order to determine whether a web needs stiffening an investigation which will lead to a safe structure can be made on the following basis:

Formulas (S) and (9), of Art. 6, show that at the neutral axis of the girder the maximum resultant compressive stress intensity approximately equals the unximum shearing stress intensity and that the line of its action makes an angle of about $45^{\circ}$ with the neutral axis. A compressive unit stress equal to the maximum shearing 
stress intensity is therefore assumed to act along the element of the web having a length of $l$ in Fig. $7 b$, and this must be less than the permissible unit stress for a column of this length. Assuming that a safe unit stress for a column is given from the formula

$$
P=16,000-70 \frac{l}{r}
$$

the notation for which needs no definition, the 16,000 should be reduced to 12,000 if the average shearing unit stress is used, as the maximum unit compression. The formula then becomes

$$
P=12,000-52.5 \frac{l}{r} \text {. }
$$

Substituting for $l$ and $r$ their values,

$$
l=d \sqrt{2}, \text { and } r=.29 t,
$$

where $t=$ the thickness of the web.

The formula then is

$$
P=12,000-52.5 \frac{d \sqrt{2}}{.29 t}=12,000-257.5 \frac{d}{\ell} .
$$

As the tension in the web below the neutral axis will prevent buckling, the value of $d$ should be $\frac{d}{2}$, and as the tension in the upper half of the web helps to prevent buckling the constant may be divided again by 2 , the formula then being

$$
P=12,000-65 \frac{d}{\ell} . \quad . \quad . \quad . \quad .
$$


It sliould be noted that d equals either the elear dintanoe between flange angles or stiffeners.

To show the method of applying this formula to now if web stiffeners are necessary let the girder of Fig. Ba be examined.

The average shearing unit stress $-\frac{193,500}{22.5}-8580 \mathrm{lbs}$. per square inch.

The allowable unit stress $-12,000 \frac{65 \times 48.5}{.375}-12,000$ $-8420=3580$ lbs. per square inch.

As the actual stress exceeds the allowable, the web must be made thicker or the stiffeners placed closer together or else both combined.

If the web be made $l^{\prime \prime}$ thick

The average shearing unit stress $-\frac{193,500}{30}=6450 \mathrm{lbs}$. per square inch.

The allowable shearing unit stress $-12,000 \frac{65-48.5}{.5}$ $-12,000-6300-5700$ lbs. per square inch, which shows that the web must be further thickened or the stiffeners placed closer together.

If the web be made is "thick and stiffeners placed 30 " apart in the clear the average shearing unit stress $-\frac{193,500}{26.25}=7380 \mathrm{lbs}$. per square inch.

The allowable shearing unit stress $-12,000-\frac{65 \times 30}{.44}$ $-12,000-4420=7580$ lbs. per sq.in. 


\section{PROBLEMS}

7a. The accompanying sketch shows the cross-section of the girder of Prob. $6 a$ and the curve of unit shear distribution. Construct the

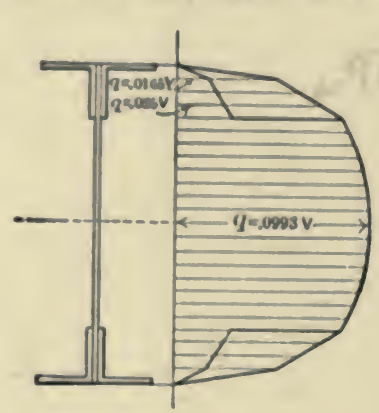

Fig. $7 c$.

figure to three times the size of the sketch shown and write in the value of the ordinates to the curve at points 1 " apart from the top to the bottom of the section.

7b. Are stiffeners required on the web of the girder of Prob. 6a? If not, show it by computation.

7c. What is the minimum thickness permissible for the web of the girder in Prob. 6a?

\section{ART. 8. STIFFENERS FOR WEB PLATES}

Stiffeners have several important functions, the chief of which are:

(a) They keep the web from buckling, due to the compressive stresses in it.

(b) They help hold the compression flange from lateral failure as a whole and from failure in detail in any direction.

(c) They are used to relieve the rivets connecting the 
loaded flange to the web, by tranterring the load directly to the web.

(d) They are used to reduce to proper amount the vertical stresese, on horizontal planes, in the web brought by local concentrated loads.

(e) They help hold the web true to ahape during manufacture and erection.

According to their principal functions they should be divided into two general classes, intermediale sfiffeners, which are chiefly used for the purposes of (a), (b) and (e); concentrated load stiffeners, for $(c)$ and $(d)$, although each class performs all the functions of course. Intermediate stiffeners act as a beam standing vertically to resist lateral displacement. They are generally made of angles in paiss and riveted to the girder web as shown in Fig. Sa. The
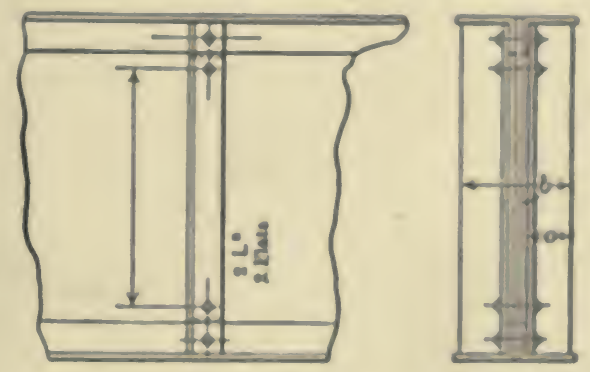

Fig. Sa.

legs of the stiffening angles which are against the fillers are near the neutral axis of the pair and therefore should be only large cnough to receive the connecting rivets;

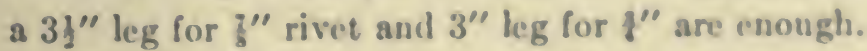

The wilth $b$ of the outstanding legs is the principal 
element of efficiency for resistance to transverse displacement. A common rule is to make the width of the outstanding leg $(O)$ equal to the depth of the girder $(d)$ in inches divided by 30 plus $2^{\prime \prime}$, or expressed as a formula

$$
0=\frac{d}{30}+2^{\prime \prime}
$$

The following is a common method of locating intermediate stiffeners.

Intermediate stiffeners should be used at points as required by (10) or wherever the unsupported depth between flange angles is more than 160 times the web thickness. Where intermediate stiffeners are required they should never be further apart in the clear than the clear distance between the flange angles, with a maximum limit of $5^{\prime}$.

Concentrated load stiffeners act to transfer a concentrated load into the web or to transfer the girder load to a support. The sketch of Fig. $8 b$ will illustrate both cases.

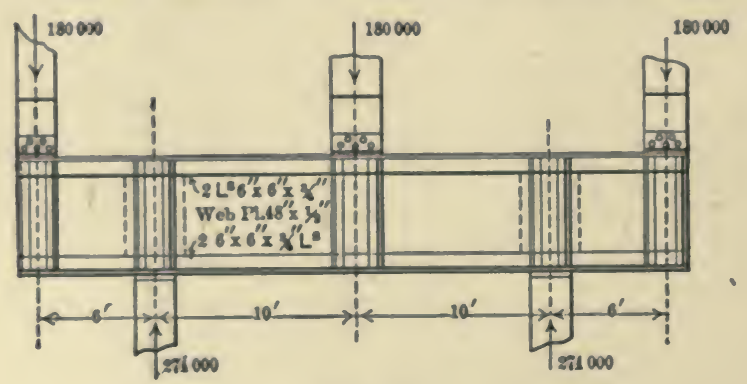

Fig. $8 b$.

The girder here shown being loaded with three concentrated loads of 180,000 , and its own weight of 250 lbs. per linear foot. The lines of maximum web stress 
for a gircler of this character are very differeat from those of the girder of problem 6a. If such a girder were construeted without stiffeners, and formula ( 7 ) were applied to finding the intensity of $p_{w}$, this intensity would be found to be very high. The heavy vertical stiffenens are added to transfer the point of applieation of these loads from the outer edges of the flanges to an averago position of the center of the web, and thereby decrease the intensity of vertienl stress on horizontal planes juet at the inuer edge of the flange angles. These stiffenen cannot fully accomplish their object, as they are of elastic material and they are shortened by compression, and, as they are fastened to the web, the web and stiffeners move together except for a variation due to the deformation of the rivets. The stiffeners also serve to relieve the flange rivets from the component due to the vertical load.

Stiffeners supporting concentrated loads may be designed as columns with the formula $P-16,000-70 \frac{1}{r}$, in which $l$ should be taken as one-half the girder depth amel $r$ as the radius of gyration about an axis in the longitudinal center line of the girder.

Wherever the combined stress intensity on a web plate exceeds the allowable unit stress the stresses una be reduced by means of side plates, as shown by dotted lines.

Where the concentrated load stiffeners are at the end of a girder they should have their outstanding leg about equal to the horizontal leg of the flange for the sake of good appearance, and where it is desired to face the ends of such girders the stiffening angles must be made thicker 
by $f^{\prime \prime}$ than theoretical considerations determine, to allow for material removed by such facing.

\section{PROBLLMS}

8n. Determine the size of the end stiffeners for the girder of Fig. $5 a$, using two pairs of angles, one on the outer and one on the inner edge of the sole plate.

8). Assuming the wall plate to be $18^{\prime \prime}$ long for Fig. $5 a$, determine the size and spacing of the intermediate stiffeners for the girder.

$8 c$. Determine the sizes of the stiffeners at the points of concentrated loading for the girder of Fig. Sb.

8d. Determine the sizes and spacing of the intermediate stiffeners for the girder of Fig. Sb.

\section{ART. 9. SPLICES FOR WEB PLATES}

Webs of plate girders should not be spliced unless necessary, but as wide plates cannot be procured in one piece, in general, for girders over $60 \mathrm{ft}$. long, splicing for long girders is unavoidable. The manufacturers furnish lists of the maximum dimensions of their plates. The number and location of the web splices should be determined by a combined consideration of the cost and resulting efficiency of the possible arrangements. The splice should be designed with the idea of transferring the stresses in the web across the cut in the most direct manner possible, just as in plate girder design as a whole the effort should be made to have the stresses developed as indicated by the theory of flexure for solid beams. Let it be required to splice the web at the center of the girder which has an effective length of $80^{\prime}$, and a composition as shown in Fig. $9 a$.

The girder has been designed on the assumption that 
fo the gross area of the wob is available as flange area The maximum bending moment $=6,300,000$ (t.-1ta. The center shear simultaneous with this moment $=0$. The maximum cester shear $=75,000 \mathrm{lbs}$, and the bending moment simultaneous with this $-3,400,000 \mathrm{ft}$. $1 \mathrm{ls}$.

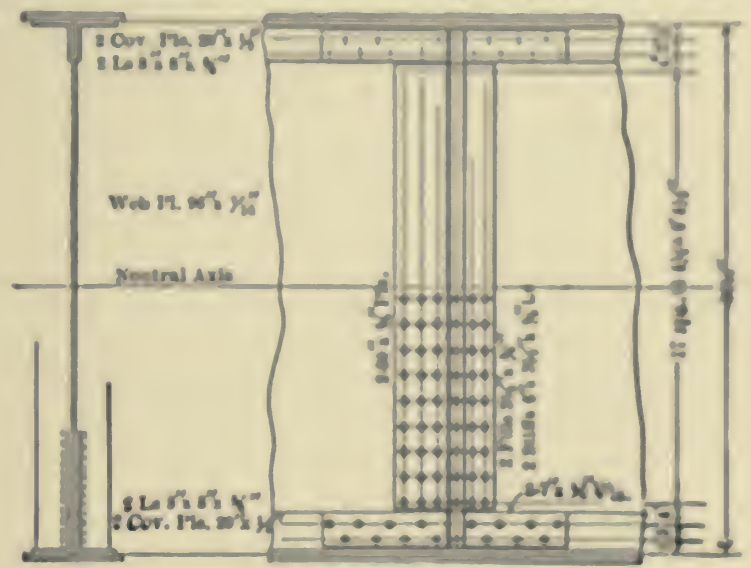

Frg. Qa.

The flange area is male up of:

$$
\frac{1}{8} \text { web }=96 \times \frac{16}{16} \times \frac{1}{6}=5.25 \mathrm{sq} \text {.in. }
$$

2 angles $8 \times 8 \times 32.7-19.23-2.50=16.73$

1 cover plate $20 \times \$-10-1.00-9.00$

1 cover plate $20 \times 1-10-1.00=9.00$

$$
\text { a total of } \quad 39.95 \text { sq.ins. }
$$

The simplest form of web splice consists of two vertical plates terminated at the top and bottom by the vertical legs of the flange angles, but this makes a normal distribution of the web stresses impossible in the vicinity of the splice. The resultant of all the forces on any beam cross-section may be represented by a shear and a couple 
as is well known from mechanies, but the proper form of splice should be designed with reference to the distribution of these forces. The portion of the web between the flange angles is so near the extreme

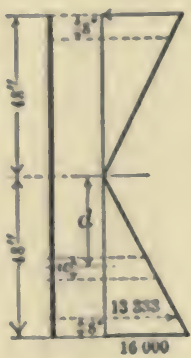

FIG. 96 . fiber that the stresses may be assumed to be horizontal throughout. The flange unit stress has been taken at 16,000 lbs.; the bearing and shearing values for rivets will be taken to correspond to this at 24,000 and $12,000 \mathrm{lbs}$. per square inch respectively, or at $50 \%$ more and $25 \%$ less than for tension. The thickness of the splice plates should be sufficient to transmit the maximum possible stresses which can occur at the point of maximum stress in the splice.

The total stress on the portion of the web between the flange angles $=\left(8^{\prime \prime}-1^{\prime \prime}\right) \times \frac{7}{16} \times 14,667=44,800 \mathrm{lbs}$; the least that can be used for this part of the splice will be $2-7 \times \frac{3}{8}$ flats for each flange. The net area of these two plates $=4.5$ sq.in., while that of the strip of the web $=3.06$ sq.in. The bearing value of the rivets is less than that for double shear, bence one rivet is worth 9190 lbs. at the edge of the web plate and $9190 \times \frac{43.75}{48}=8350$, an average for this part of the splice. The number of rivets on each side of the splice for splicing the strip $=\frac{44,800}{8350}$ $=5.37$ or 6 .

For the condition of maximum moment there is no shear at the splice and the web stresses are horizontal.

The number of vertical rows of rivets is evidently a 
function of the vertical pitch, the more verical rows the greater the vertical pitch.

Let $w=$ the pitch of the rivets in a vertical direction;

$n=$ number of vertical rows of rivers:

$d$-distance from the neutral axis to horizontal row of rivets.

For three vertical rows

$$
(w-1) \frac{3}{16} \times 16,000 \times d / 48-3 \times 9190 \times d / 48
$$

or

$$
w=34.570 / 7000-4.94^{\prime \prime}, \text { say } 4 z^{\prime \prime} .
$$

For two vertical rows

$$
(w 0-1) \frac{2}{16} \times 16,000 \times d / 48=2 \times 9190 \times d / 48
$$

or

$$
w=25,380 / 7000-3.62 \text {, say } 3^{\prime \prime} \text {. }
$$

For this splice 3 vertical rows on each side spaced $4 \frac{1}{2}$ will be used, as it gives a web plate with leas reduction of strength at the splice.

The splice should now be examined for the ease of 75,000 shear and simultaneous moment of $3,400,000 \mathrm{ft}$ - $1 \mathrm{bs}$.

From (5) the flange pitch at the center $p=\frac{9190 \times 96}{75,000}$ -11.6 " for no part of the web acting as flange. The flange as designed uses 5.25 sq.ins. of the web for flange area; the pitch of the rivets connecting the flange anglos to the web is $\frac{9190 \times 96}{75,000 \times \frac{34.73}{39.98}}-11.6 \times \frac{39.98}{34.73}-13.3^{\prime \prime}$.

The $7 \times$ flats on the vertical legs of the flange angles will therefore be made to take about 6 or 8 rivets on each side of the splice. 
For a web splice at some point other than the center of the girder, the number of rivets in the flange plates on the side toward the center will be the number required for splicing the web; on the side toward the end the number will be the sum of those for connecting flange to web plus those for web splice.

The extreme fiber stress on the web for a moment of $6,300,000$ ft.-lbs. was 16,000 ; for a moment of $3,400,000$ ft.-lbs. it is 8630 . For the strip of web between the flange angles the previous determination is evidently ample. A study of the stress intensity at different points in the web for this condition of loading would show that the stress intensity was nowhere as great as for the case for which the splice was designed.

A safe resultant rivet bearing of 9190 should not be exceeded.

The vertical component on a rivet at either edge of the main splice plates will not exceed $75,000 / 54=1390$ lbs., the horizontal component $=3.5 \times \frac{7}{16} \times 8630 \times 38 / 48 \times \frac{1}{3}$ $=3480$ per rivet. The resultant $=\sqrt{\overline{1390}^{2}+\overline{3480}^{2}}=3800$.

\section{PROBLEMS}

9a. What is the relative efficiency of the unriveted plate of Fig. $9 a$ to that of the section of the plate through the first vertical line of rivets in the splice.

9b. Compute and compare the resisting moment of the rivets in the splice of Fig. $9 a$ with that of the net section of the web plate through the first vertical line of rivets.

9c. Make a sketch of a splice for the girder, using only two vertical rows of rivets on each side of the splice. 


\section{ART. 10. SPLICES FOR THE COMPONENT PARTS OF TIE FLANGES}

Splicing any of the component purts of a gircler flanger should te avoided, as it is never necensary exrept to mees some emergency, or reduce the eost slightly. The flange angles and cover plates, for girilers of the maximum deugth now used, may be obtained in one piece. The cont of a fiew very long pieces, however, may te no high, due to the cxpense of shipment in lose than proper amounts or the need of the completed structure may $b_{x}$ so urgent, as to make it alvisable to permit splieing of component parts of the flange.

Flange angle splices should the located when prosible as follows:

a. Where there is an excess of flange section over the required amount;

b. Between adjacent pairs of stifeners, where these pairs of stiffeners are far enough apart to permit a splice of proper length to be made:

c. So that not more than two flange anglos shall be spliced in any cross-section of the girder:

d. So that the flange angles on opposite sides of the girder flange will be splieed on opposite sides of the eenter of the girder.

The splicing material should be disposed with roference to the shape of the section spliced. The splice for an angle with equal legs should be made by a cover angle with two equal legs. The net area of each leg of the splice 
should equal the not area of the leg spliced. In general in splicing or connecting material under stress the splice or connection should be arranged to avoid any redistribution of stress. This requires that angles with unequal legs be spliced by cover angles with unequal legs, and that the net area of each leg of the one be equal to the net area of each leg of the other.

The number of rivets in the splice on each side of the point where the angles are cut should be determined with care. The duty of the rivets in developing the flange stress as well as in connecting the spliced parts should be clearly understood. For the purpose of illustration let it be supposed that for the girder of Fig. $5 a$ the only material available for the flange angles is 4 angles $6 \times 6 \times \frac{1}{2}$ $-16^{\prime} 4 \frac{1}{2}$ ' long and 4 angles $6 \times 6 \times \frac{1}{2}-28^{\prime} 4 \frac{1}{2}$ "long. This makes it necessary to splice the bottom flange at a point $6^{\prime}$ from the center of the girder. Fig. 10 shows the splice in considerable detail. The net area of the two angles $=9.52$ sq.ins., and this at $16,000=152,320$ lbs. as the strength which must be developed by both the rivets and angles of the splice. Two $6 \times 6 \times \frac{9}{16}$ angles with the legs cut to $5 t^{\prime \prime}$ each and the corner of the angle planed so to fit the fillet of the flange angles will be used for the splicing material.

The shear, at the point of splicing, simultaneous with maximum flange stress, is $50,000 \mathrm{lbs}$. The pitch of the rivets cannot be less than $6^{\prime \prime}$ in each line without reducing the flange section (see Art. 3).

The horizontal flange increment $I$ per rivet from Formula $(5)=\frac{50,000}{59} \times 3=2540$ when none of the web is assumed 
to act as flange area; for this girter, however, 281 sofin. of the web was assumed to act as flange area. The value of $l$ therefore is $2540-2540 \times \frac{2.81}{24.33}=2540-290-2250$ It $=$.

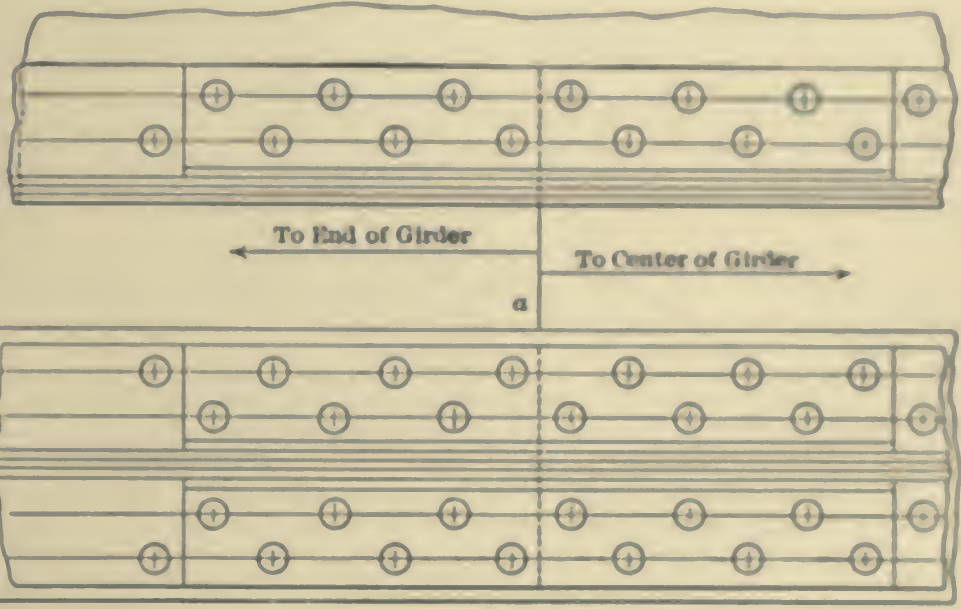

b

Fic. $10(a$ and $b)$.

Fig. 10 (c) shows the forces on a rivet through the wel, and vertical legs of the splice and flange angles due to increment $l$.

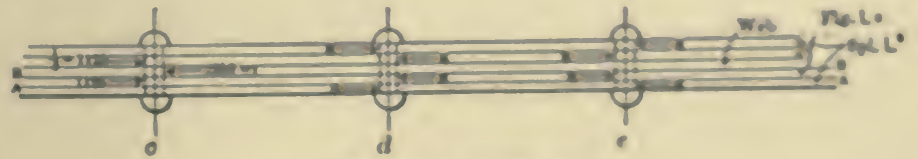

Fic. 10 (e, $d$ and e).

Fig. 10 (d) shows the forees on a rivet through the web and vertical legs of the splice and flange angles due to splicing, for the left portion of the splice.

Fig. 10 (e) shows the forees on a rivet through the 
web and vertical legs of the splice and flange angles due to splicing, for the right portion of the splice.

The unit stresses on the rivet will be taken at 12,000 lbs. per square inch for shear, and 24,000 lbs. per square inch for bearing.

Consideration of the forces on the rivets and the thickness of flange and splice material shows that the shearing value of the rivets is the determining one along the plane A A

The number required in the vertical legs $=\frac{152,320}{4 \times 7216}$ $=5.3$ or 6 .

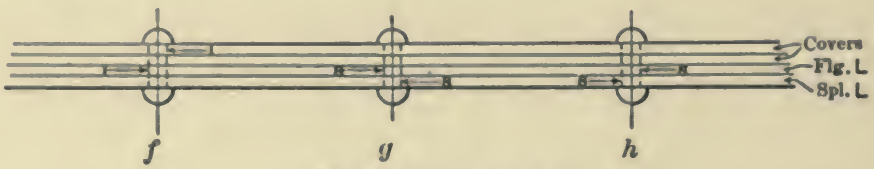

Fig. $10(f, g$ and $h)$.

Fig. $10(f),(g)$ and $(h)$ show the forces on the rivets through the horizontal legs of the flange angles of the top flange splice. It is readily seen that the number of rivets required $=\frac{152,320}{4 \times 7216}=5.3$ or 6 .

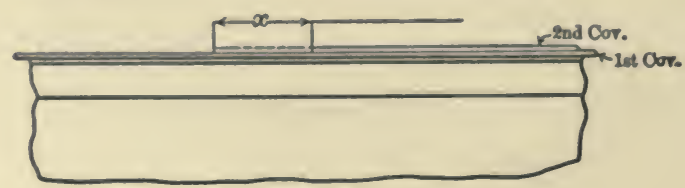

Fig. 10i.

Cover plate splices should be located so that a simple lengthening of an outer cover plate will form the splice. For example if a splice were required in the first cover 
plate of the girder of Art. $t$, it should be splieed by extending the second cover a distance $z$, which must be enough to permit the location of a proper number of rivets, shown by the dotted lines in Fig. 10 (i).

\section{PROBL.KM}

10. Design a splice for the flange angles of the girster of Prots. ta, which shall be located at the same point in the tengeth of the gainker an was the one used to illustrate this artick.

\section{ART. 11. CONNECTING ONE GIRDER TO ANOTHER}

The problem of framing one girder into another is one so frequently met with that a connection for two adjacent stringers and the floorbeam between them will be designed to illustrate the method of making the computations for such connections.

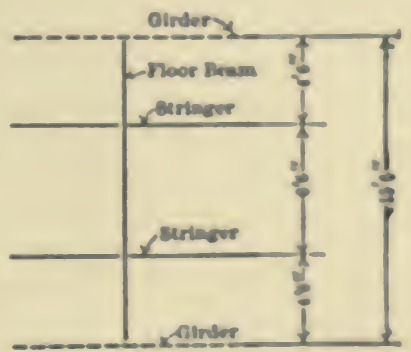

Fic. 110 .

Fig. $11 a$ is a line drawing of a plan showing the relative position of girders, floorbeams, and stringers. A loal on - any stringer is carried first to the floorbeams at its ends. The floorbeam earries it to the girdens and the ginders to the abutments or other end supports. 
The stringer is composed of 1 web plate $27 \times \frac{1}{2}$;

4 angles $5 \times 3 \frac{1}{2} \times 13.6\left(\frac{1}{2}{ }^{\prime \prime}\right)$.

The floorbeam is composed of 1 web plate $38 \times \frac{1}{2}$;

4 angles $5 \times 3 \frac{1}{2} \times 19.8\left(\frac{3}{4}{ }^{\prime \prime}\right)$

The maximum stringer reaction is $97,800 \mathrm{lbs}$. $(l l=48,800$ Imp. $=46,600$ and $d l=2400$ ).

The maximum reaction for two stringers is $131,700 \mathrm{lbs}$. $(l l=66,300$, Imp. $=60,600$ and $d l=4800)$.

The requirements of construction will be assumed to demand that the bottom flange of the stringer be $4 \frac{1}{2}$ " above the bottom flange of the floorbeam. The connection between the stringer and floorbeam is made by two vertical angles which are riveted onto the stringer in the bridge shop. The rivets through the outstanding legs of the connection angles and the floorbeam web must be field driven. The unit stresses are 12,000 and 24,000 for shear and bearing for shop rivets and $20 \%$ less than these values for field-driven rivets; $\frac{7}{8}$ " rivets will be used and the connection angles will be made ${ }_{2}^{\prime \prime}$ thick so that after they are faced on the back of their outstanding legs they will not be less than $\frac{3}{8}$ " thick on these legs.

Fig. $11(d)$ shows how the load $W$ is applied to each rivet and carried to the stiffeners. The rivet should be examined for crushing by the web for $W$ and for shear for $\frac{W}{2}$.

The number required for crushing $=\frac{97,800}{10,500}=9.3$ or 10 . For shear the number $=\frac{97,800}{2 \times 7216}=6.8$ or 7 . The upper and lower rivet in the lines $x x$ and $z z$ of $(b)$ cannot be 
counted for this connection, as they have other duty to perform. Therefore, in orler that the rivets be not eloser than $3^{\prime \prime}$, a leg for the connection angles which will contain 2 rows of rivets must be used. As 10 rivets are required, a symmetrical arrangement demands 11 . Thene rivets pas through fillers and a good requirement is to extend the fillers for such cases and put $50 \%$ additional rivets through

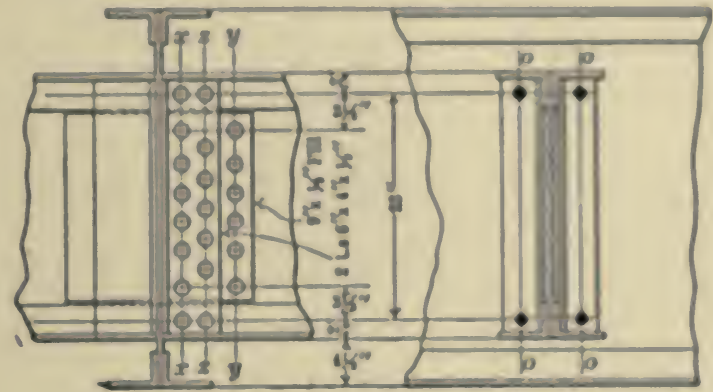

(b)

(c)

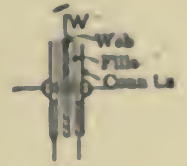

(d)

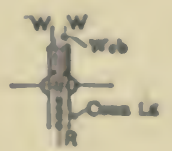

(e)

F10. 11.

them. Many good designers consider it allowable to assume that fillers connected to web plates by a line of rivets. such as $y y$ increase the bearing value of rivets in lines $x x$ and $z z$ by the entire bearing value of the rivets in yy.

Consideration of $(c)$ of Fig. 11 shows that it will be possible to get

16 rivets in the two lines oo and have them a litsle over $3^{\prime \prime}$ apart, and 
18 rivets in the two lines oo and have part of them 23 and part $3^{\prime \prime}$ apart.

Fig. $11(c)$ shows how the forces act on a rivet connecting the outstanding legs of the connection angles to the floorbeam web.

The bearing value of a field rivet in the $\frac{3}{8}$ (net thickness) stiffener leg is 6300 .

The shearing value of a field rivet is 5770 .

For the maximum stringer load the number of rivets required for shear $=\frac{97,800}{5770}=16.95$ or 18 , which would enable two lines of rivets to be used, if part of the number are $23^{3 \prime \prime}$ apart.

The rivets must also be examined for bearing on the floorbeam web when both stringers are bringing their combined maximum loads at this connection. The bearing value of a ficld rivet in the $\frac{1}{2}$ " floorbeam $w \mathrm{eb}=8400 \mathrm{lbs}$. The number of rivets required $=\frac{131,700}{8400}=15.6$ or 16 , which is one less than the number which are required for maximum shear on the rivets for one stringer loaded.

The number of rivets by the second computation is usually, though not in this case, the larger and hence the governing one. The rivets should be located on the lines oo in $(c)$ of Fig. 11. The two fillers under the connection angles and on the stringer web must be ${ }^{\prime \prime}$ thick and $3^{\prime \prime}$ wider than the angle leg. They should therefore be $9^{\prime \prime} \times \frac{1}{2} "$ flats.

The requirement of two lines of rivets for the leg of the connection angle against the stringer web demands a 
6" leg. One line between each leg of the consection angle and the floorbeam web fixes the width of the out. standing leg at 3 b or 4 ".

The connection angles cannot be low than f $^{\prime \prime}$ in shiekness. Examination of this net section through lines $2 x$ and oo shows them to be ample to resist shear. Some. times they must be increased in thickness for this.

The connection angles are therefore made $6 \times 4 \times 16.2$ (b).

\section{PROBLEM}

11. Design the connection between two adjacent stringers and their floorbeam. The stringer consisting of

1 web $24 \times$ is;

4 angles $5 \times 3\} \times 15.2$ ( 20$)$

The floorbeam consisting of

1 web $34 \times \frac{1}{\text {; }}$;

4 angles $5 \times 3 \frac{1}{2} \times 13.6\left(\frac{1}{2}\right)$;

2 covers $11 \times \frac{1}{2}$.

The shears being the same as for the example solved in this artick.

\section{ART, 12. END BEARINGS}

The end bearings of a girder must receive the load brought to the end of the girder and distribute the same over the masonry or other support. For the single-track girder of Art. 4, which was taken to illustrate the method of finding lengths of cover plates an end reaction of 193,500 Ibs. was assumed. For girders less in length than $60^{\circ}$ one end of the girder is bolted to the masonry and the other 
allowed to slide on a plate. This arrangement makes the determination of the reactions possible.

The area of the bearing on the wall, assuming the bridge seats to be of granite and $600 \mathrm{lbs}$. per square inch as a unit stress, should be $\frac{193,500}{600}=323$ sq.in.

It is not advisable to make an end bearing of the simple nature indicated in Fig. 12 too long. The tendency of

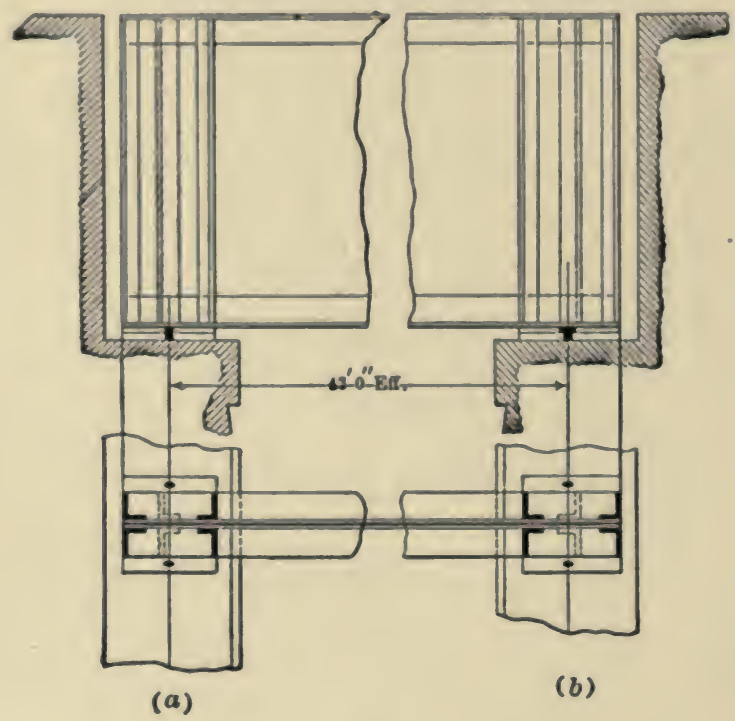

Fig. 12.

such a bearing is to overstress the bearing along its inner edge.

The upper plate of the two shown at each end is called the sole plate, and is connected by rivets, countersunk on the bottom, to the girder. The bottom of the sole plate at $(b)$, the expansion end, should be planed. 
The lower plate of the two shown at each end is ealled the wall plate.

The upper surface of the wall plate at (b), the expansion end, should be planed.

The wall plates are held in position by the two anchor bolts at each end.

The bearings at the ends of the girder, when of two simple plates, should not be too wide, as the tendency of the bearing is to overload the masonry along the portion covered by the bottom flange of the girder.

The bearing for this case will be made $18 \times 18^{\prime \prime}$.

The two plates which project beyond the bottom flange angles must be strong enough in flexure to distribute the load on the bridge seat. Each inch of length of the plates may be considered acted on in a transverse direction by the forces shown in $(d)$.

The bending moment then $-5.400(9 / 2-6.18 / 2)-5400 \times 1.41-7614$ in.-lbs.

If the sole and wall plates be made of equal thickness, then the resisting moment of each plate must be 3507 in.-lbs.

The depth (or thickness) of plate required may be obtained from $M=\frac{S I}{c}=\frac{S \cdot b d^{2}}{6}-3807$ or $d^{2}=\frac{3807}{16,000} \times 6-1.43^{\circ}$ and $d-1.25^{\prime \prime}$ about.

These plates should neither of them be less than ?" thick, even if a less thickness would furnish proper strength.

For small spans generally only two pairs of stiffeners, one over the outer and the other on the inner edge of the bearing plates, are used. 
The end stiffeners for this case should be $5 \times 3 \frac{1}{2}$ angles and their radius of gyration in a direction transverse to the web is $2.7 S^{\prime \prime}$ approximately. The required area for

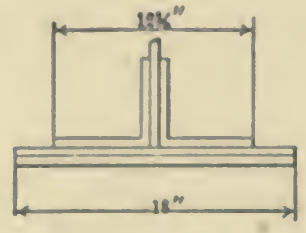

(c)

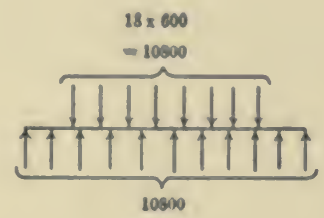

(d)

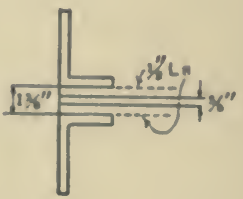

$\cdot(e)$

FIG. 12.

these stiffeners $=\frac{193,500}{15,250}=12.7$ sq.in. $\quad\left[P=16,000-70 \frac{30}{2.78}\right.$ $=16,000-750=15250$ ].

Therefore 4 angles $5 \times 3 \frac{1}{3} \times 12\left(\frac{7}{16}\right)=14.11$ sq.in. will be ample.

The addition of another pair of stiffeners over the center of the bearings would help greatly in distributing the pressure over the wall plates, as their outstanding

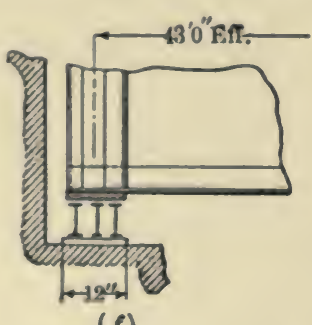

(f)

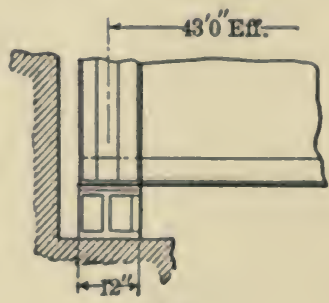

(g)

Fig. 12.

legs would prevent an upward deflection of the piates and angles between the pairs of stiffeners. The additional stiffeners are shown by dotted lines in Fig. $12(a)$ and $(b)$. 
A better bearing for the ends of this girder could bo made by making it shorter in the direction of length of the girder and using either a cast or built-up pedental to distribute the load in a transvense direction an is indicated in $(\Omega)$ and $(g)$ of Fig. 12. For a length of 12" the width should be $27^{\prime \prime}$. The sizes for either case $(\Omega)$ or $(g)$ should be determined from the laws of flexure, and direct atrese.

For longer girdens with greater end reactions to secure proper distribution of the load on the masoury and proper application of the reaction to the girder, a bearing should be used which by means of its form and action will isure this result. This is generally accomplished by means of an upper and lower shoe, both of which may freely rotate about a pin. These upper and lower shoes should have

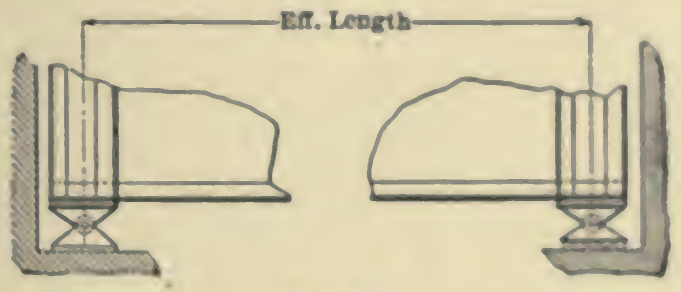

Fro. $12 h$.

proper bending strength and proper bearing on the pin and masonry. These shoes may be either built up of rolled material or east in one piece. Their detailed design will not be undertaken here, as no new principles are to be developed.

\section{PROBLFA}

12. Design an end bearing for a girder of a singhemerack milway bridge of $36^{\circ}$ effective length, the eroesection of the girder at the 
end being 1 web plate $48 \times \frac{2}{16}$ and 4 angles $6 \times 6 \times 19.2\left(\frac{1}{3}\right)$, the end reaction being $180,000 \mathrm{lbs}$.

\section{APPENDIX}

\section{ART. 13. POSITIONS OF LOADING FOR MAXIMUM SHEAR AND MOMENT}

The shears and moments, which are necessary for the design of plate girder bridges, are required for such a great variety of span lengths within the limiting lengths of span for such structures, that special methods of computing and tabulating them are advisable. In the principal Railway Engineers' Bridge Works and Consulting Engineers' offices the major part of the structures designed will be made for some standard loading. The loading known as Cooper $\mathrm{E}_{50}$ is perhaps more widely used than any other for railway bridges. The quantities given in Table No. 1 are for Cooper's $\mathrm{E}_{50}$ and are similar to those which should be determined and kept on record for any standard loading to enable design to be made with proper facility.

\section{ShFars}

In computing shears it should be noted that for deck bridges the maximum end shear is given for the engine located so that either the first or last driving wheel stands at the end of the span.

The maximum shear at an interior point on the left of the center of the span is given when the load extends from the right and up to the point and perhaps a little beyond. Every load that passes from just to the right 
of the point to just the left of the point under conideration causes a decrense in shear by the amourt of that loal. Any further movement of the system to the left increans the shear until another load passes from the right to the left of the point. The maximum shear must therefore be determined by trial and generally will occur for the fint or sccond engine wheel just to the right of the given point.

For through bridges the maximum shear in any panel is given when the well-known critcrion $P-\frac{W}{m}$ is satisfied, in which $P$ is the load in the panel, $W$ the total loal on the bridge and $m$ the number of equal panels in the span. Sometimes two or even three positions of the load satisy the criterion, in which case the maximum shear is determined by comupting the shear for all positions which satiofy the criterion.

For maximum concentrated load brought to a floor beam or trestle bent by two adjacent stringers or girlers: The criterion for position is $P=\frac{n W}{n+m}$, in which $n$ and $m$ are the lengths of the adjacent spans and $P$ the load on the span of length $n$, and $W$ the load on both spans.

\section{Bending Momests}

The bending moment, due to a certain number of moving loads at any definite point in a girder either deck or through, is a maximum when $P=\frac{n W}{m}$, in which $P$ is the load on the left of the point, $W$ the total load on the structure and $n$ the distance from the point to the left 
end and $m$ the span length. This criterion enables any group of loads to be placed to produce a maximum moment. The criterion will sometimes be satisfied by more than one position of the live load, generally that position which has the heaviest loal at the point under consideration and in addition the greater load on the structure is the one giving maximum moment. The moment for all positions of load which satisfies the criterion must be computed for a certain determination of the maximum.

For a deck structure the point of maximum bending moment occurs at or near the center, generally a little distance away from the center, the location of this point of maximum moment being different for different systems of loading. To aid in determining the position of the loading for absolute maximum it should be remembered that:

(a) The maximum moment must occur where the shear passes through zero;

(b) For a system of concentrated loads the shear must pass through zero at one of the loads;

(c) The amount of loal on either segment, into which the point of maximum moment divides the span, is to the total load on the span as the length of the segment is to the span length.

These requirements for practical cases fix the point of maximum bending moment under one of the two wheels adjacent to the resultant of the system. The criterion for the exact position of the loading to produce maximum bending moment follows: 
For any given system of loaling, the loods should to so placed that the center of the rpan is half soug between the resultant of the system and one of the two loads which en neareat to the rexultant. This criterion may be cotablibhed as follows:

lat Fig. 13 a show any girder carrying the symtem of moving loads shown.

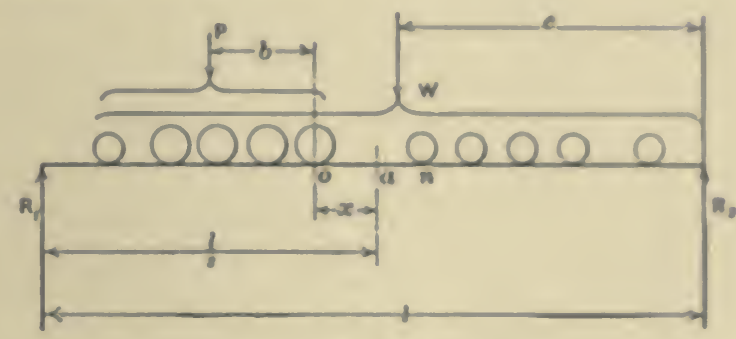

Fic. 13a.

Let $a$ be the center of the span;

o be the point of maximum moment which secun under o or $n$;

the resultant of the system $-W$;

$c$ be the distance of $W$ from the right end:

the resultant of the loads to the left of o be $P$ :

$b$ be the distance from $o$ to $P$;

$x$ be the distance from o to $a$;

Then the bending moment at

$$
\begin{aligned}
0-M-R_{1}\left(\frac{l}{2}-x\right)-P b & =\frac{W c}{l}\left(\frac{l}{2}-x\right)-P b \\
& -\frac{W c}{2} \frac{W c x}{l}-P b . .
\end{aligned}
$$


Now suppose the loading to advance a small distance to the left of $d x$, then $b=b, x=x+d x$, and $c=c+d x$, and the bending moment

$$
\begin{aligned}
M^{\prime} & =R_{1}\left(\frac{l}{2}-[x+d x]\right)-P b \quad \text { as } \quad R_{1}=\frac{(W c+d x)}{l} \text { this } \\
& =\frac{W(c+d x)}{l}\left(\frac{l}{2}-[x+d x]\right)-P b ;
\end{aligned}
$$

neglecting terms containing $d x^{2}$,

$$
M^{\prime}=\frac{W c}{2}-\frac{W c x}{l}-\frac{W c d x}{l}+\frac{W d x}{2}-\frac{W x d x}{l}-P b .
$$

Subtracting $(\alpha)$ from $(\beta)$

$$
\begin{aligned}
M-M^{\prime}=d m & =\frac{W d x}{2}+\frac{W x d s}{l}+\frac{W c d x}{l} \\
\frac{d m}{d x} & =-\frac{W}{2}+\frac{W x}{l}+\frac{W c}{l},
\end{aligned}
$$

and for a maximum this must equal 0 .

$$
\begin{aligned}
\therefore \quad-\frac{W}{2}+\frac{W x}{l}+\frac{W c}{l} & =0 \\
-\frac{l}{2}+x+c & =0 \\
x & =\frac{l}{2}-c,
\end{aligned}
$$

and

which establishes the criterion as stated.

\section{PROBLEMS}

13a. Compute the maximum bending moment for a deck plate girder of $18^{\prime}$ effective span length for Cooper's $\mathrm{E}_{50}$. Assume the girder to carry one-half the loading.

13h. Compute the maximum bending moment for a $25^{\prime}$ span, same loading as $13 a$.

13c. Compute the maximum center moment for a $25^{\prime}$ span, same loading as $13 a$. 


\section{ART. 14. PREPARATION OF A TABLE OF BENDIFG MOMEMTS, SHEARS, AND CONCENTRATED LOADS FOR COOPER'S E. LOADING}

The great alvantage of a table of moments and shears is that it may be prepared in a few days for all spans for which it is at all likely to be needed. Computations for a swntem of quantities made at one time show by the law of the increase or decrease of the quantities any error, and the similarity of the computations enables them to be vwry rapidly made. When a system of many loads move oves spans of varying length it is evident that one load producea maximum moment for spans up to a certain length, two loads for a certain other length, and so on.

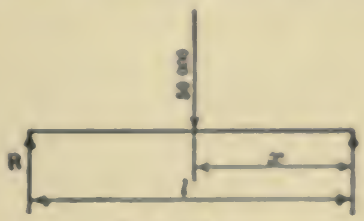

Fig. Ha.

For one loal on a span see Fig. $14 a$.

$$
\begin{gathered}
M=R(l-x)=\frac{50,000 x}{l}(l-x)-50,000 x \frac{50,000 x^{3}}{l} \\
\frac{d M}{d x}-50,000 \frac{100,000 x}{l}=0 \\
M=\text { a max., when } \quad x=\frac{l}{2} .
\end{gathered}
$$

or $\quad M-a$ max., when

$\therefore M=\frac{50,000 l}{4}$, which, as is well known, is the general expression for max. moment for any span with one load. 
The general equation for moment for two loads spaced $5^{\prime}$ apart is

$$
\begin{aligned}
M & =R(l-5-x)=\frac{250,000+100,000 x}{l}(l-x-5) \\
& =250,000 \times 100,000 x-750,000 \frac{x}{l}-100,000 \frac{x^{2}}{l}-\frac{1,250,000}{l}, \\
\frac{d . M}{d x} & =100,000-\frac{750,000}{l}-\frac{200,000 x}{l}=0 . \quad \therefore x=\frac{l}{2}-3.75 .
\end{aligned}
$$

FIG. $14 b$.

Substituting for $x$ its vlaue, we have for

$$
\begin{aligned}
M & =\frac{250,000+100,000\left(\frac{l}{2} \cdot-3.75\right)}{l}\left[l-\frac{l}{2}+3.75-5\right] \\
& =250,000 l-125,000+\frac{156,250}{l} .
\end{aligned}
$$

By plotting the curves of moments for different lengths of spans we see that somewhere between $S^{\prime}$ and $9^{\prime}$ one load and two loads produce the same moment.

To find this point exactly we make the equations for moments simultaneous and solve to find the value of $l$ for which the moments are equal.

For this case $\frac{50,000 l}{4}=250,000 l-125,000+\frac{156,250}{l}$, whence $l=8.54^{\prime}$.

The next step is to get the general equation of moments for three loads. Make it simultaneous with that for two 
loads, and solve for $l$, which gives the upper limit for two loads as $11.125^{\circ}$.

The equation for 4 loals is

$$
. I=50,000 l-5(0), 000+\frac{312.500}{l} .
$$

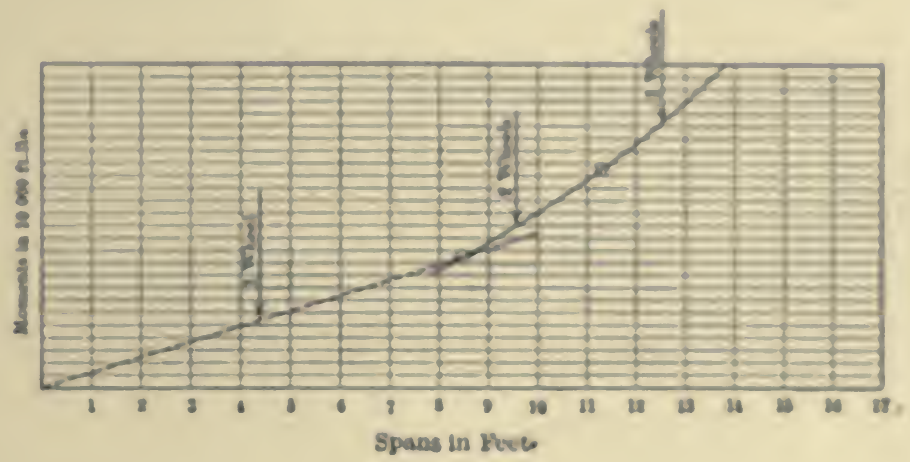

Fic. Ite.

The equation for five loads will now be written

$$
\text { dist. of c.g. from right load }-\frac{2,075,000}{225,000}-9.22 \text {. }
$$

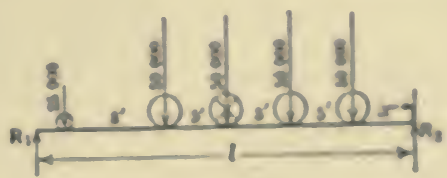

Fic. Itd.

The point of max. moment will be under the second driver.

Reaction at $R_{1}-\frac{2,075,000+225.000 \pi}{l}$ 
Maximum bending moment

$$
\begin{gathered}
=\frac{2,075,000+225,000 x}{l} \times(l-x-23+13)-575,000 \\
=\frac{2,075,000+225,000 x}{l} \times(l-x-10)-575,000 \\
=2,075,000+225,000 x-\frac{2,075,000 x+225,000 x}{l} \\
-\frac{20,750,000+2,250,000 x}{l}-575,000 \\
\frac{d M}{d x}=225,000-\frac{2,075,000}{l}-\frac{450,000 x}{l}-\frac{2,250,000}{l}=0 \\
-\frac{450,000 x}{l}=-225,000+\frac{2,075,000+2,250,000}{l} \\
450,000 x=225,000 l-4,325,000 \\
x=\frac{l}{2}-9.61 .
\end{gathered}
$$

Substituting this value for $x$ in the following simplified expression for the moment

$1,500,000+225,000 x-\frac{4,325,000 x}{l}-\frac{225,000 x^{2}}{l}-\frac{2,075,000}{l}$

there is given

$$
\begin{aligned}
M=1,500,000 & +225,000\left(\frac{l}{2}-9.61\right)-\frac{4,325,000}{l}\left(\frac{l}{2}-9.61\right) \\
& \frac{225,000}{l}\left(\frac{l}{2}-9.61\right)^{2}-\frac{20,750,000}{l} \\
=1,500,000+ & 112,500 l-2,162,500-2,162,500+\frac{41,568,056}{l} \\
& -56,250 l+2,162,500-\frac{20,783,925}{l}-\frac{20,750,000}{l} \\
= & -662,500+\frac{34,131}{l}+56,250 l=56,250 l-662,500+\frac{34,131}{l} .
\end{aligned}
$$


Making the moments for four and five loals equal, we have:

$$
\begin{gathered}
5\left(1,000 l-500,000+\frac{312,500}{l}=-662,500+\frac{34,131}{l}+56,260 l\right. \\
-1250 l=-162,500 \frac{278,3690}{l} \\
6250 l^{2}-162,500 l=+278,369 \\
l^{2}-26 l=44.54 \\
l^{3}-26 l+169=44.54+169 \\
l-13- \pm 213.54= \pm 14.61 \\
l=13 \pm 14.61=27.61^{\prime}
\end{gathered}
$$

as the limiting length of span for which four losuls prose luer maximum moments.

The tabulation following shows the moments and the positions of the loaks that produce then for the spans from 9 to $2 \mathbf{I}^{\prime}$ for intervals of $\mathrm{I}^{\prime}$.

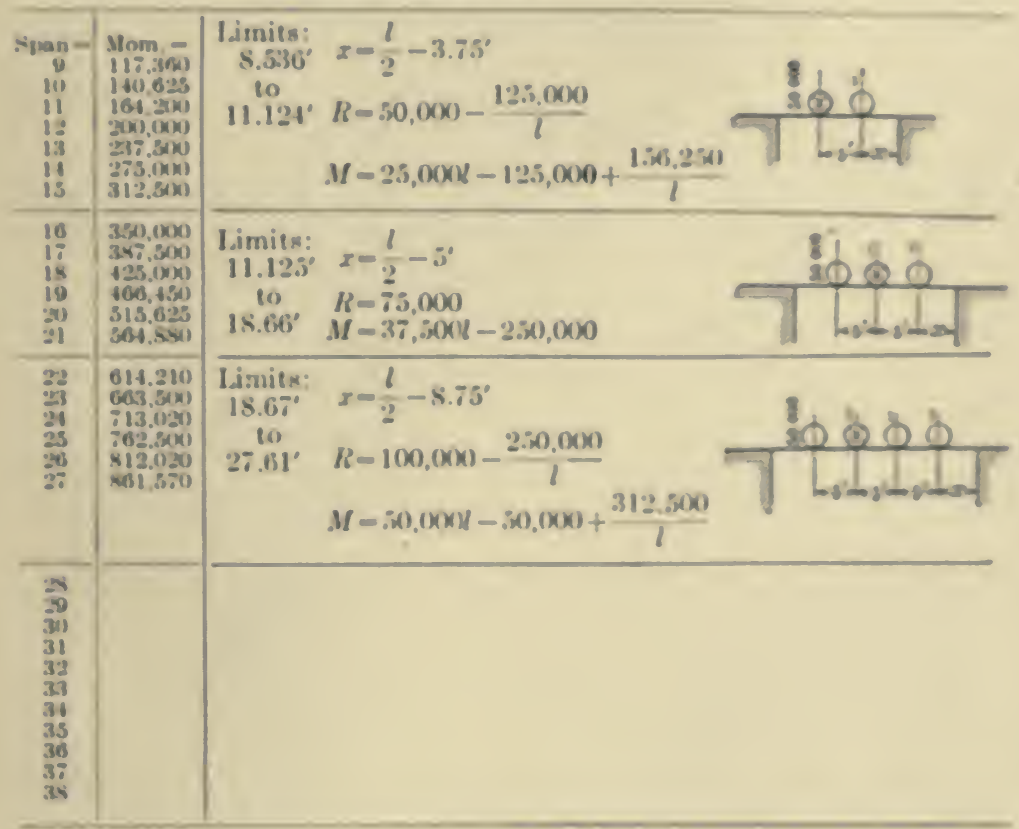




\section{PROBLEMS}

14a. Compute the foregoing table up to $3 S^{\prime}$.

14b. Compute the maximum $1 /$ end shear for one girder of a $3 s^{\prime}$ effective single-track deck plate-girder bridge. Two girders carry one track. Cooper's Eso.

\section{ART. 15. TABLE OF MOMENTS, SHEARS AND CONCENTRATED LOADS FOR COOPER'S $E_{s 0}$}

The method of writing equations for bending moments of Art. 14 need not be followed for spans over $30^{\prime}$ long. For spans over $30^{\prime}$ in length the maximum center moment is only a small fraction of one per cent. less than the absolute maximum moment. The following table gives a convenient arrangement of the quantities for spans up to $75^{\prime}$ effective length.

For through spans tables of moments at the pancl points and shears in all the panels for varying number of panels and panel length are realily prepared and should be made for any loaling as much used as Cooper's systems.

PROBLEMS. Loading Cooper's E $\mathrm{E}_{80}$.

15a. Compute the live load concentration for a trestle bent which rarries adjacent spans of $30^{\prime}$ and $60^{\prime}$. Show hy a sketch the position of loads.

15h. Compute the maximum center moment for a $60^{\prime}$ span. Show by sketch the position of loads.

15c. Compute the maximum shear at the center of a $60^{\prime}$ span. Show by sketch the position of loads.

15\%. Compute the maximun shear at a point 15' from one end of a $60^{\prime}$ span. Show by sketch the position of the loads. 


\begin{tabular}{|c|c|c|c|c|c|c|c|c|c|c|c|}
\hline $\lim _{11}$ & $\frac{B-1}{8 b}$ & 45 & c. & in & nitis & & is & $\frac{10}{N}$ & $8 \mathrm{n}$ & $\dot{k}$ & $N=$ \\
\hline $10^{\circ}$ & 730 & 0,0 & 250 & 140.6 & $I(x), 0$ & : & $8 x^{\circ}$ & 165,8 & 1321 & 83 & $10 \% 3$ \\
\hline $11^{\circ}$ & 810 & $: .3$ & 28.3 & 164.3 & $|(x)|$, & 8 & $14^{\circ}$ & 201.4 & 129.5 & 00 & $1 \mathrm{SaN}$ \\
\hline $12^{\circ}$ & 58.3 & t. 1 & 30.1 & 2000,0 & 1166 & i & 19 & Dos a 2 & 125, & 5.6 & $3 \times n$ \\
\hline $13^{\circ}$ & 92.3 & 3.8 & 30.8 & 238.6 & 123.1 & 요 & $65^{\circ}$ & $20: 0$ & II & 3 & $x=8, a$ \\
\hline $14^{\circ}$ & $(n)+$ & & $3: 1$ & 275.0 & 1304 & & $10^{\circ}$ & 300,0 & 124 & 9 & 2166.6 \\
\hline $15^{\circ}$ & $(00.0$ & & $3: 3,4$ & 312.5 & 1346 & 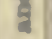 & $45^{\circ}$ & 212.6 & .3 & 60.1 & 2810 \\
\hline $16^{\circ}$ & 16.2 & & 34.4 & 350,0 & $1+2.3$ & 3 & $40^{\circ}$ & 213.4 & 0 & 13 & $820 \%$ \\
\hline $1 i^{\circ}$ & 11.8 & & & 357.5 & 1480 & & $8 x 0^{\circ}$ & 218,1 & Ias of & 8 1 & 2578 \\
\hline is & 6.6 & & & $42:$ & 131.6 & $\theta$ & $81^{\circ}$ & 200,0 & & a. 0 & $285: 6$ \\
\hline $19^{\circ}$ & 1.0 & ) & & +603.5 & 157.3 & है & $32^{\circ}$ & $223:$ & 1369 & 3. 5 & 25000 \\
\hline $20^{\circ}$ & 83.0 & 0 & 35 & $31:$ & 163.9 & 1 & $83^{\circ}$ & 238.3 & 1 & 8 & 8013,1 \\
\hline $21^{\circ}$ & 5.6 & 3) & 37. & 56 & 169.9 & 2 & $38^{\circ}$ & $2 \times 0$ & 1801 & 63 & Irog. \\
\hline $23^{\prime}$ & 9 & & 3 & 61. & 175.4 & & $35^{\circ}$ & 23 & 0 & 0 & 2.015 \\
\hline $23^{\circ}$ & 4.8 & & & 623 & 180,4 & a & $56^{\circ}$ & $234+$ & $183 \mathrm{~s}$ & 6 & 2069 \\
\hline $31^{\circ}$ & 57.5 & & & ils & 181.9 & & $3 i^{\prime}$ & 238,1 & 3 & $68 \cdot 3$ & Po6 9 \\
\hline $25^{\circ}$ & 120 & 9 & 4 & 5) & 1 & & $45^{\prime}$ & 2398 & 1 & 7.9 & 901: 6 \\
\hline$: 6^{\circ}$ & 1 & & 4 & 0 & .3 & हू & $89^{\circ}$ & 4 & 6 & 5.5 & 3150.5 \\
\hline $27^{\prime}$ & 1 & 9 & 42.1 & 3 & 200.3 & 8 & a & 21 & 3 & 6 & 1 \\
\hline $25^{\circ}$ & 131.1 & 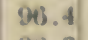 & $\$ 2.9$ & 8 & 205.5 & & $61^{\circ}$ & $28 i$ & s & $s$ & 2363 \\
\hline $29^{\circ}$ & 153.9 & 3 & 43 & 9 & 210.9 & & $62^{\circ}$ & 28 & .3 & 3 & 1160 \\
\hline $30^{\circ}$ & 7.6 & 0.0 & 44,1 & 1020.1 & 215.6 & $\Xi$ & $63^{\circ}$ & 253.6 & 134.5 & 720 & 50: 3 \\
\hline $31^{\prime}$ & 161.1 & 1.9 & 45,5 & 108. & & & $64^{\circ}$ & 2308 & 1563 & 82.5 & $\sin 8 \mathrm{~s}$ \\
\hline $32^{\circ}$ & 34.3 & & 46.9 & & & & $63^{\circ}$ & 259,3 & 157.8 & 3.5 & gis s \\
\hline $33^{\circ}$ & 167.4 & 6.9 & 45.1 & & ๘ँ & & $66^{\circ}$ & 20 & 3 & 1.3 & Shas of \\
\hline $34^{\prime}$ & 170.3 & 6.8 & 49,3 & 1251.0 & & & ti" & & 8 & 1.9 & feos: \\
\hline 3 & 9 & 5] & 50 & 1307.4 & & & 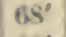 & 261 & 3 & 3.6 & ins \\
\hline $36^{\circ}$ & 6.4 & .1 & 51 & 1371.7 & ¿ & & $69^{\circ}$ & 273 & 8 & 3.2 & 116 \\
\hline $3 i^{\prime}$ & 0.6 & 2.3 & 52.4 & 35.9 & & & $70^{\circ}$ & 276.3 & 16.3 & i6 9 & foos s \\
\hline $35^{\circ}$ & 152.8 & 113.8 & 53.3 & 1300.0 & & 气̆ & ilo & 259.3 & $160 \mathrm{~s}$ & 78.8 & 4186.0 \\
\hline $39^{\circ}$ & 185.8 & 115.0 & 54.1 & 1566.6 & & & $72^{\prime}$ & 243,4 & 1 Gs. 3 & 78.3 & 16813 \\
\hline $40^{\circ}$ & 155.5 & 116.9 & 530 & 1639.1 & गै. & & $83^{\circ}$ & 257,0 & 160.9 & iv.2 & $4 \operatorname{Sin} 1$ \\
\hline $41^{\circ}$ & 192.0 & 15.8 & 53.8 & 1711.6 & & & $81^{\circ}$ & 2906 & $1: 13$ & (N) 0 & 1.000 \\
\hline $42^{\prime}$ & 195.3 & 20.3 & 56.3 & 1784.1 & $\ddot{\ddot{0}}$ & & $75^{\prime}$ & 34.3 & $2 \cdot 6$ & (20:- & ist3.5 \\
\hline
\end{tabular}




\title{
Short-title Catalogue
}

\author{
Oy $2 \mathrm{kn}$
}

\section{PUBLICATIONS}

08

\author{
JOHN WILEY \& SONS \\ NeW YORK
}

\author{
LosDos: CH.APMAN \& HAI.L, L.MITE
}

\author{
ARRANGED UNDEK SUBJECTS
}

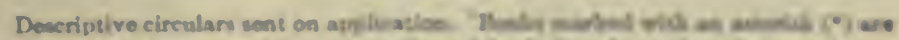

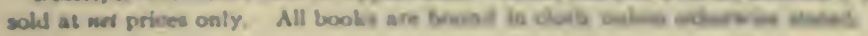

\section{AGRICULTURE - HORTICULTURE-FORESTRY.}

Armiby's I'rinciples of Animal Sutrithe, ...........

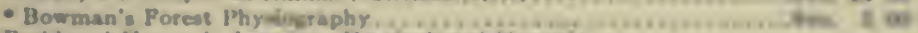
Budd and Hanen's American Horteditural Mesical:

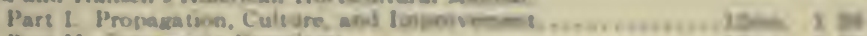

Pare II Syetonacie fromolbey

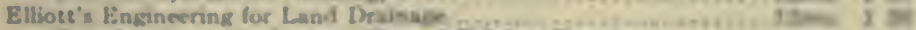

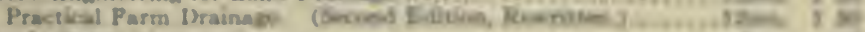

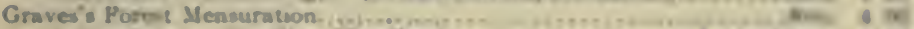

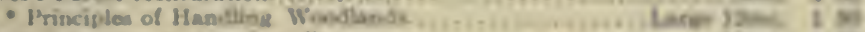

Greea's l'rinciples of American Poreatry.

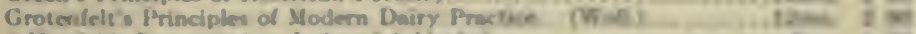

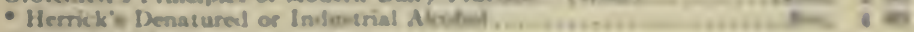

Holm' Malk in Denmark, (In prees.)

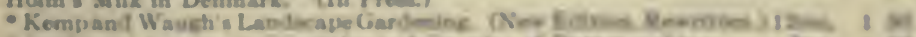

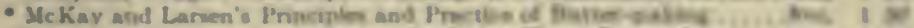

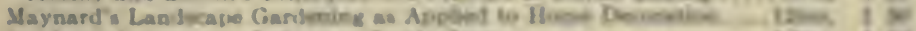

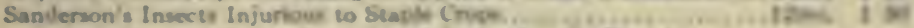

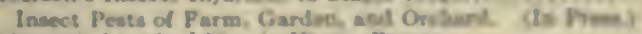

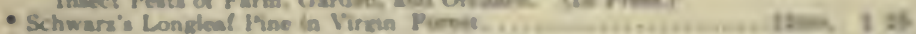

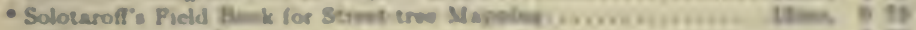

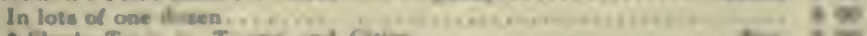

- Shaile Trees in Towns and Cries - ...

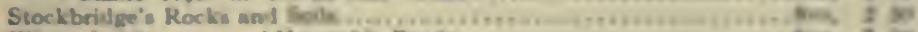

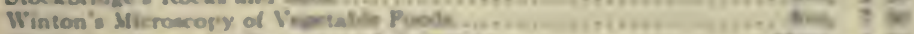

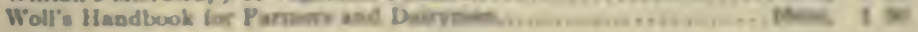

\section{ARCHITECTURE.}

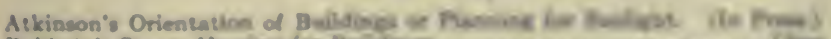

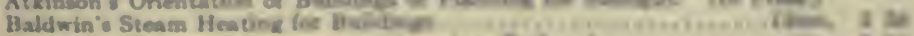

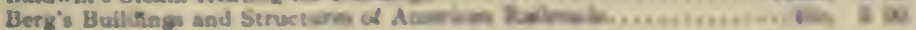


Birkmire's Architectural Iron and Steel......................8vo, \$3 50 Compound Riveted Girders as Applied in Buildings...............8vo, 2 00

Planning and Construction of American Theatres................. 3 oo

Planning and Construction of Iligh Office Buildings............ 8vo, 380

Steleton Construction in Buildings.........................8vo, 300

Brikgs's Modem American School Buildings....................... svo, \& 00

Byrne's Inspection of Materials and Workmanship Emplojed in Construction.

$\begin{array}{rr}16 \mathrm{mo}, & 300\end{array}$

- Corthell's Allowable Pressure on Deep Foundations.................12mo, 125

Eckel's Building Stones and Clays. (In Press.)

Treitag's Architectural Engineering...........................8vo, 3 50

Fire Prevention and Fire Protection. (In Press.)

Pireproofing of Steel Buildings........................8vo, 250

Gerhard's Guide to Sanitary Inspections. (Fourth Edition, Entirely Re-

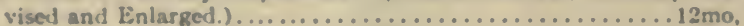

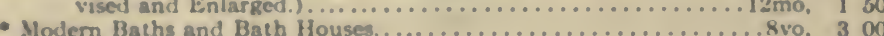

Modern Baths and Bath Houses...................... 3 00

Theatre Fires and Panics........................... I 50

- The Water Supply. Sewerage and Plumbing of Modern City Buildings,

Johnson's Statics by Algebraic and Graphic Methods..............8vo, 200

Kellaway's How to Lay Out Suburban Home Grounds............... . svo, 200

Kidder's Architects' and Builclers' Pocket-book............... 16mo, mor. is (n)

Merrill's Stones for Building and Decoration..................8vo, 500

Monckton's Stair-building..............................4to, 400

Patton's Practical Treatise on Foundations......................8vo, 500

Peabody's Naval Architecture................................8vc, 750

Rice's Concrete-block Manufacturc.......................... 8vo, 200

Richey's Handbook for Superintendents of Construction ....... 16 mo, mor. 400 .

Building Foreman's Pocket Book and Ready Reference. . 10mo, mor. 500

- Building Mechanics Ready Reference Series:

* Carpenters' and Woodworkers' Edition...........16mo, mor. 150

- Cement Workers and Plasterers Edition.............. $16 \mathrm{mo}$ mor. 150

- Plumbers', Steam-Fitters', and Tinners' Edition. . 16mo, mor. I (5)

- Stone- and Brick-masons' Edition..............16mo. mor. I 10

Sabin's House Painting..................................... 100

Siebert and Biggin's Modern Stone-cutting and Masonry............... . . I 50

Snow's Principal Species of Wool.........................8vo, 350

Wait's Engineering and Architoctural Jurisprudence...............8vo, 600

Law of Contracts.

Law of Operations Preliminary to Construction in Engineering and Architecture.

Sheer, 550

TWilson's Air Conditioning.

Worcester and Atkinson's Small Hospitals. Establishment and Maintenance, Suggestions for Hospital Architecture, with Plans for a Small

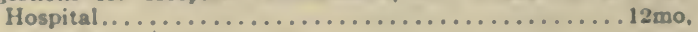

\section{ARMY AND NAVY.}

Bernadou's Smokeless Powder, Nitro-cellulose, and the Theory of the Cellu-

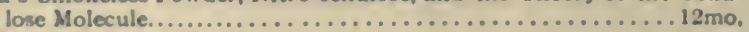

Chase's Art of Pattern Making........................ $12 \mathrm{mo}$, Screw Propellers and Marine Propulsion........................ . . . . .

- Cloke's Enlisted Specialists' Examiner..................... . . . . . . . 8vo,

* Gunner Examiner.............................. 8vo,

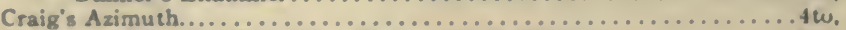
Crebore and Squier's Polarizing Photo-chronograph................ 8vo.

- Davis's Elements of Law................................ 8vo,

- Treatise on the Military Law of United States.............. 8vo.

- Dudley's Military Law and the Procedure of Courts-martial. .Large $12 \mathrm{mo}$,

Durand's Resistance and Propulsion of Ships.................... 8vo. 


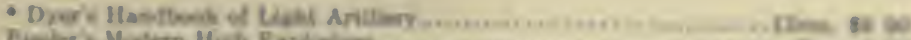

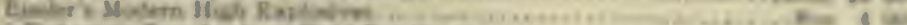

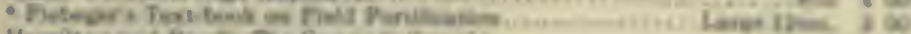

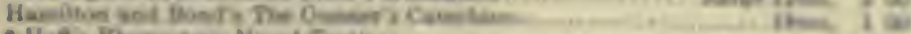

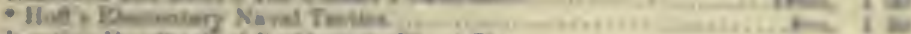

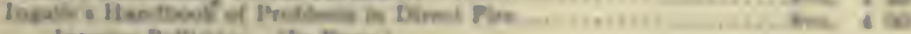

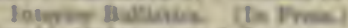

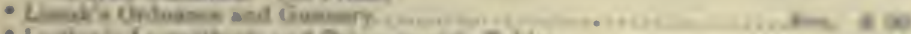

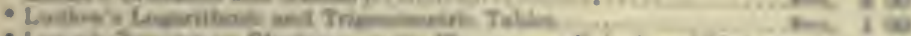

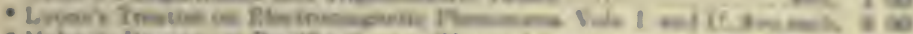

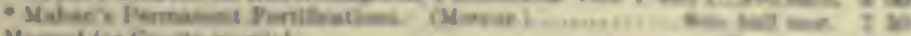

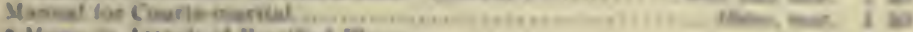

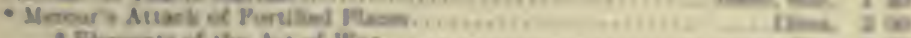

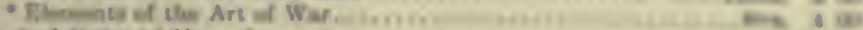

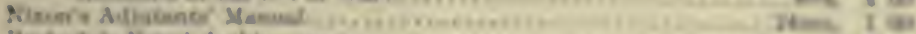

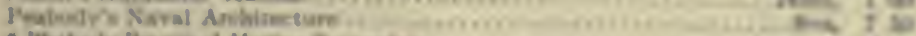

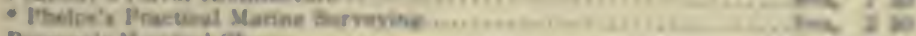

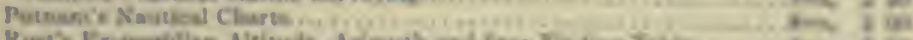

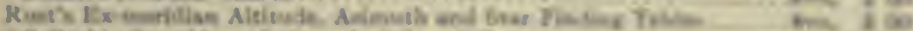

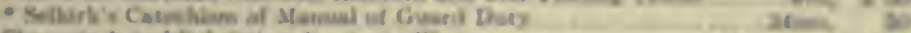

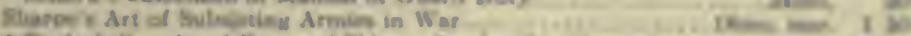

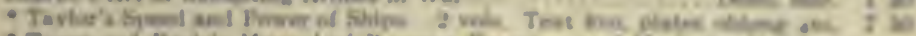

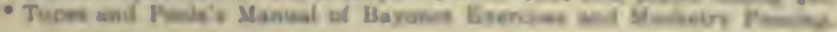

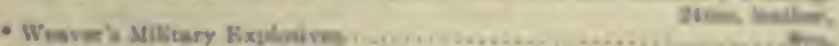

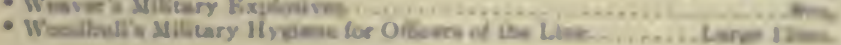

\section{ASSAYING.}

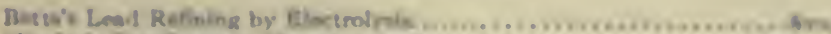

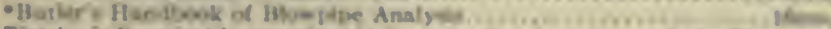

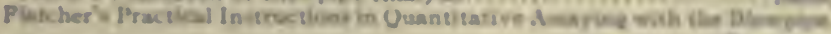

ien of it:

Parman and Partocis Nenaal of Practical Amavine.

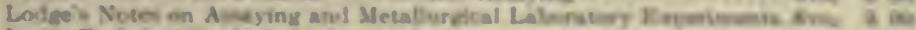

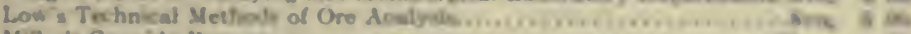

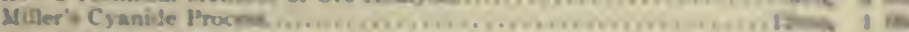
Manjal of A sayincs...............................

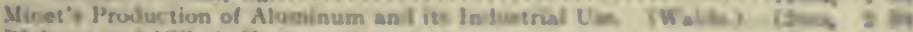
Rickets ant Mitler's Notes on Avaying in.......................

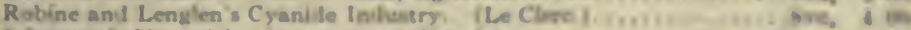
- Seamon's Manual for A mayers anil Chmalats....... Lare izes is is Ulke's Monjern Rlectrolytic Cosper Resnimg ......................

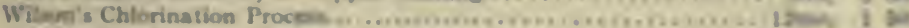

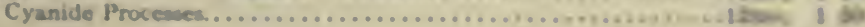

\section{ASTRONOMY.}

Corntek's Piels Aitronomy for Bngibeenw....................

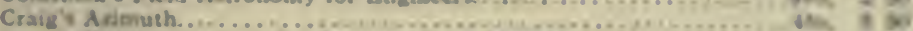

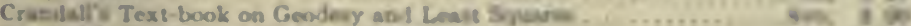

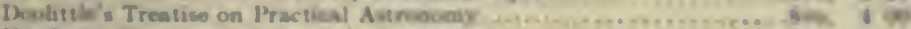

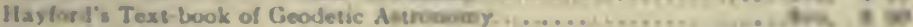

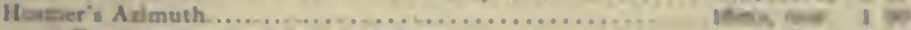

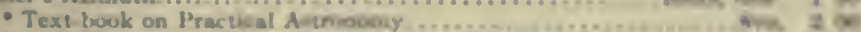

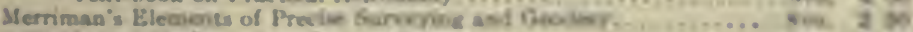
- Miehie add Hariow's Practical A-trominay f.........

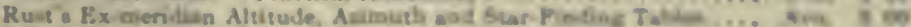

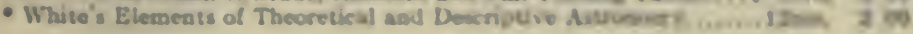

\section{CHEXISTRY.}

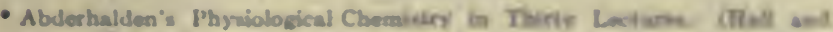
Detren). . H........

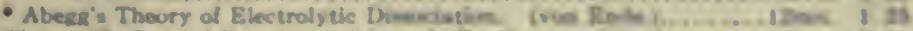

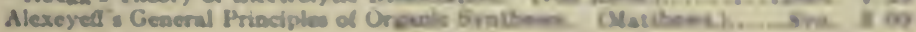


Allen's Tables for Iron Analysis........................ 8vo, \$3 00

Armuby Principles of Animal Nutrition....................... svo, 400

Arnolu's Compendium of Chemistry. (Mandel.)................... 12mo, 350 Association of State and National Food and Dairy Departments, Hartford

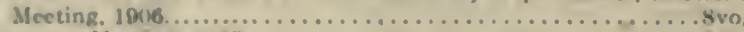

Autten is Notes for Chemical Students.......................

Ilackerville's Chemical Elements. (In Preparation.)

Bernadou's Smokeless l'owder - Nitro-cellulose, and Theory of the Cellulose

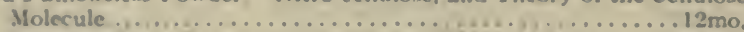

- Hiltz's Intraluction to Inorganic Chemistry. (IIall and Phelan). . 12mo, Laboratory Methods of Inorganic Chemistry. (Ifall and I3lancharcl.)

8vo, 300

- Bingham and White's Laboratory Manual of Inorganic Chemistry. . 12mo. 100

- Blanchard's Symehetic Inorganic Chemistry...................12mo, 100

Bot:ler's Varnish Making. (Sabin.) (In Press.)

- Hrowning's Introduction to the Karer Elements................... Svo, 150

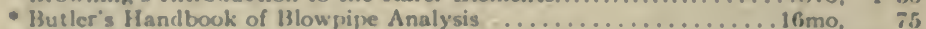

- Claassen s lBcet-sugar Manufacture. (Hall and Rolfe.)................... 3 voo

Classen's Quantitative Chemical Ana!ysis by Electrolysis. (Boltwood.).8vo, 300

Cohn's Indicators and Test-papers.......................... $12 \mathrm{mo}^{2} \quad 200$

Tests and Reagents................................ 300

Cohnheim's Functions of Enzymes and Perments. (In Press.)

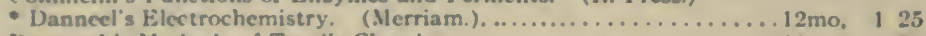

Dannerth's Methods of Textile Chemistry................... 12mo, 2 (x)

Duhem's Thermodynamics and Chemistry. (Burgess.).............8vo, 400

Efront's Enzymes and their Applications. (Prescott.)............... 3 . 300

Eissler's Modern High Explosives............................. \&vo. \& 00

- Fischer's Oedema................................ 8vo, 200

- Physiology of Alimentation. ............................ 12mo, 200

Pletcher's Practical Instructions in Quantitative Assaying with the Blowpipe.

$16 \mathrm{mo}$, mor. 150

Fowler's Sewage Works Analyses......................... 2 mo, 20

Fresenius's Manual of Qualitative Chemical Aralysis, (Wells.).......... Svo, ; 00

Manual of Qualitative Chemical Analysis. Part I. Descriptive. (Wells.)8vo, 300 Quantitative Chemical Analysis. (Cohn.) 2 vols.............8ve, 1250 When Sold Separately, Vol. I, \$6. Vol. II, \$8.

Fuertes's Water and Public Health......................... I 50

Furman and Pardoc's Manual of Practical Assaying...............

- Getman's Exercises in Physical Chemistry.......................12mo, 200

Gill's Gas and Fuel Analy'sis for Engincers................... 12mo, 125

* Gooch and Browning's Outlines of Qualitative Chemical Analysis.

Lange 12mo, 125

Grotenfelt's Principles of Modem Dairy Practice. (Woll.)........... $2 \mathrm{mo}^{2} 200$

Gmth's Introduction to Chemical Cry'stallography (Marshall)......... 12mo, 125

- Hammarsten's Text-book of Physiological Chemistry. (Mandel.)....8vo, 400

Hanausek's Microscopy of Technical Products. (Winton.).............8vo, 500

- Haskins and Macleod's Organic Chemistry..................... 12mo, 200

- Herrick's Denatured or Industrial Alcohol......................... 8vo, 400

Hinds's Inorganic Chemistry.................................. 300

- Laboratory Manual for Students. . ....................... $12 \mathrm{mo}, 100$

- Holleman's Laboratory Manual of Organic Chemistry for Beginners. (Walker.)................................... 100

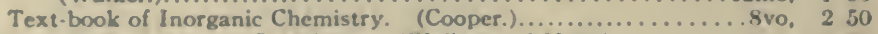

Text-book of Organic Chemistry. (Walker and Mott.)...........8vo, 250

Holley's Analysis of Paint and Varnish. Products. (In Press.)

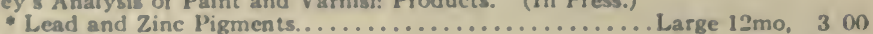

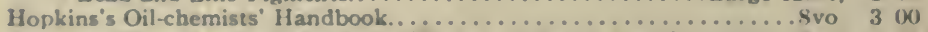

Jackson's Directions for Laboratory Work in Physiological Chemistry..8vo, 125

Johrson's Rapid Methods for the Chemical Analysis of Special Steels, Steelmaking Alloys and Graphite............................... 300

Landaucr's Specerum Analysis. (Tingle.)....................8vo, 300

Lassar-Cohn's Application of Some General Reactions to Investigations in

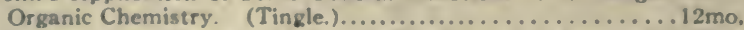

Leach's Inspection and Analysis of Pood with Special Reference to State

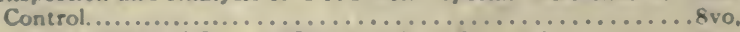

Lsb's Electrochemistry of Organic Compounds. (Lorenz.......... svo. 7 50 


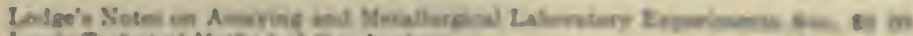

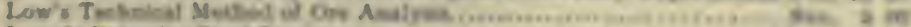

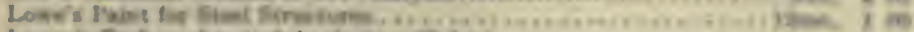

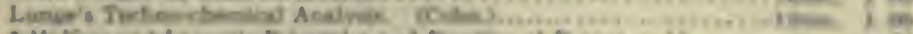

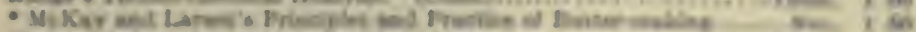

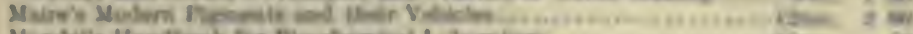

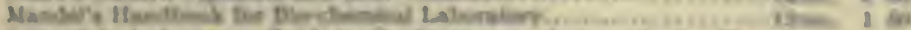

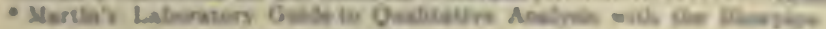

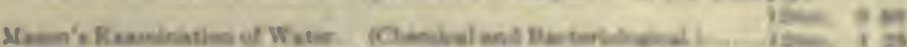

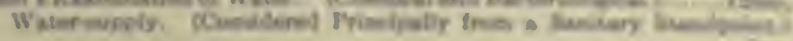

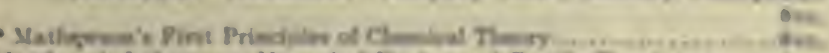

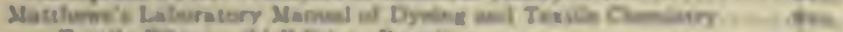

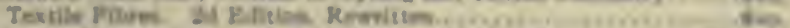

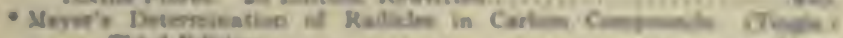

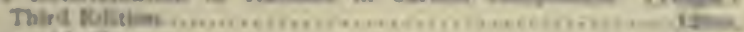

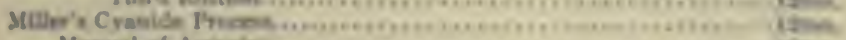

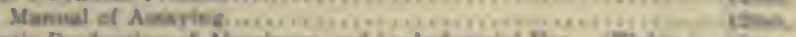

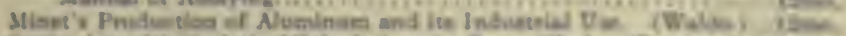

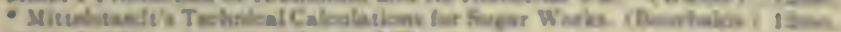

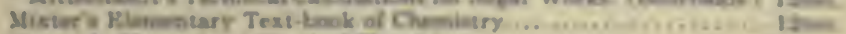

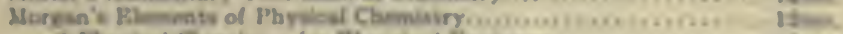

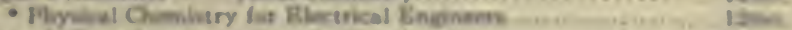

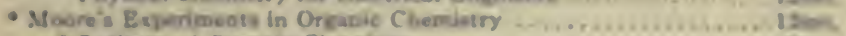

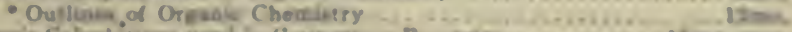

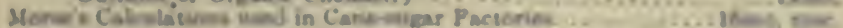

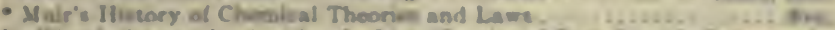

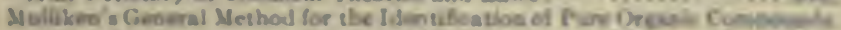

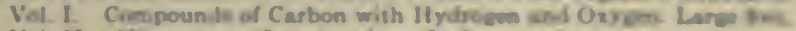

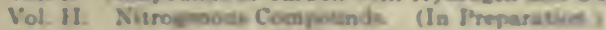

Vol III The Comiscreial Drosuff. ................Larasus.

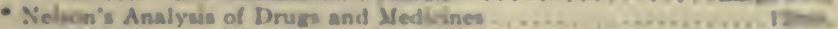

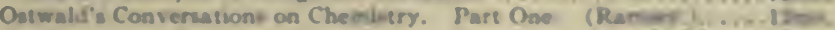

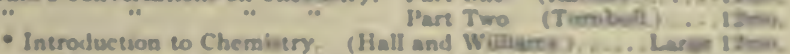

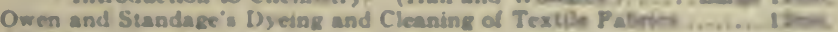

- Palinier's Practical Test Book of Chemiatry .............................tans.

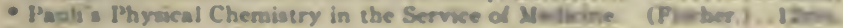

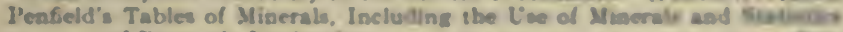

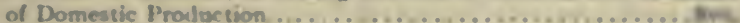

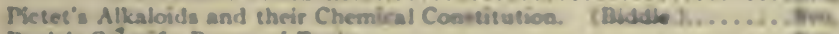

Poole is Calerific Powes of Puelk................................. by

Prescots and Winslow's Elemente of Wiater Bacteriolory, vith finerlat Reler ence to Sanitary Water Aralfwik.......................... Ither Is

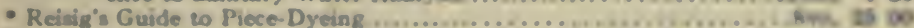

Richards and Woodman's Air. Water, and Pood trom a Snitary funes. poine..............................................

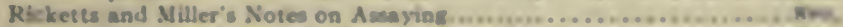

Kideal's Disisfection and the Preservation of Pood .............................

Kiez's Elerentar: Manual for the Chernical Laboratory.................. Mra.

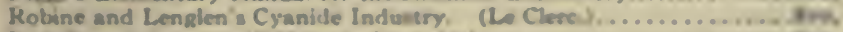

Kud liman' Incompatibilieses in Preacriptiona......................... Brs.

Whys in Pharmacy.......................................... 13n

- Ruer is Elements of Metallography (Mathemoa) ................... 5 .

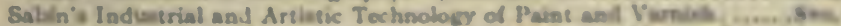

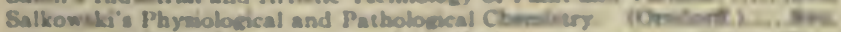

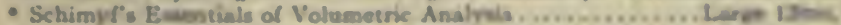

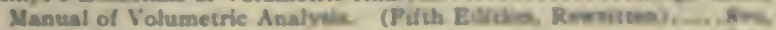

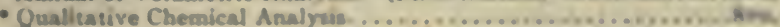

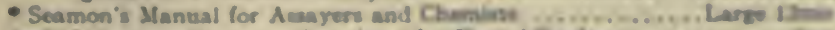

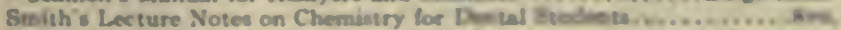

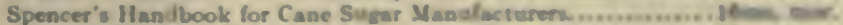

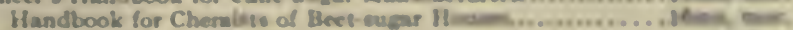

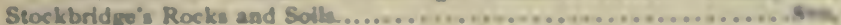

Stone is Practical Testing of Gas and Gas Neter. ................... $3=$

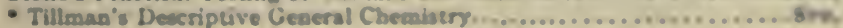


- Tillman's Elementary Leseons in Heat ................... 8vo, \$1 50 Treadwell' Ou olstative Analysis. (Hall.)................... 8vo, 300

Quantitative Analyais. (Hall.).............................. 400

Tumeaure and Russell's Public Water-supplies....................8vo, is 00

Van Deventer's Physical Chemistry for Beginners. (Boltwood.).....12mo, 1 Bn

Venable's Methorls and Devices for Bacterial Treatment of Sewage..... Svo, 300

Ward and Whipple's Freahwater Biology. (In Press.)

Ware's Beet-sugar Manufacture and Refining. Vol. I..............8vo, 400

" $"$ Vol. II.................. " 8 . 00

Washington's Manual of the Chemical Analysis of Rocks................ 8 vo, 200

- Weaver's Military Lixplosives............................... 8vo, 300

Wells's Laboratory Guide in Qualitative Chemical Analysis............8vo, 150

Short Course in Inorganic Oualitative Chentical Analysis for Lingineering

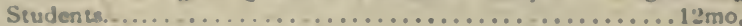

Text-book of Chemical Arithmetic.

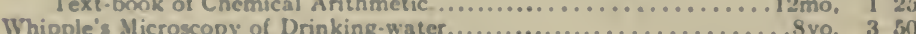

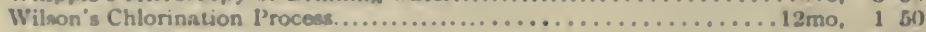

Cyanide Processes...................................... is

Winton's Microscony of Vegetable Foods...................8vo, 7 so

Zsigmondy's Colloids and the Uiltramicroscone. (Alexander.)..Large 12mo, 300

\section{CIVIL ENGINEERING.}

\section{BRIDGES AND ROOFS. HYDRAULICS. MATERIALS OF ENGINEER-} ING. RAILWAY ENGINEERING.

- American Civil Engincers' Pocket Book. (Mansfield Merriman, Editor-

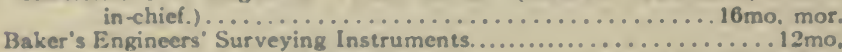

Bixby's Graphical Computing Table.............. Paper $191 \times 24\}$ inches. Breed and Hosmer's Principles and Practice of Surveying. Vol. I. Elemen-

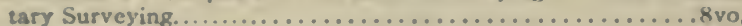

- Burr's Anciene and Modern Engincering and the Isthmian Canal......8vo, 350

Comstock's Field Astronomy for Engineers.................

- Corthell's Allowable Pressure on Deep Foundations ............. 12mo, 125

Crandall's Text-book on Geodesy and Least Squares..............8vo, 300

Davis's Elevation and Stadia Tables....................... 8vo, 100

Elliott's Engineering for Land Drainage...................... 12mo, 150

- Piebeger's Treatise on Civil Engincering............................ 500

Flemer's Phototopographic Methods and Instruments...............8vo, 500

Folwell's Sewerage. (Designing and Maintenance.)................8vo, 300

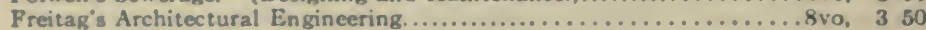

Prench and Ives's Stercotomy......................... 2 8vo, 50

Gilbert. Wightman, and Saunders's Subways and Tunnels of New York.

(In Press.)

- Hauch and Rice's Tables of Quantities for Preliminary Estimates...12mo, 125 Hayford's Text-book of Geodetic Astronomy..................8vo, 3 0n Hering's Ready Reference Tables (Conversion Factors.).........16mo, mor. 250 Hosmer's Azimuth...............................16mo, mor. 10 on

- Text-book on Practical Astronomy........................... 200

Howe's Retaining Walls for Earth................................. 125

- Ives's Adjustments of the Engineer's Transit and Level....... 16mo, bds. 25 Ives and Hils's Problems in Surveying. Railroad Surveying and Geod.

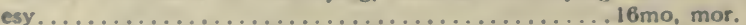

- Johnson (J.B.) and Smith's Theory and Practice of Surveying. Large 12mo, Johnson's (L. J.) Statics by Algebraic and Graphic Methods............ 8vo,

- Kinnicutt. Winslow and Pratt's Sewage Disposal. ............... . . .

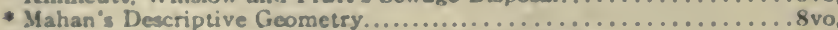

Merriman's Elements of Precise Surveying and Geodesy............. 8vo

Merriman and Brooks's Handbook for Surveyors.............. 16mo, mor.

Nugent's Plane Surveying.............................8vo

Ogden's Sewer Construction............................ . . . . . . .

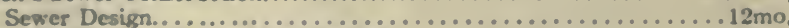

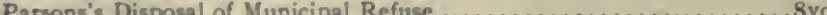

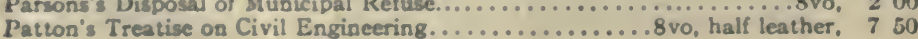




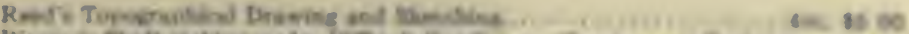

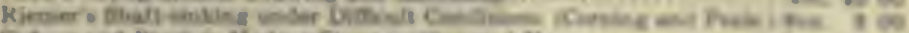

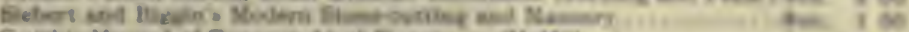

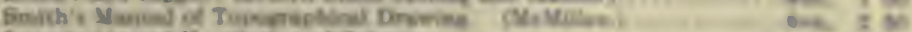

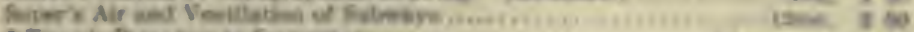

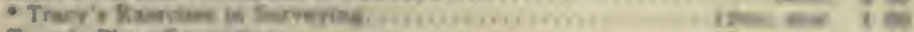

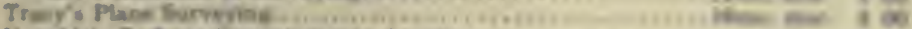

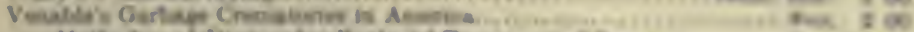

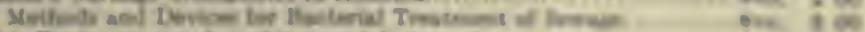

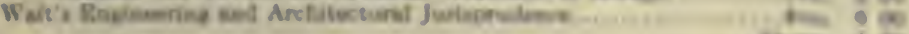

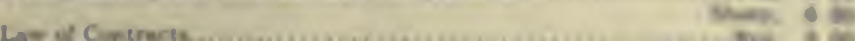

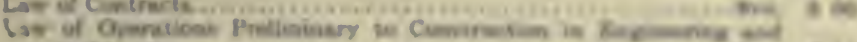

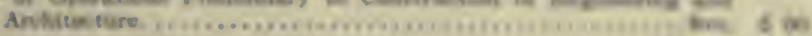

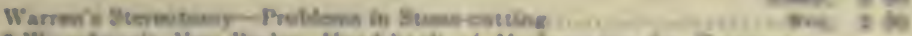

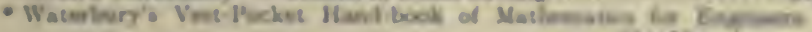

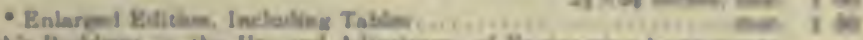

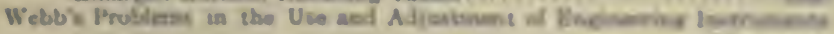

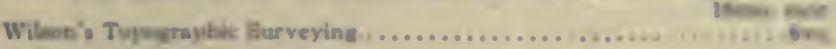

\section{BRIDGES AND ROOPS}

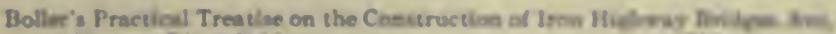

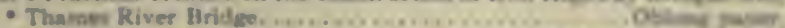

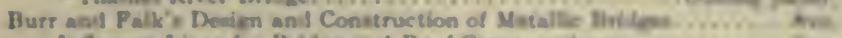

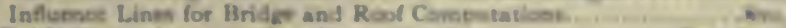

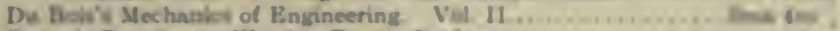

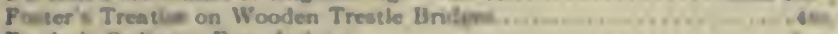

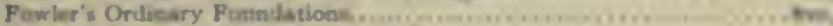

Greene's Arches in Wood. Iron, and Stone.................. , . ...

Bride Truins.........................................

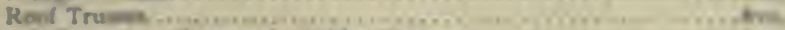

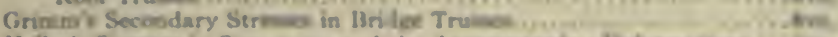

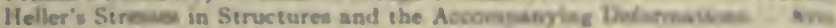

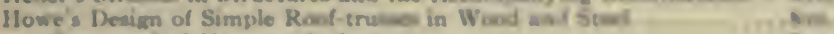

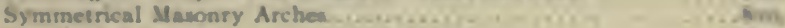
Treatise on Arches.

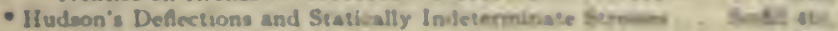

- Plate Girder Deaien .

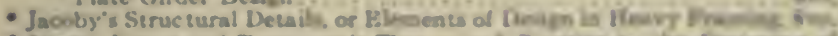

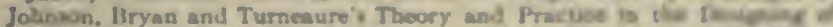

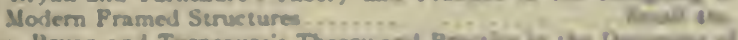

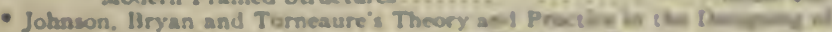

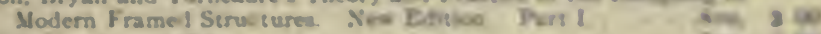

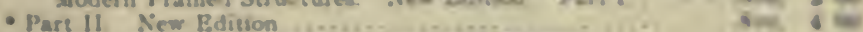

Merriman and Jacoby"s Text-book on Rools aod linkeve-

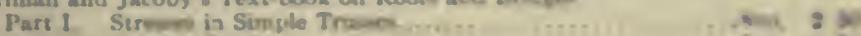

Part II. Graphic Station.....

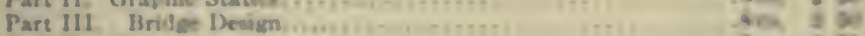

Part IV. Hukher Structure . H..........

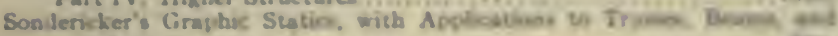

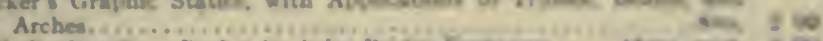

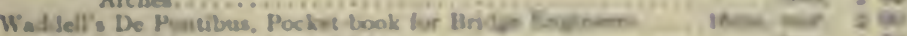

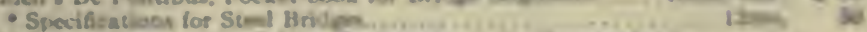

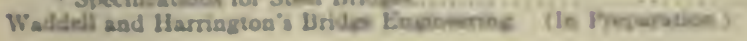

\section{HYDRAELES.}

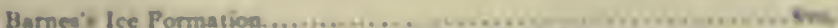

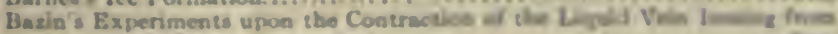

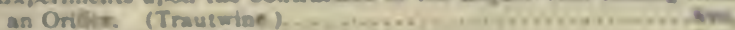

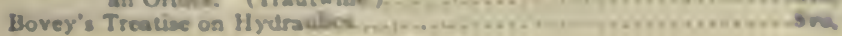


Church's Diagrams of Mean Velocity of Water in Open Channels.

Oblong 4to, paper, $\$ 150$ Pluids (Being Part IV of Mechanics of Engineering) . Bvo, 30 )

Coffin's Graphical Solution of Hydraulic Problems...........16mo, mor. 250 Placher's Dynamometers, and the Measurement of Power............. 300 Folwell's Water-supply Engineering ........................8vo, \& 00

Prizell's Water-power...............................8vo, 500

Puertes is Water and Public Health..................... 12mo, I 50

Waser-filtration Works................................... 250

Ganguillet and Kutter's General Formula for the Uniform Flow of Water in Rivers and Other Channels. (Hering and Trautwine.).....8vo, \& on

Hasen's Clean Water and How to Get I ....................... 12mo, i 50 Filtration of Public Water-supplizs...................8vo, 300

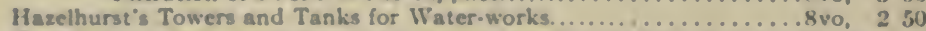

Herschel's 115 Experiments on the Carrying Capacity of Large, Riveted, Metal

Conduits....................................... 200

Hoyt and Grover's River Discharge.............................. 200

Hubbard and Kiersted's Water-Works Management and Maintenance.

- Lyndon's Development and Electrical Distribution of Water Power.

Mason's Water-supply. (Considered Principally from a Sanitary Standpoint. .................................... 400

Merriman's Treatise on Hydraulics..........................8vo, 5 0n

- Molitor's Hydraulics of Rivers, Weirs and Sluices..............8vo, 200

- Morrison and Brodie's High Masonry Dam Design................... 8vo, i 50

- Richards's Laboratory Notes on Industrial Water Analysis.......... 8vo, 50

Schuyler's Reservoirs for Irrigation. Water-power, and Domestic Watersupply. Second Edition. Revised and Enlarged........Large 8vo, 600

- Thomas and Watt's Improvement of Rivers.................4to, 600

Turneaure and Russell's Public Water-supplies..................8vo, 500

-Wegmann's Design and Construction of Dams. 6th Ed., enlarged....4to, 600 Water-Supply of the City of New York from 1658 to $1595 \ldots . . . .4$ to, 1000

Whipple's Value of Pure Water............................... 12mo, 100 Williams and Hazen's Hydraulic Tables.................... 8vo, 150 Wilson's Irrigation Engineering............................8vo, 400

Wood's Turbines...................................... 8vo, 250

\section{MATERIALS OF ENGINEERING}

Baker's Roads and Pavements...........................8vo, 500 Treatise on Masonry Construction........................ 500 Black's United States Public Works...................... Oblong 4to, 500 Blanchard and Drowne's Highway Engineering. (In Press.)

Bleininger's Manufacture of Hydraulic Cement. (In Preparation.)

Bottler's Varnish Making. (Sabin.) (In Press.)

Burr's Elasticity and Resistance of the Materials of Engineering.......8vo, 750

Byrne's Highway Construction........................... 8vo, 500 Inspection of the Materials and Workmanship Employed in Construction.

Church's Mechanics of Engineering.......................... 8 vo, 00 Mechanics of Solids (Being Parts I, II, III of Mechanics of Engineer-

ing................................... 450

Du Bois's Mechanics of Engineering.

Vol. I. Kinematics, Statics, Kinetics............... Small 4 to, 750

Vol. II. The Stresses in Framed Structures, Strength of Materials and Theory of Plexures......................... Small 4to, 1000

Eckel's Building Stones and Clays. (In Press.)

- Cemenes, Limes, and Plasters............................. of on

Powler's Ordinary Foundations........................... 3 vo, 3 50

- Greene's Structural Mechanics...............................8vo, 250

Holley's Analysis of Paint and Varnish Products. (In Press.)

- Lead and Zine Pigments......................... Large 12mo, 3 on

- Hubbard's Dust Preventives and Road Binders.................8vo, 300 


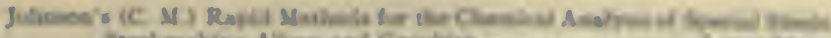

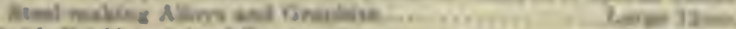

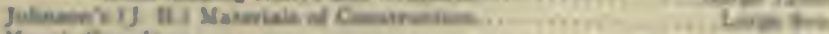
Kimb's Caet lim,

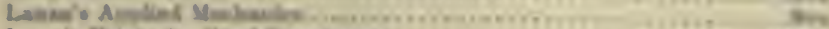

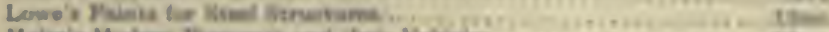

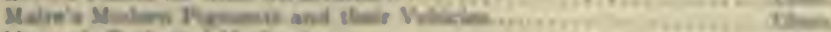

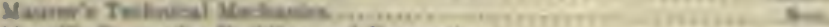

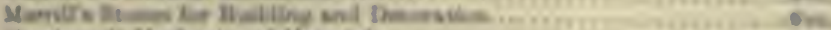

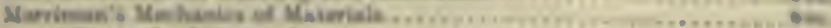

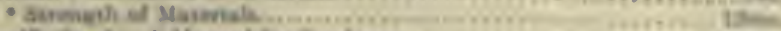

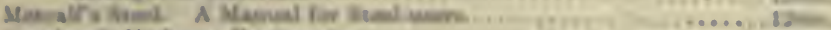

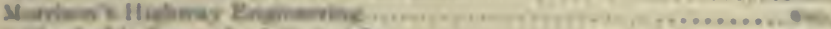

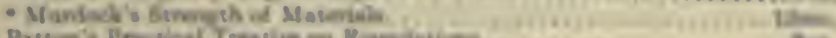

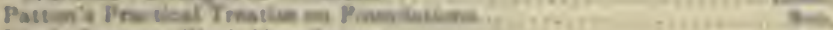

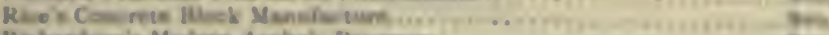

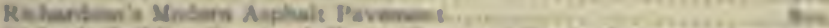

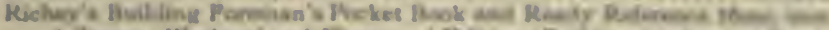

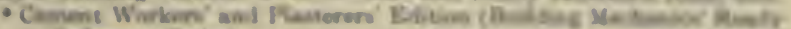

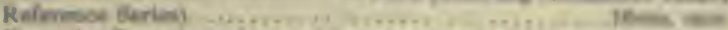

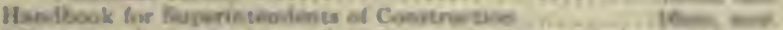

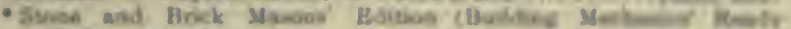

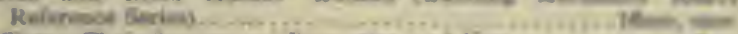

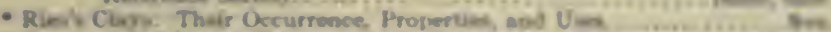

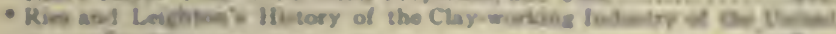

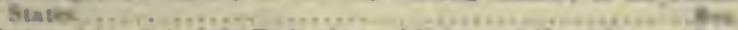

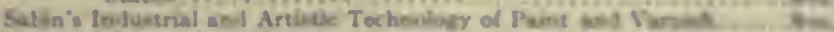

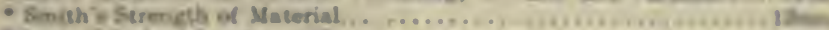

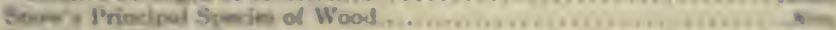

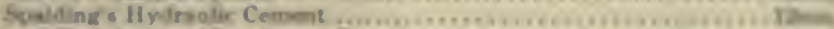

Text-took on Roade ans Paveruente......................

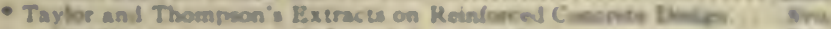

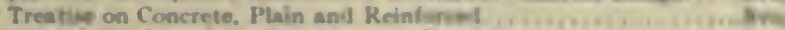

Thuruton' i Materiala of Bacineering In Thre Parta.....

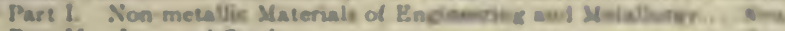

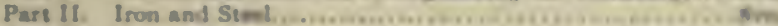

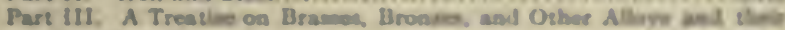
Constituents. ................................................. Sma

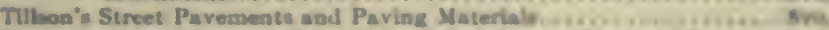

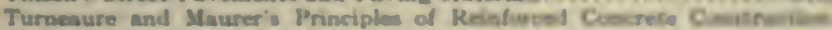

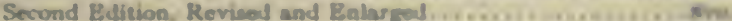

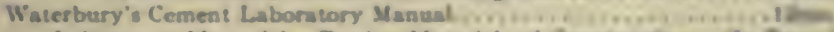

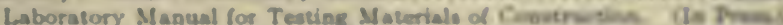

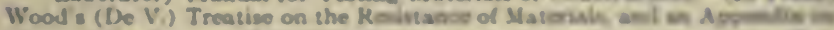

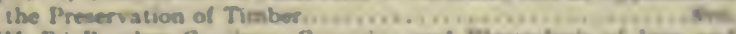

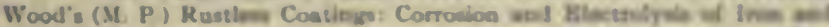

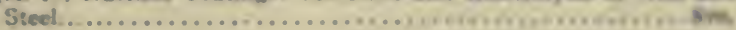

\section{RAILWAY ENGINERRINC}

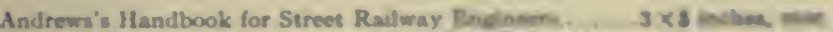

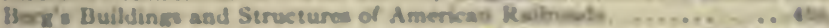

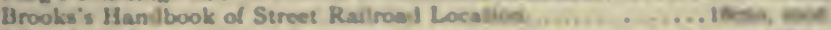

- Burt's Rilway Station Service...............

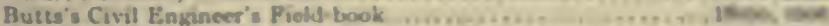

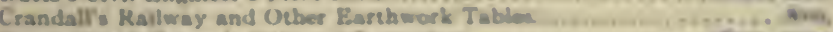

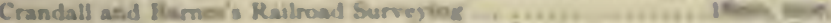

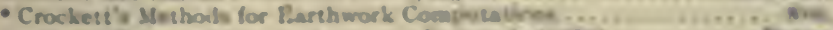

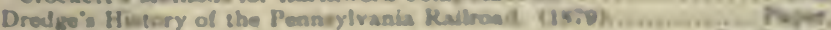

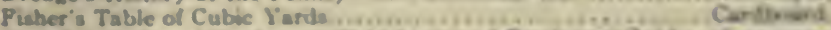

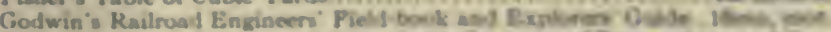

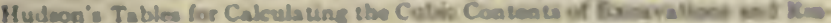
bankmenta ........................................... 9 sm

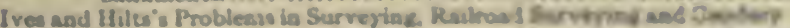

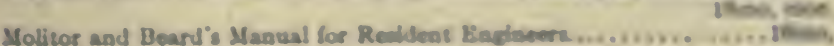


Nagle's Field Manual for Raitrond Lingineera...............16mo, mor. $\$ 300$

- Orrock's Railroad Structures ant Eistimates...................... 8vo, 300 Philbrick's Field Manual for Linsineers..................... 16mo, mor. 300

Raymond's Railraal Field Gcometry ................... 16mo, mor. 2 (o) Elemen ts of Railroad Enkineering ............................. 3 30 Railroad lingineer's Field Book. (In Preparation.)

Roberts Track Formule and Tables...................16mo, mor. 300

Searles is Field Engrineering......................... 16mo, mor. 300 Railnoad Spiral.............................. 16mo, mor. 1 s0

Taylor's Prismoidal Formule and Farthwork....................8vo, is 50

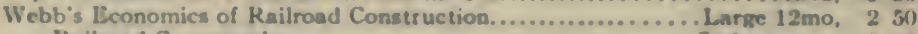

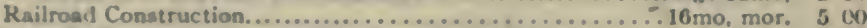

Wellington's Economic Theory of the Location of Railways..... Large $12 \mathrm{mo}$, 500 Wilson's Elements of Railroad-Track and Construction.............12mo, 200

\section{DRAWING}

Barr and Wood's Kinematics of Machinery ................ 8vo, 2 50 - Bartlett's Mechanical Drawing................................... ? 00

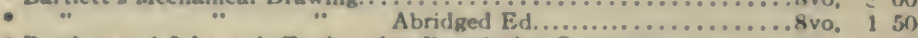

- Bartlett and Johnson's Fngineering Descriptive Geometry.......... 8vo, 1 50

Blessing and Darling's Descriptive Geometry. (In Press.)

Elements of Drawing. (In Press.)

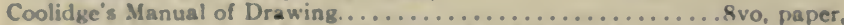

Coolidge and Freeman's Elements of General Drafting for Mechanical Engi-

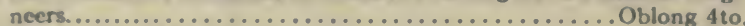

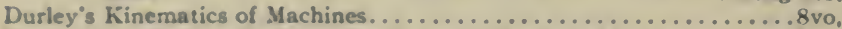

Emch's Introduction to Projective Geometry and its Application......8vo.

Hill's Text-book on Shades and Shadows, and Perspective ............8vo,

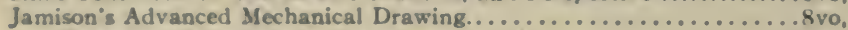

Elements of Mechanical Drawing...................... 8vo,

Jones's Machine Design:

Part 1. Kinematics of Machinery.........................8vo, 150

Part 11. Form, Strength, and Proportions of Parts................8vo, 300

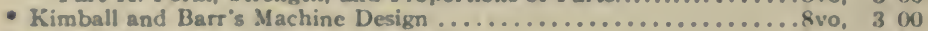

MacCord's Elements of Descriptive Geometry.................8vo, 3 (0)

Kinematics; or. Practical Mechanism............................ 500

Mechanical Drawing................................4to, 400

Velocity Diagrams..................................... I 50.

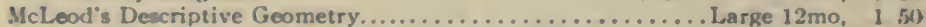

- Mahan's Descriptive Goometry and Stone-cutting.............8vo, I 50

Industrial Drawing. (Thompson.)...................... 350

Moyer's Descriptive Geometry...........................8vo, 200

Reed's Topographical Drawing and Sketching..................... 500

- Reid's Mechanical Drawing. (Elementary and Advanced.)........ 8vo, 2 (0)

Text-book of Mechanical Drawing and Elementary Machine Design..8vo, 300

Robinson's Principles of Mechanism..........................8vo, 300

Schwamb and Merrill's Elements of Mechanism....................... 8vo, 300

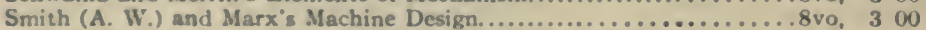

Smith's (R. S.) Manual of Topographical Drawing. (McMillan.).......8vo, 250

- Titsworth's Elements of Mechanical Drawing.............. Oblong 8vo, 125

Tracy and North's Descriptive Geometry. (In Press.)

Warren's Elements of Descriptive Geometry. Shadows, and Perspective. 8vo, 350

Elements of Machine Construction and Drawing...............8vo, 7 50

Eilements of Plane and Solid Free-hand Geometrical Drawing....12mo, 100

General Problems of Shades and Shadows................... 300

Manual of Elementary Problems in the Linear Perspective of Forms and

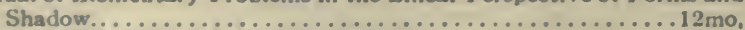

Manual of Elementary Projection Drawing...................

Plane Problems in Elementary Geometry..................... 12 mo,

Weisbach's Kinematics and Power of Transmission. (Hermann and

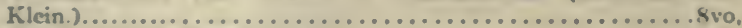

- Wilson's (V. T. ) Doscriptive Geomet

Free-hand Lettering. . . . . . . . . . . . . .

Pree-hand Perspective...................................... 250

Woolf's Elementary Course in Descriptive Geometry.................... 8vo, 300 


\section{ELECTRICITY AND PIYYSICS.}

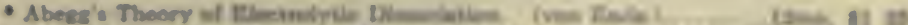

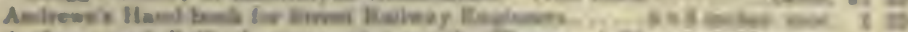

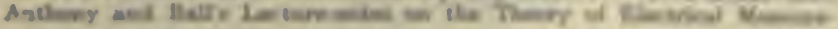

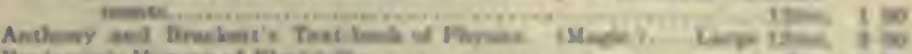

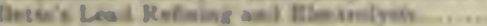
Bition. (Is Primat)

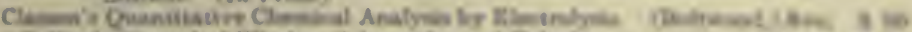

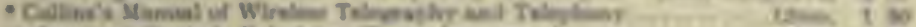

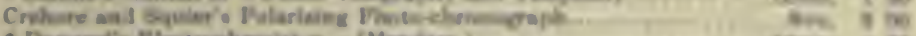

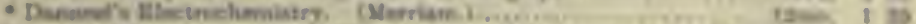

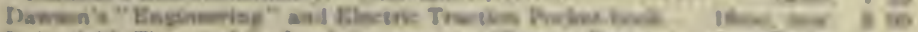

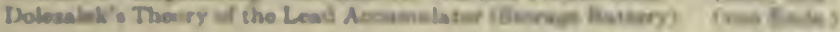

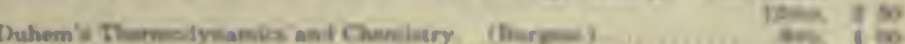

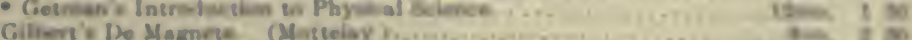

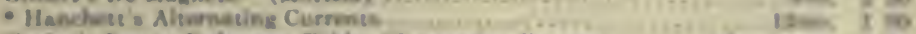

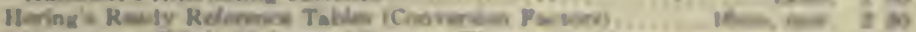

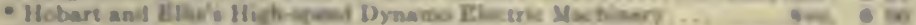

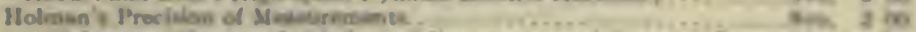

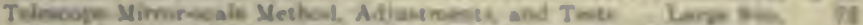

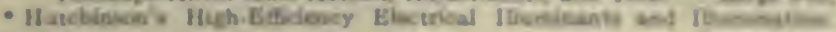

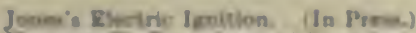

Laretion 1 ss

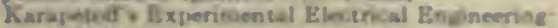

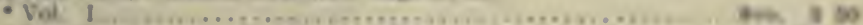

- Vol Il.

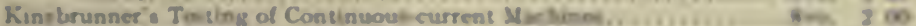

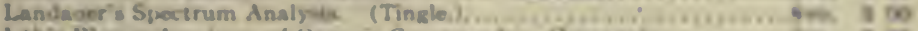

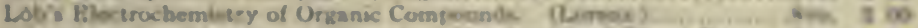

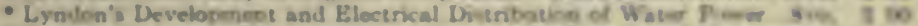

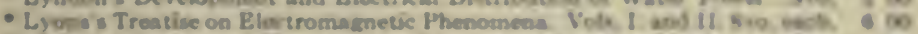

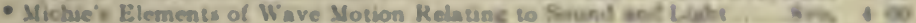

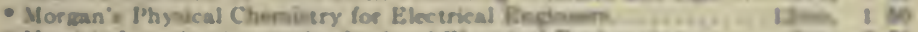

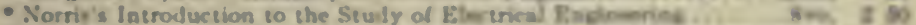

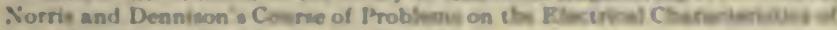
Circuite ans Machint. (In Prems)

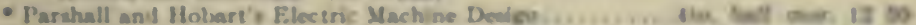

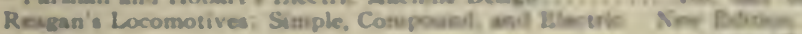

Lary 12

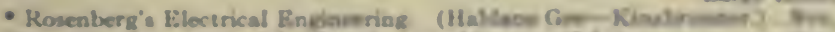

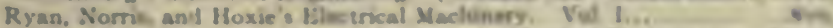

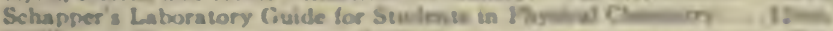

- Tillman's Elementary Lemoen in Heat....

- Timbie s Blersents of Electricity. ....................

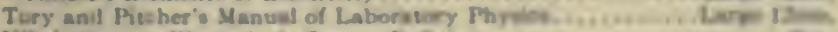

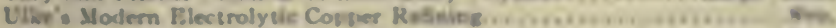

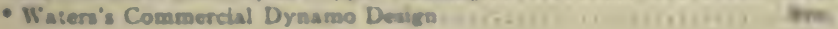

\section{LAW.}

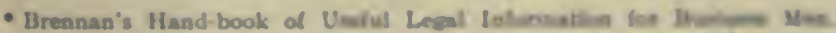

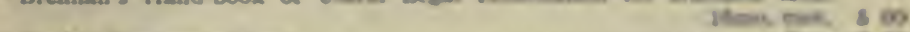

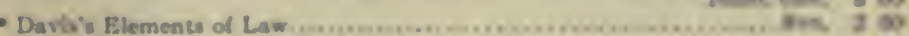

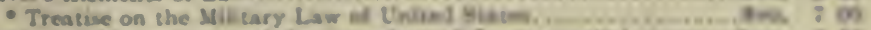

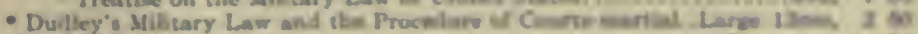

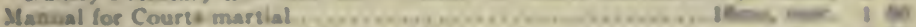

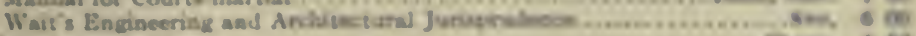

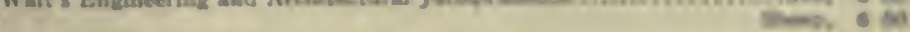

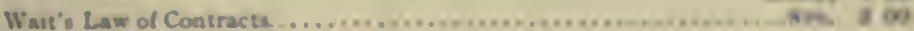


Wait's Law of Operations Preliminary to Construction in Engineering and Architecture............................... svo, \$ 5

\section{MATHEMATICS.}

Bake:s Elliptic Punctions.............................. svo, I go

Brigrs's Elements of Plane Analytic Geometry. (Bocher.) ..........12mo, i 00

- Buchanan's Mlane and Spherical Trigonometry....................

Byerly's Harmonic Punctions ............................................ 100

Chandler's Flements of the Infinitesimal Calculus............... 200

- Coffin 's Vector Analysis. .............................. 12mo, 250

Compton's Manual of Logarithmic Computations...............12mo, I 30

- Dickson's College Algebra................................. 12mo, isge 1 .

- Introduction to the Theory of Algebraic Equations........ Large 12mo, 125

Fmch's Introduction to Projective Geometry and its Application.....8vo, 2 80

Piske's Functions of a Complex Variable.................... 8vo, 100

Halsted's Elementary Synthetic Geometry.................... 8vo, 1 50

Elements of Goometry................................ i 75

- Rational Geometry....................................... i 50

Synthetic Projective Geometry................................. I 1 (n)

* Hancock's Lectures on the Theory of Elliptic Functions. . . . . . . . . . 8vo, 5 on

Hyde's Grasemann's Space Analysis....................... 8vo, 100

- Johnson's (J. B.) Three-place Logarithmic Tables: Vest-pocket size, paper, 15

100 copies, 500

* Mounted on heavy cardboard, $8 \times 10$ inches, 25

Johnson's (W. W.) Abridged Editions of Differential and Integral Calculus. 200

Large $12 \mathrm{mo}, 1$ vol. 250

Curve Tracing in Cartesian Co-ordinates................. $12 \mathrm{mo}$, 1 on

Differential Equations.................................... 100

Elementary Treatise on Differential Calculus........................ $12 \mathrm{mo}$, 50

Elementary Treatise on the Integral Calculus......................... 12mo, 150

* Theoretical Mechanics................................... 3 mo, 00

Theory of Errors and the Method of Least Squarcs............. $12 \mathrm{mo}$, 150

Treatise on Differential Calculus........................... $12 \mathrm{mo}, 300$

Treatise on the Integral Calculus.......................................... 300

Treatise on Ordinary and Partial Differential Equations....Large 12mo, 350

* Karapetoff's Engineering Applications of Higher Mathematics. Large $12 \mathrm{mo}, 075$ Koch's Practical Mathematics. (In Press.)

Laplace's Philosophical Essay on Probabilities. (Truscott and Emory.).12mo, 200

* Le Messurier's Key to Professor W. W. Johnson's Differential Equations.

- Ludlow's Logarithmic and Trigonometric Tables. . . .............. 8 8vo,

* Ludlow and Bass's Elements of Trigonometry and Logarithmic and Other

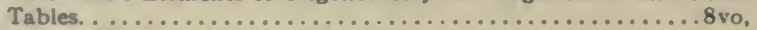

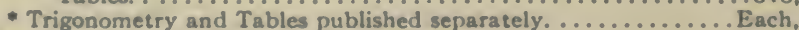

Macfarlane's Vector Analysis and Quaternions. . . . . . . . . . . . . . . 8vo,

Mc.Mahon's Hyperbolic Punctions. ..................................

Manning's Irrational Numbers and their Representation by Sequences and

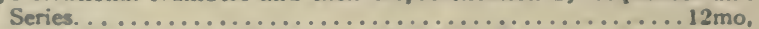

Mathematical Monographs. Edited by Mansfield Merriman and Robert

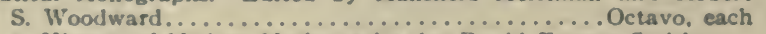

No. 1. History of Modern Mathematics, by David Eugene Smith.

No. 2. Synthetic Projective Geometry, by George Bruce Halsted.

No. 3. Determinants, by Laenas Gifford Weld. No. 4. Hyper-

bolic Functions, by James McMahon. No. 5. Harmonic Functions, by William E. Byerly. No. 6. Grassmann's Space Analysis, by Edward W. Hyde. No. 7. Probability and Theory of Ërrors by Robert S. Woodward. No. 8. Vector Analy'sis and Quaternions. by Alexander Macfarlane. No. 9. Differential Equations, by William Woolsey Johnson. No. 10. The Solution of Equations, by Mansfield Merriman. No. 11. Functions of a Complex Variable, by Thomas S. Piske.

Maurer's Technical Mechanics........................8vo, 400 ,

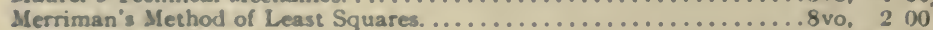

Solution of Equations. .............................. 100 


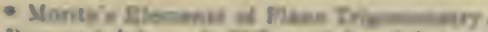

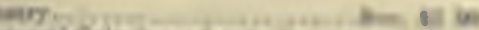

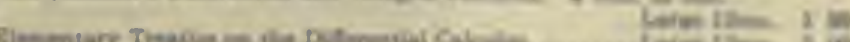

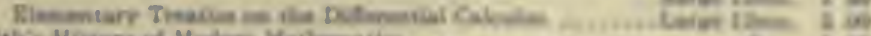

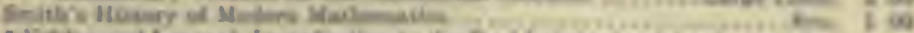

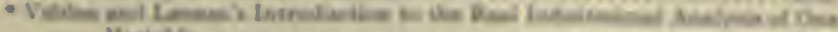

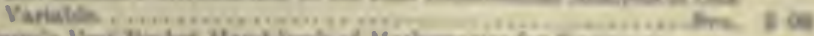

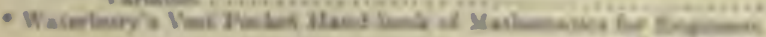

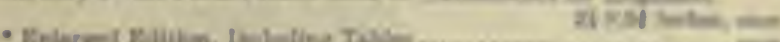

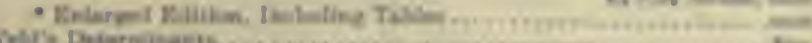

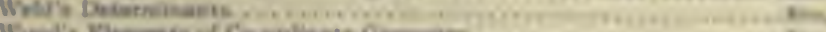

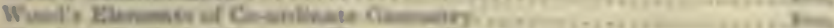

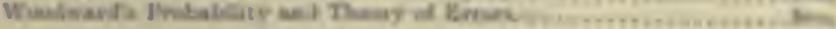

\section{MECHANICAL ENGINEERING.}

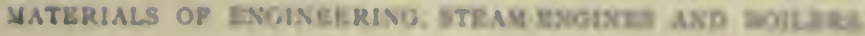

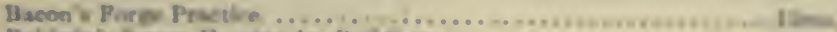

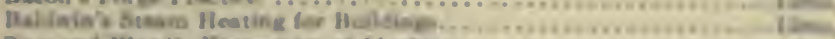

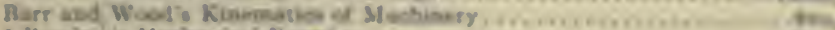

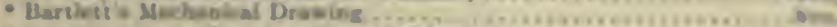

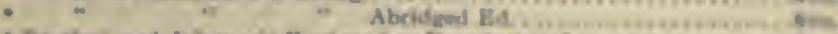

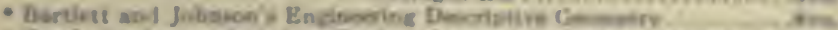

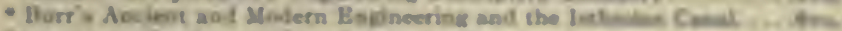

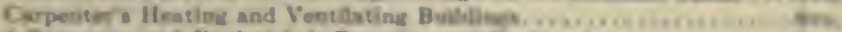

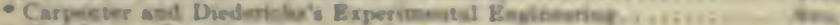

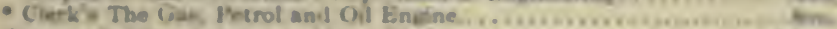

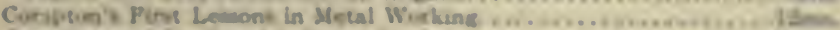

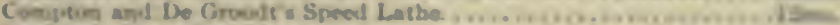

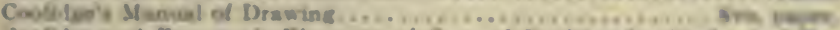

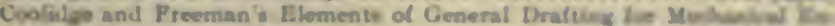

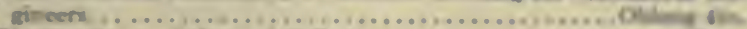

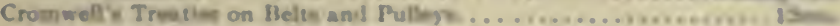

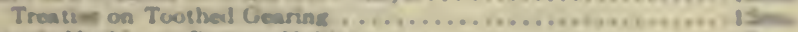

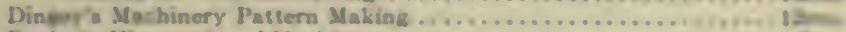

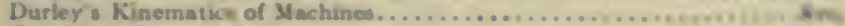

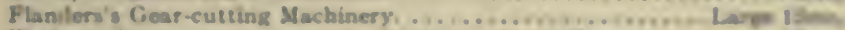

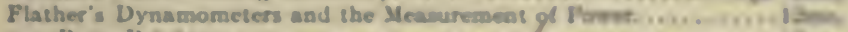

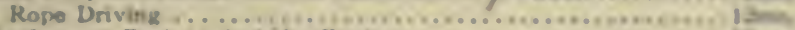

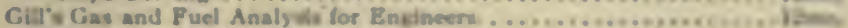

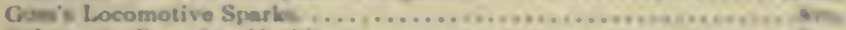

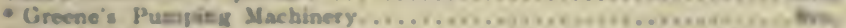

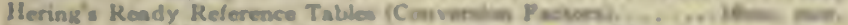

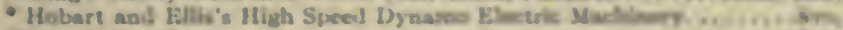

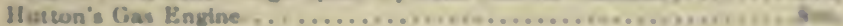

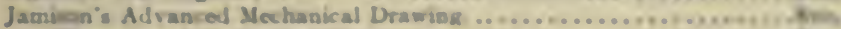

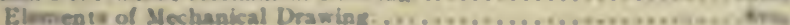

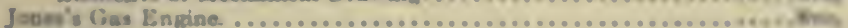
Machine Design:

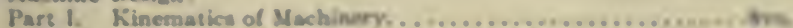

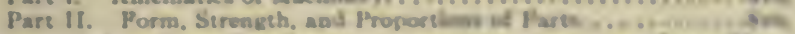

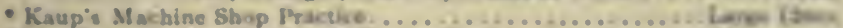

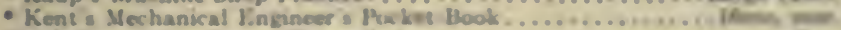

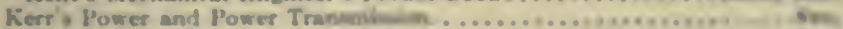

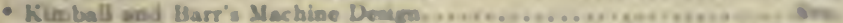

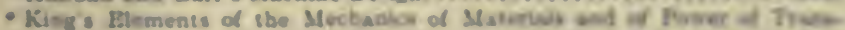

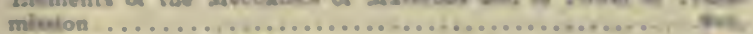

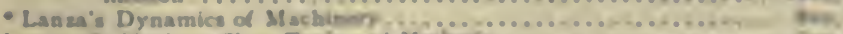

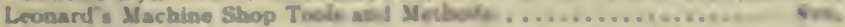

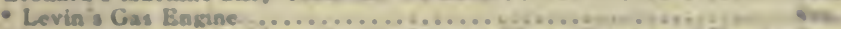

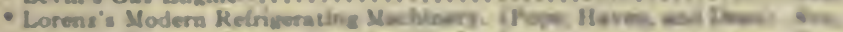

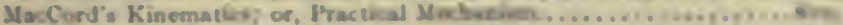

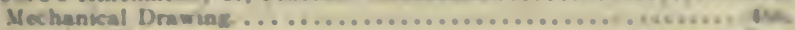

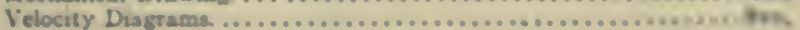


MacParland's Standard Reduction Factors for Gases. ............. Svo, \$1 50 Mahan's Industrial Drawing. (Thompeon.).................. 350

Mehrtens's Cas Engine Theory and Design..................arge 12mo, 250

Miller. Berry, and Riley's Problems in Thermodynamics and Heat Fongineer-

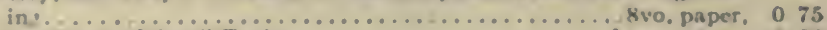

Oberg's Handbook of Small Tools.................................... 12 mo, 2 s0

- Passhall and Hobart's I.lectric Machine Design. Small fto, half leather. 12 50

- Peele's Compresed Air Plant. Second Edition. Revised and Enlarged .8vo, 350 Perkins's General Thermodynamics. (In Press)

Poole's Calorific Power of Fueis. ......................... svo. 300

- Porter's Engincering Reminiscences, 1555 to 1852.............8vo, 300

Randall's Treatise on Heat. (In Press.)

- Reid's Mechanical Drawing. (Elementary and Advanced).........8vo, 200 Text-book of Mechanical Drawing and Elementary Machine Design 8vo, 300

Richards's Compressed Air.................................. I 80

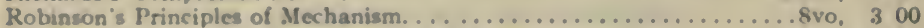

Schwamb and Merrill's Elements of Mechanism................ 8vo, 300

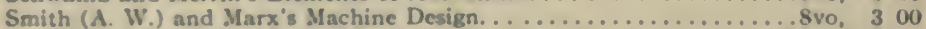

Smith's (O.) Press.working of Metals......................... Svo, 300

Sorel's Carburcting and Combustion in Alcohol Engines. (Woodward and Preston.).............................................. 300

Stone's Practical Testing of Gas and Gas Meters..................

Thurston's Animal as a Machine and Prime Motor, and the Laws of Energetics.

$12 \mathrm{mo}, 100$

Treatise on Friction and Lost Work in Machinery and Mill Work. .8vo, 300

- Tillson's Complete Automobile Instructor. ................ $16 \mathrm{mo}$, I 50

- Titsworth's Elements of Mechanical Drawing............... Oblong 8vo, 125

Warren's Eleneots of Nachine Construction and Drawing. ........8vo, 750

- Waterbury's Vest Pocket Hand-book of Mathematics for Engineers.

- Enlarged Edition, Including Tables................. mor

Weisbach's Kinematics and the Power of Transmission. (Hermann-

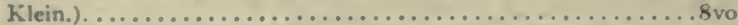

Machinery of Transmission and Governors. (hermann-Klein.)..8vo,

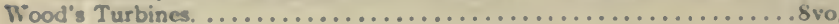

\section{MATERIALS OF ENGINEERING.}

Burr's Elasticity and Resistance of the Materials of Enginecring. . . . . Svo, 750

Church's Mechanics of Engineering. . . . . . . . . . . . . . . . . . svo, 600

Mechanics of Solids (Being Parts 1. II. III of Mechanics of Engineering)

Svo, 450

- Greene's Structural Mechanics..........................8vo, 2 50

Holley's Analysis of Paint and Varnish Products. (In Press.)

- Lead and Zinc Pigments............................... 12mo, 300

Johnson's (C. M.) Rapid Methods for the Chemical Analysis of Special Stecls, Stcol-Making Alloys and Graphite ......... Large $12 \mathrm{mo}$,

Johnson's (J. B.) Matorials of Construction. . . . . . . . . . . . . . . . 8vo

250

- King's Elements of the Mechanics of Materials and of Power of Transmission

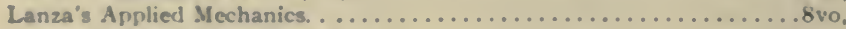

Lowe's Paints for Stoel Structures........................ 12mo,

Maire's Modern I'igments and their Vehicles................. 12mo,

Maurer's Technical Mechanics.............................. svo,

Merriman's Mechanics of Materials........................ \&vo,

- Strength of Mlaterials. ........................... 12mo

Metcalf's Steel. A Manual for Steelusers.....................12mo,

- Murdock's Strength of Materials....................... 12mo,

Sabin's Industrial and Artistic Tochnology of l'aint and Varnish. . . . .8vo,

Smith's (A. W.) Matcrials of Macbines. . . . . . . . . . . . . . . . . 12mo,

- Smith's (H. E.) Sirength of Material....................... 12mo,

Thurston's Materials of Enkincoring........................... 8vo vols.

Part I. Non-metallic Materials of Engincering. ............. . . .

Part II Iron and Steol. ........................... 8vo

Part III. A Treatise on Bsasses, Branzes, and Other Alloys and their

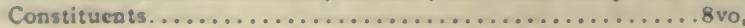




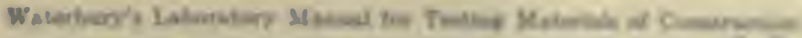

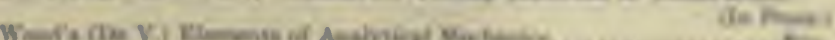

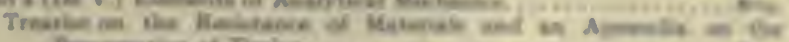

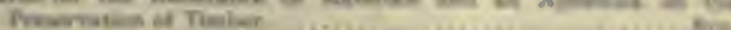

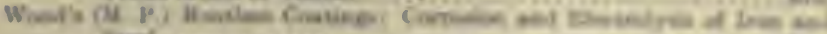
Nand ...

\section{STEAY-ENGITES AKD BOILERS.}

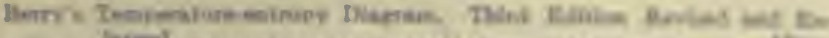

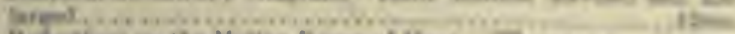

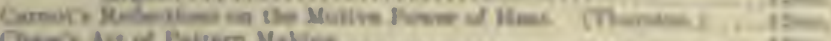

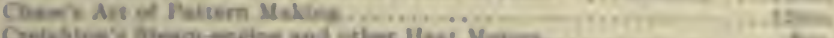

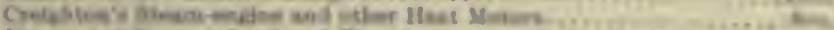

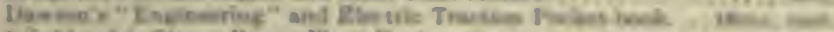

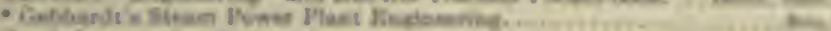

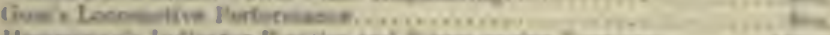

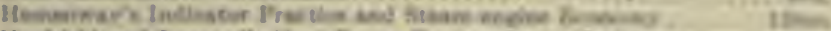

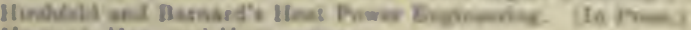

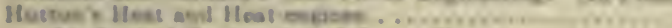

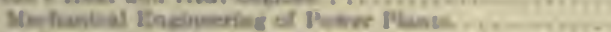

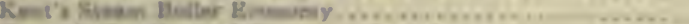

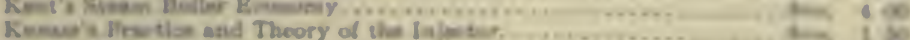

the 1 in

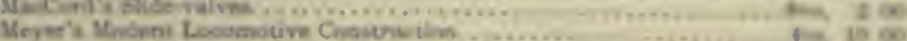

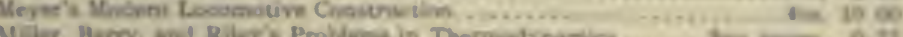

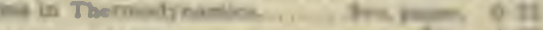

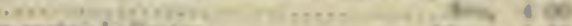

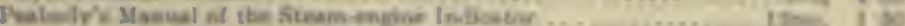

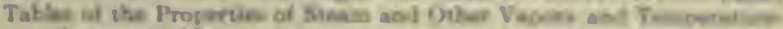

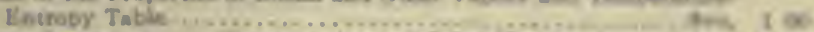

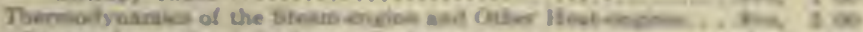

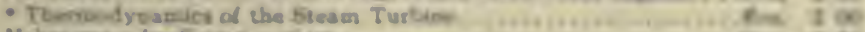

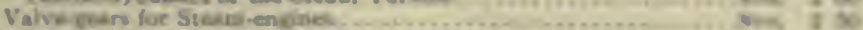

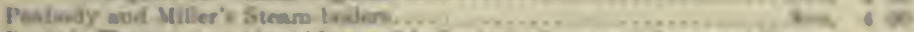

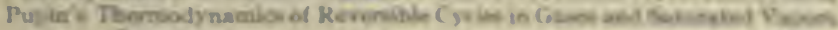

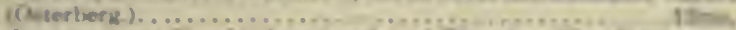

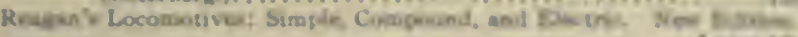

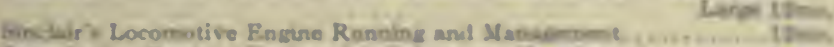

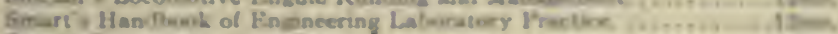

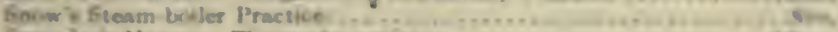

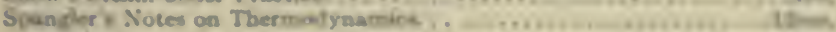

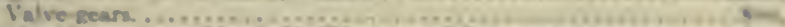

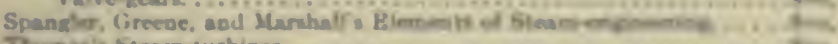

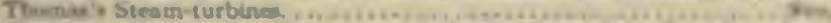

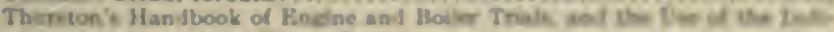
cator and the Prony Brake................................. 5 .

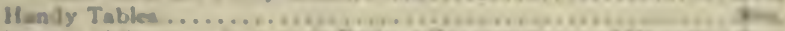

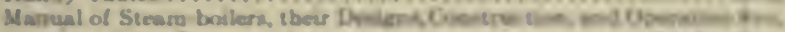

Manual of the Stearn-erupee.

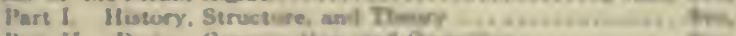

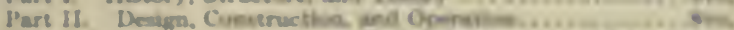

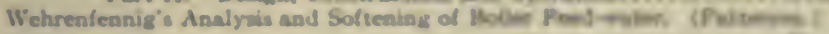

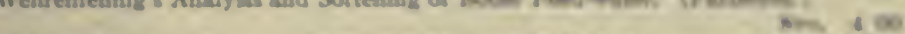

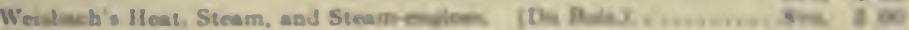

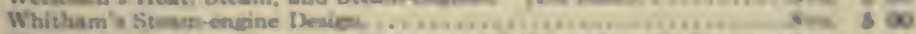

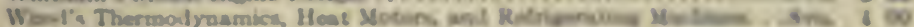

\section{MECHANICS PURE AND APPLIED.}

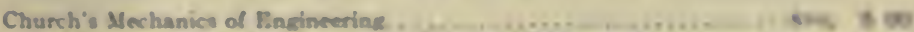

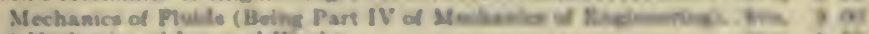

- Mechanice of Internal Work

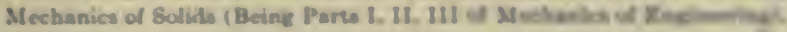

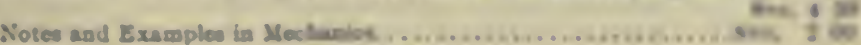


Dana's Texi-book of Elementary Mechanica for Colleges and Schools .12mo, $\$ 150$ Du Bois's Elementary I'rinciples of Mechanics:

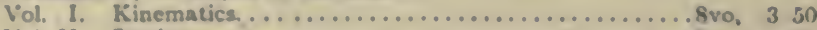

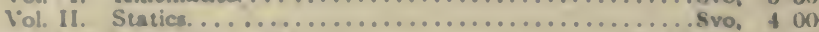

Mechanics of Engineering. Vol. 1................ Small tto, I 5) Vol. II. .................. Small tto, 10 on

- Greene's Structural Mechadics. ........................... Svo. 250

- Hartmana's Elementary Mechanic for Engineering Students. ....12mo, 1 25

James's Kinematics of a Point and the Rational Mechanics of a Particle.

Large 12mo. 2 no

- Johnson's (W. W.) Theoretical Mechanics................... 12mo, 300

- King's Elements of the Mechanics of Materials and of Power of Trans.

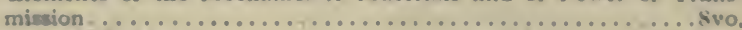

Lanza's Applied Mechanics. ............................. Svo.

- Martin's Text Ibook on Mechanics, Vol. I. Statics. ... . . . . . . . . . 12mo.

- Vol. II. Kinematics and Kinetics....................12mo,

- Vol. III. Mechanics of Materials..................... 12mo,

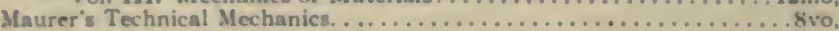

- Merriman's Elements of Mechanics. . . . . . . . . . . . . . . . . . 12mo,

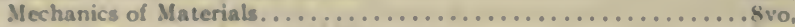

- Michie is Elements of Analytical Mechanics...................... 8vo.

Robinson's Principles of Mechanism. . . . . . . . . . . . . . . . . svo. Sanborn's Mechanics Problems. .............................. 12mo,

Schwamb and Merrill's Elements of Mochanism. ................. Svo,

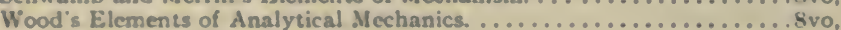
Principles of Elementary Mechanics...................12mo, 125

\section{MEDICAL.}

- Abderhalden's Physiological Chemistry in Thirty Lectures. (Hall and

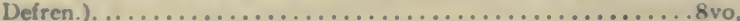
von Behring's Suppression of Tuberculosis. (Bolduan.). . . . . . . . . . . . 12mo. - Bolduan Immune Sera ............................ 12 mo.

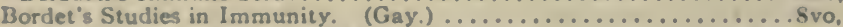
- Chapin's The Sources and Modes of Infection.............. Large 12mo, Davenport's Statistical Methods with Special Reference to Biological Variations. ............................16mo, mor.

Ehrlich's Collected Studies on Immunity. (Bolduan.). . ........... \&vo,

- Fischer's Nephritis.............................. Large 12mo,

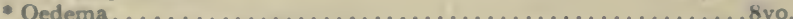

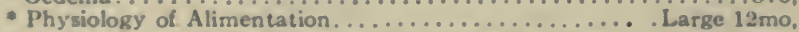

- de Pursac's Manual of Psychiatry. (Rosanoff and Collins.). . Large $12 \mathrm{mo}$,

- Hammarsten's Text-book on Physiological Chemistry. (Mandel.)....8vo, Jackson's Directions for Laboratory Work in Physiological Chemistry. . 8vo, Lassar-Cohn's Praxis of Urinary Analysis. (Lorenz.)............. . 12mo. Mandel's Hand-book for the Bio-Chemical Laboratory.............. . $12 \mathrm{mo}$.

- Nelson's Analysis of Drugs and Medicines................... 12mo.

- Pauli's Physical Chemistry in the Service of Medicine. (Fischer.)..12mo,

- Pozzi-Escot's Toxins and Venoms and their Antibodies. (Cohn.). 12mo,

Rostoski's Serum Diagnosis. (Bolduan.).................... 12mo,

Ruddiman's Incompatibilitics in Prescriptions. .............

Whys in Pharmacy. ...........................12mo,

Salkowski's Physiological and Pathological Chemistry. (Orndorff.) .....8vo.

- Satterlee's Outlines of Human Embryology. . . . . . . . . . . . . . . 12mo.

Smith's Lecture Notes on Chemistry for Dental Students. . . . . . . . . . . 8vo,

- Whipple's Tyhpoid Fever. .......................... Large $12 \mathrm{mo}$,

- Woodhull's Military Hygiene for Officers of the Line..... . . . Large 12mo,

- Personal Hygiene. .............................. 12mo.

Worcester and Atkinson's Small Hospitals Establishment and Maintenance, and Suggestions for Hospital Architecture, with Plans for a Small

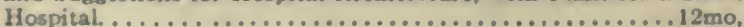

\section{METALLURGY.}

Bets's Lead Refining by Electrolysis. ...................... 8vo

Bolland's Encyclopedia of Founding and Dictionary of Foundry Terms used in the Practice of Moulding. 


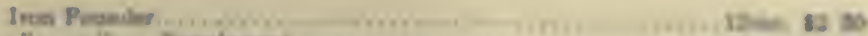

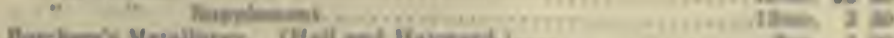

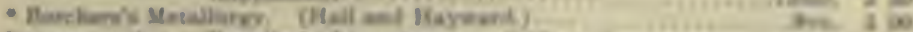

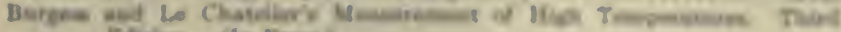

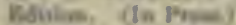

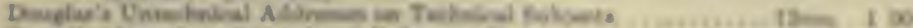

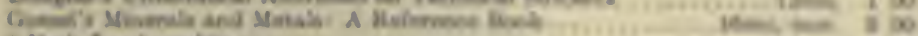

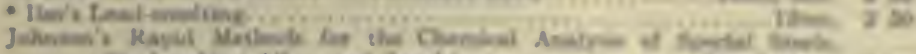

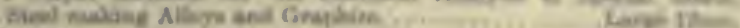

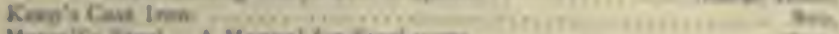

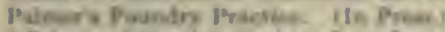

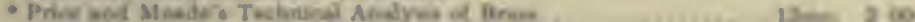

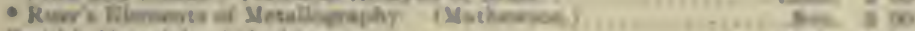

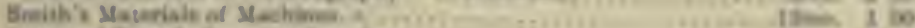

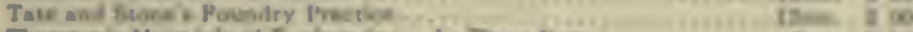

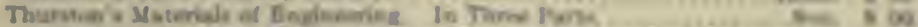

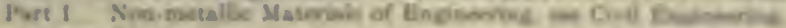
maso 0

Part IL. Irom aed Stoct. ... ....

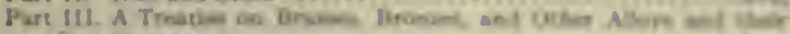
Cometientas:

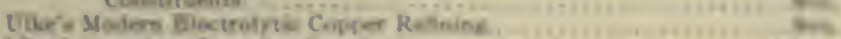

Weit Arowican Poondr Proctire....

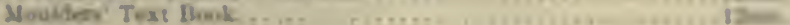

\section{MINERALOGY.}

Baskerville's Chemikal Eilurvents. (In Preparatias)

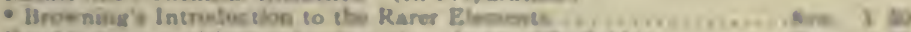

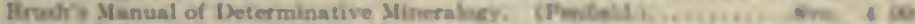

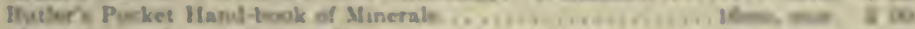

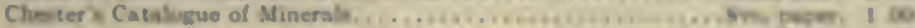

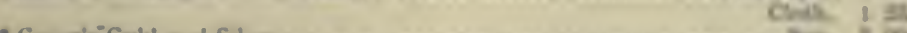

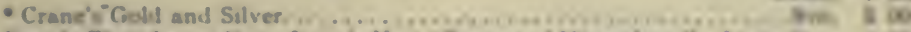

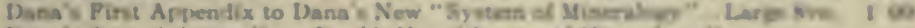

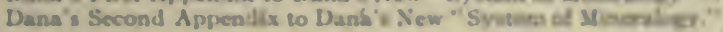

targ sive

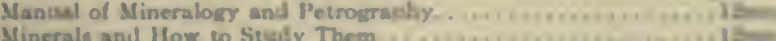

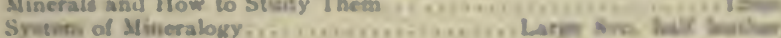

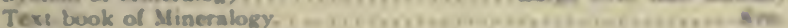

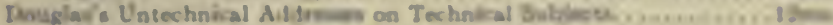

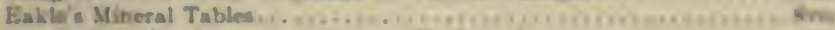
Fakel's Building Stones and Clays. In Prem.

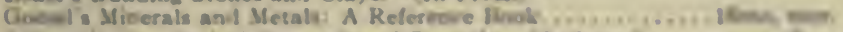

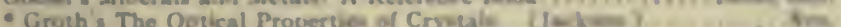

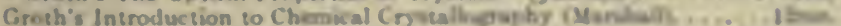

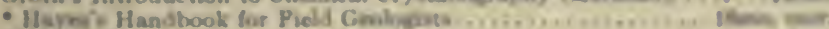

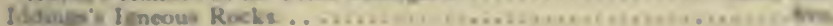

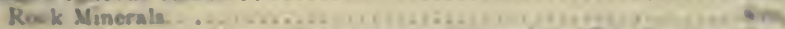

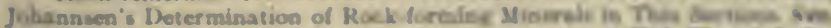

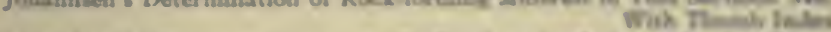

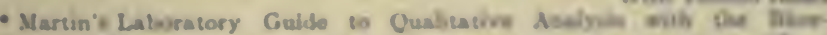

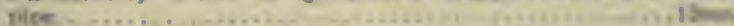

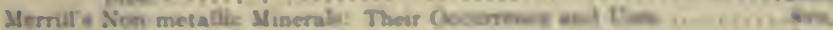

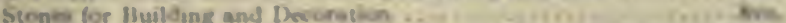

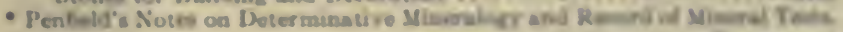
ins rere.

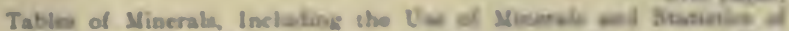

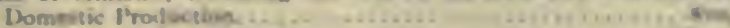

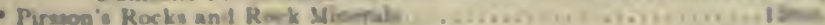

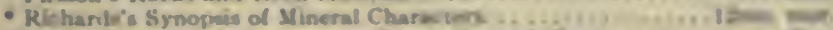

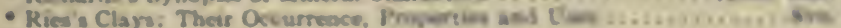


- Ries and Leighton's History of the Clay-working inaustry of the United States...................................... \$2 50

- Rowe's Practical Mineralogy Simplified..................... 12mo, i 25 - Tillman's Text-book of Important Minerals and Rocks............. 8vo, 200 Washington's Manual of the Chemieal Analysis of Rocks. . . . . . . . . . 8vo, 200

\section{MINING.}

- Beard's Mine Gáses and Explosions. ................. Large 12mo, 300

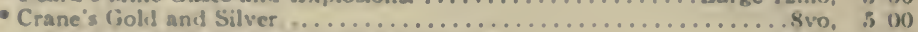

- Index of Mining Engineering Literature.................... \&vo, \& 00

- svo, mor. 500

- Ore Mining Methods ...... 8vo, 300

- Dana and Saunders's Rock Drilling ...................... 8vo, \& 00

Douglas s Untechnical Addresses on Technical Subjects. ............12mo, i 00

Ei=ler's Morlern High Explosives........................... 8vo, \& 00

Goesel's Minerals anid Metals: A Reference Book............. 16mo, mor. 300

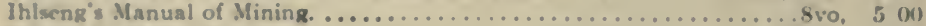

- lles's Lead Smelting. ............................... 12mo, 250

- Peele's Compressed Air Plant. . ... . . . . . . . . . . . . . . . Svo, 350

Riemer's Shaft Sinking Under Difficult Conditions. (Corning and Peele.)8vo, 300

- Weaver's Military Explosives ...........................8vo, 300

Wilson's Hydraulic and Placer Mining. 2d edition, rewritten......12mo, 250

Treatise on Practical and Theoretical Mine Ventilation........12mo, i 25

\section{SANITARY SCIENCE.}

Association of State and National Food and Dairy Departments, Hartford

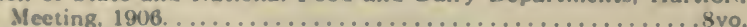

8vo, 300

- Bashore's Outlines of Practical Sanitation. ..................... 125

Sanitation of a Country House. .....................12mo, 100

Sanitation of Recreation Camps and Parks................ $12 \mathrm{mo}, \quad 100$

- Chapin's The Sources and Modes of Infection..................... 12mo, 300

Folwell's Sewerage. (Designing, Construction, and Maintenance.)....8vo, 300

Water-supply Engineering. ............................. 400

Fowler's Sewage Works Analyses, ......................12mo, 200

Puertes's Water-filtration Works............................... 2 51)

Water and Public Health. ................................ I 51)

Gerhard's Guide to Sanitary Inspections..................

- Modern Baths and Bath Houses............................... 3 00)

Sanitation of Public Buildings. . ................... $12 \mathrm{mo}, 150$

- The Water Supply, Sewerage, and Plumbing of Modern City Buildirss.

Hazen's Clean Water and How to Get It. . . . . . . . . . . Large 12mo, is 50

Filtration of Public Water-supplies...................... Svo, 300

- Kinnicutt, Winslow and Pratt's Sewage Disposal................ 8vo, 300

Leach's Inspection and Analysis of Food with Special Reference to State Control. ...................................... T 50

Mason's Examination of Water. (Chemical and Bacteriological)........... 125 Water-supply. (Considered principally from a Sanitary Standpoint).

- Mast's Light and the Behavior of Organisms.................... $12 \mathrm{mo}, 250$

- Merriman's Elements of Sanitary Engineering. . . . . . . . . . . . . . 8vo, 200

Ogden's Sewer Construction .................................. 300 Sewer Design.................................. 12mo, 200

Persons's Disposal of Municipal Refuse......................... 200

Prescott and Wintlow's Elements of Water Bacteriology, with Special Reference to Sanitary Water Analysis. . ................... $12 \mathrm{mo}$.

Richards's Conservation by Sanilation....

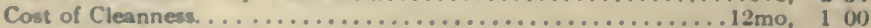

Cost of Pood. A Study in Dietaries.....................12mo, 100

Cost of Living as Modified by Sanitary Science. . . . . . . . . . . . 12mo, 100

Cost of Shelter. .................................. $12 \mathrm{mo}^{1} 00$

- Richards and Williams's Dictary Computer................... 8vo, 150 


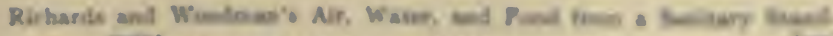

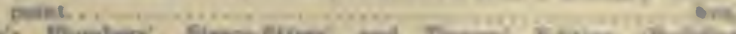

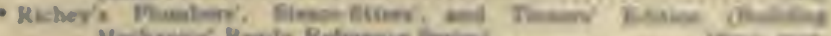

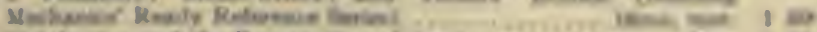

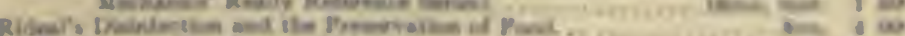

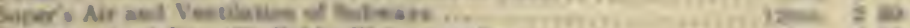

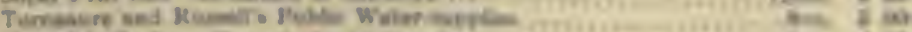

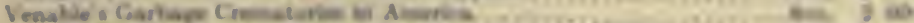

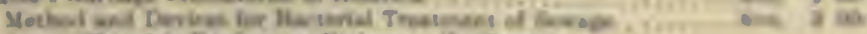

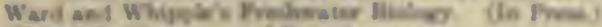

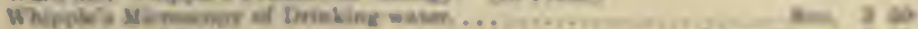

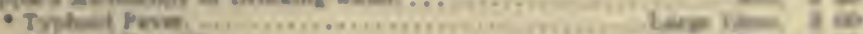

Vabied Here Wabes........

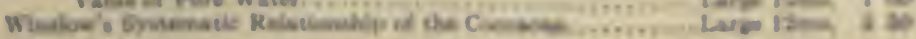

\section{MISCELLAVEOUS.}

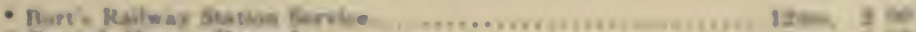

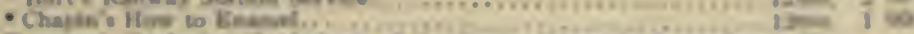

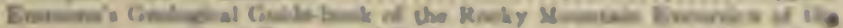

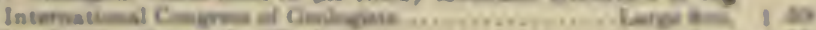

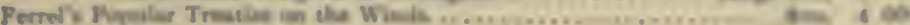

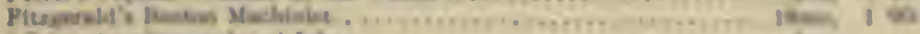

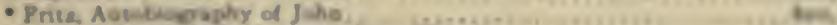

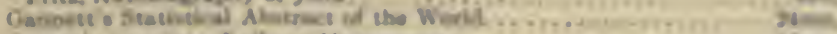

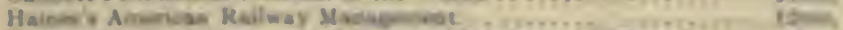

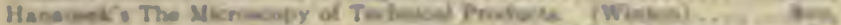

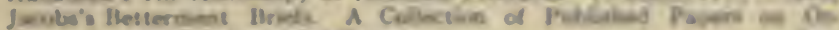

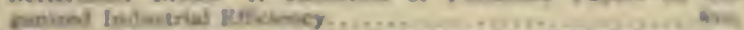

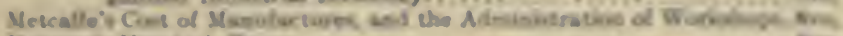

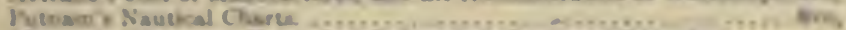

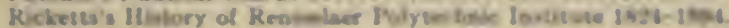

Lage izinat

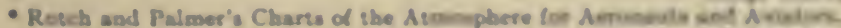
Celion ate

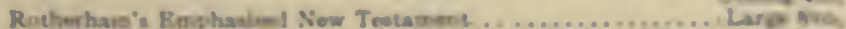

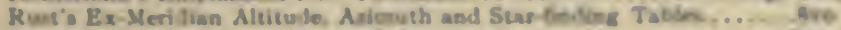

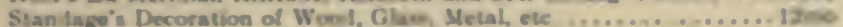

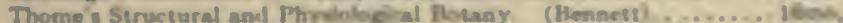

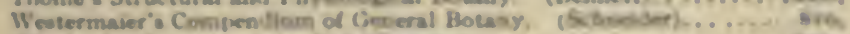

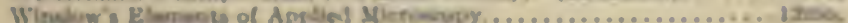

\section{HEBREW AND CHALDEE TEXT-BOOKS.}

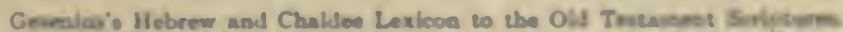

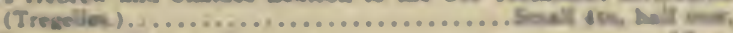

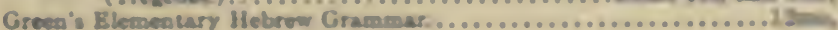




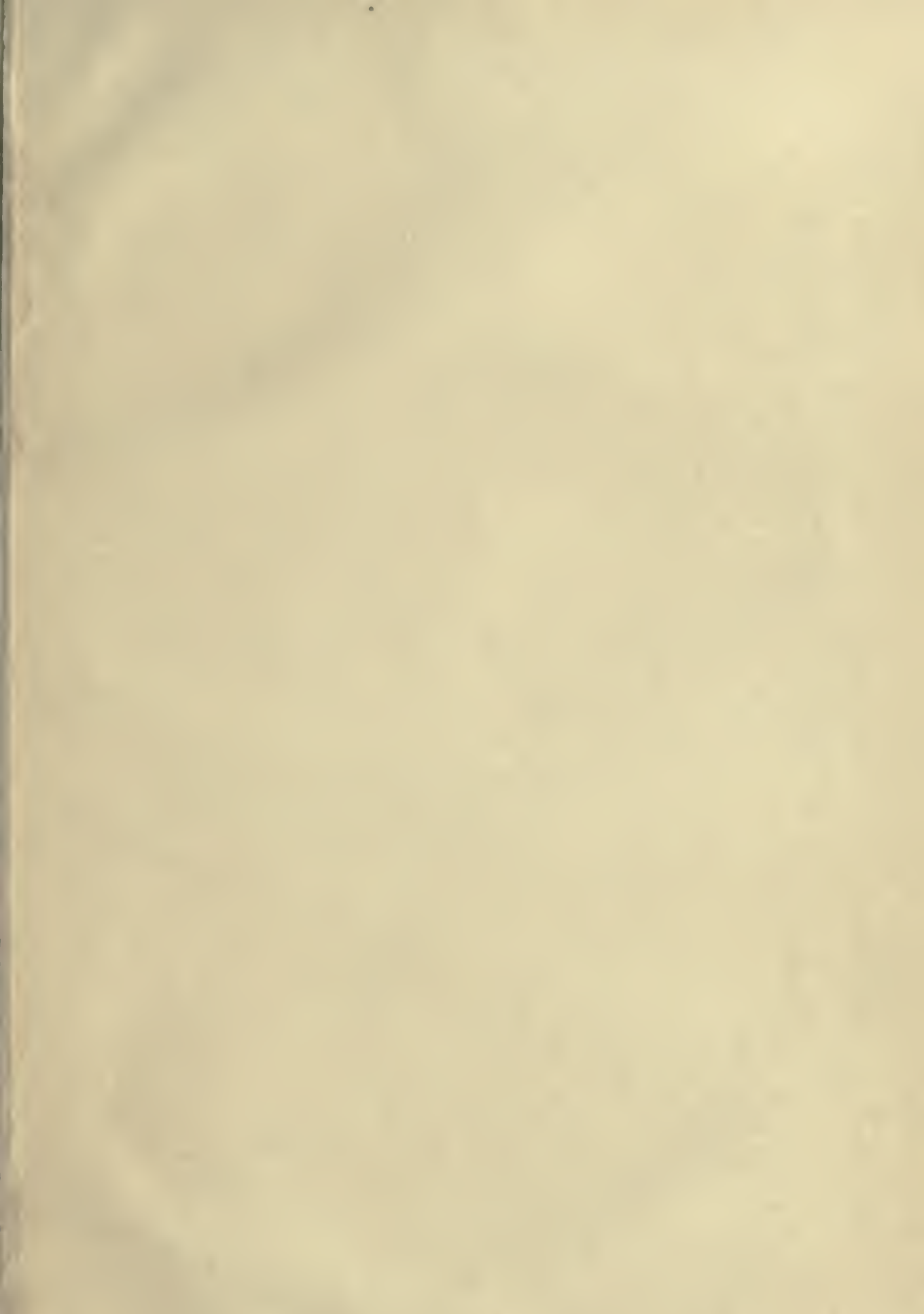

.
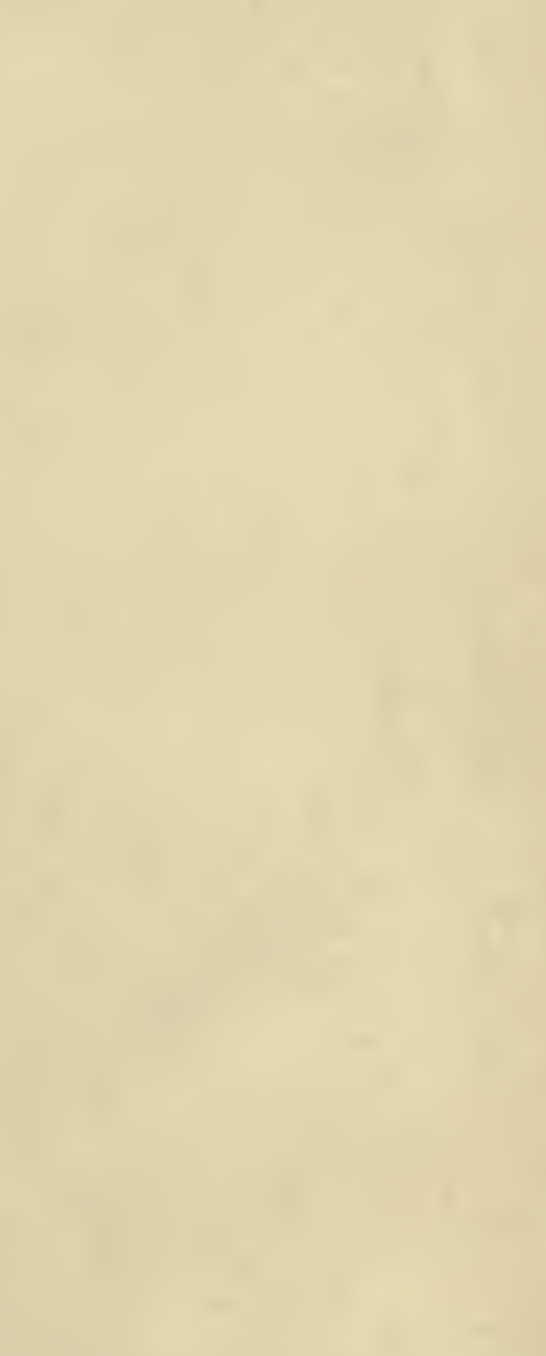

$+$ 



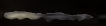




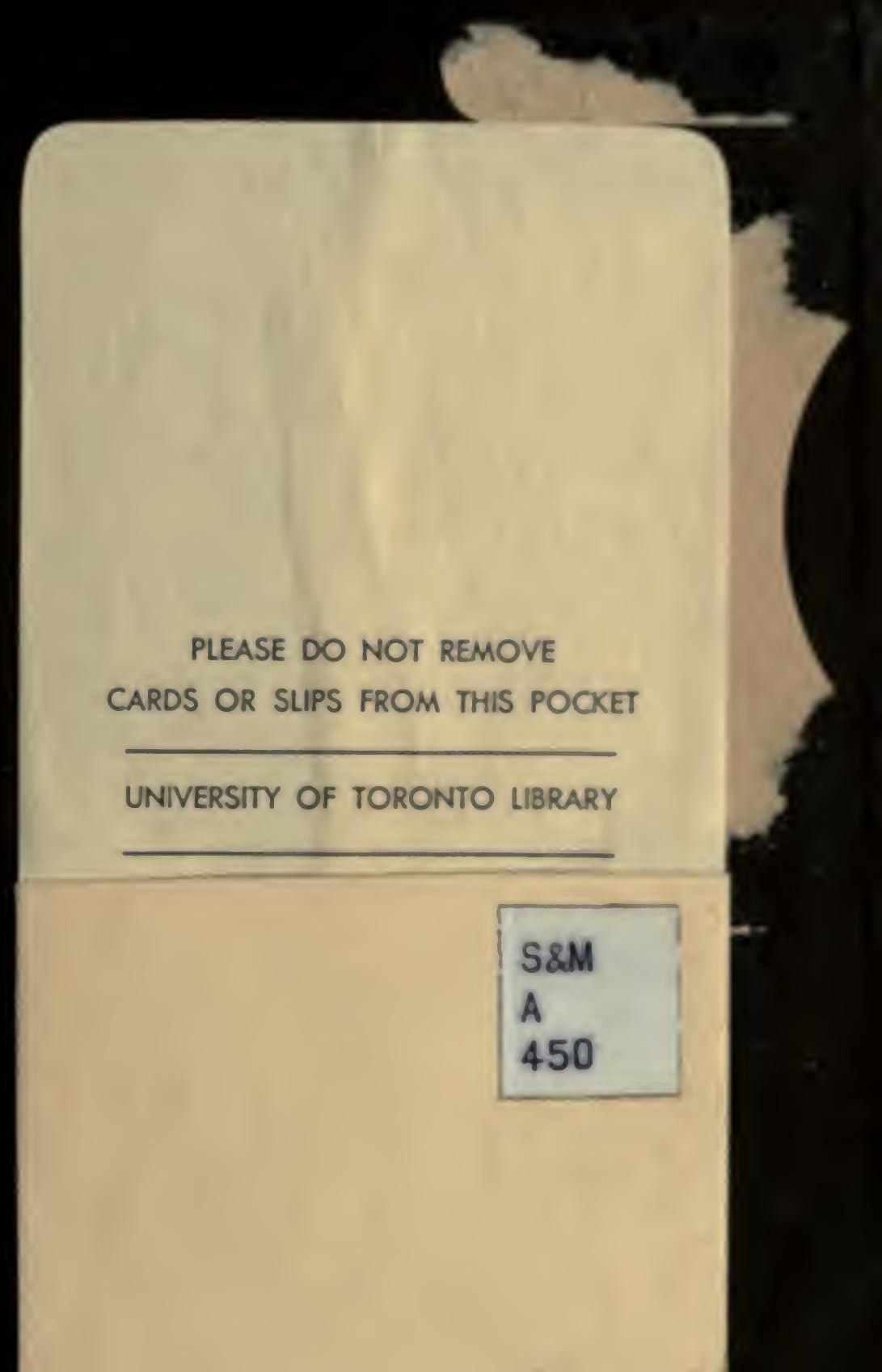


